\title{
Treatment Techniques for Edema Reduction During the Acute Stage of the Inflammatory Cycle: A Systematic Review
}

\author{
Adam D. Graham \\ West Virginia University
}

Follow this and additional works at: https://researchrepository.wvu.edu/etd

\footnotetext{
Recommended Citation

Graham, Adam D., "Treatment Techniques for Edema Reduction During the Acute Stage of the Inflammatory Cycle: A Systematic Review" (2011). Graduate Theses, Dissertations, and Problem Reports. 4723.

https://researchrepository.wvu.edu/etd/4723

This Thesis is protected by copyright and/or related rights. It has been brought to you by the The Research Repository @ WVU with permission from the rights-holder(s). You are free to use this Thesis in any way that is permitted by the copyright and related rights legislation that applies to your use. For other uses you must obtain permission from the rights-holder(s) directly, unless additional rights are indicated by a Creative Commons license in the record and/ or on the work itself. This Thesis has been accepted for inclusion in WVU Graduate Theses, Dissertations, and Problem Reports collection by an authorized administrator of The Research Repository @ WVU. For more information, please contact researchrepository@mail.wvu.edu.
} 
Treatment Techniques for Edema Reduction During the Acute Stage of the Inflammatory Cycle: A Systematic Review

Adam D. Graham, BS, ATC

Thesis submitted to the College of Physical Activity and Sport Sciences at West Virginia University in partial fulfillment of the requirements for the degree of

Master of Science

in

Athletic Training

Michelle A. Sandrey, Ph.D., ATC, Chair

Benjamin Moorehead, MD

Elizabeth Bunn, MS., ATC

Damien Clement, Ph.D., ATC

Department of Sport Sciences

Morgantown, WV

2011

Keywords: lymphatic, acute, treatment, edema 


\begin{abstract}
Treatment Techniques for Edema Reduction During the Acute Stage of the Inflammatory Cycle: A Systematic Review
\end{abstract}

Adam D. Graham

Objective: To evaluate the methodological quality of edema reduction during acute injury studies found in the current literature. Data Sources: Pubmed (1951-2010), MEDLINE, ScienceDirect (1995-2010), CINAHL with Full Text (1982-2010), SPORTDiscus Full Text (1800-2010), MDConsult (1980-2010), Science Direct (1940-2010), Google Scholar were searched using the terms lymphatic system, edema reduction, inflammation process individually. Second, the term lymphatic system was combined with each of the following words: injury, acute, treatment, edema, cryotherapy, electrical stimulation, compression, deep oscillation and Kinesio Tape. Third, citations were cross referenced from studies to include literature not found in the original search. Study Selection: Studies were included based on the following inclusion criteria: 1) written in the English language; 2) edema reduction or a form of the word lymphatic must be in the title; 3) the abstract must include the terms lymphatic system, edema, modalities and treatment; 4) acute injury must be the chief complaint in the study; 5) and the study must be a randomized controlled trial. The exclusion criteria included any chronic injuries or conditions. Data Extraction: All the studies that meet the inclusion criteria were collected and evaluated via the PEDro Scale and a comparison of their effect size. Each study was read first without the use of the PEDro Scale, then upon completion it was read again with the PEDro Scale by both evaluators. Depending on the checklists completed by the evaluators each study was given a score from 0-10. Upon completion the final scores of the investigators were compared, and differences were discussed until a final score was agreed upon. Data Synthesis: There were 13 studies extracted in this review. They varied in population, location, type of treatment, inclusion/exclusion criteria, methodological quality and effect size. The methodological quality ranged from a 2 to a 8 with an average of 4.5. The effect size comparison ranged from -3.27 to 0.93 which shows the confidence interval crossed 0 demonstrating that most of the treatments were ineffective with only one massage study proven to have a significant treatment effect. Conclusions: Treatment methods for edema reduction through the lymphatic system is not well researched. There are several different treatments that have yet to be studied. Athletic trainers currently perform treatments without empirical evidence to support it. 


\section{ACKNOWLEDGEMENTS}

To my mother and my hero, Debi, for everything that she has given up and sacrificed to help me get to where I am today. I am so very thankful for her unyielding support, guidance and patience throughout the years.

To the rest of my family, and Creighton, their continual support through the years helped me to realize who I wanted to be and for continuing to push me to strive to be the best that I can.

I would like to thank Dr. Benjamin Moorhead, Liz Bunn and Dr. Damien Clement for being on my committee and for all of the help. I am very grateful for the help, and Dr. Clement for joining so late, in guiding me through this lengthy process.

I would also like to thank Liz Bunn for helping me score the studies using the PEDro scale. Thank you for taking the time to assist me with this, I appreciate the time and effort that went in to scoring these studies.

To my friends throughout the years, and especially the new ones I've made here at WVU, for their support, understanding and great memories that have kept us going through these two years.

I would like to thank Dr. Sandrey for her numerous hours of support throughout this process. I am very grateful for your assistance and guidance throughout this difficult process. 
TABLE OF CONTENTS

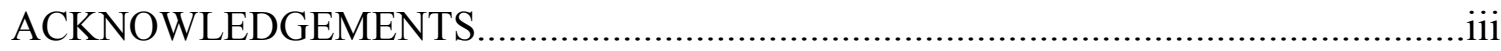

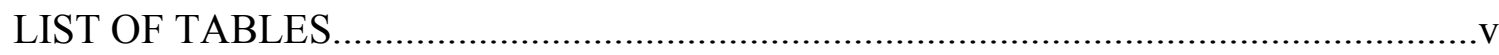

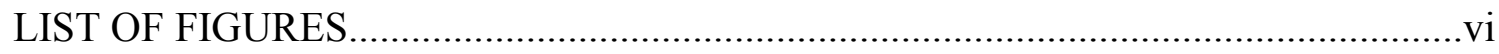

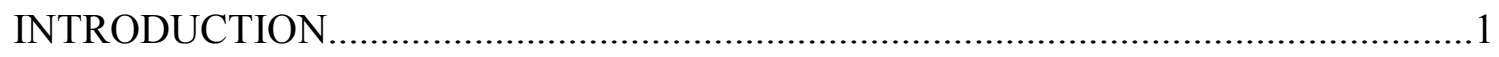

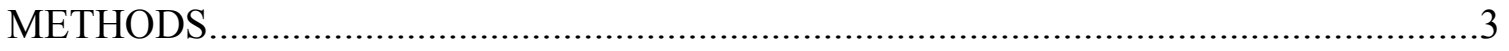

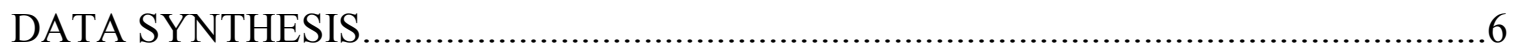

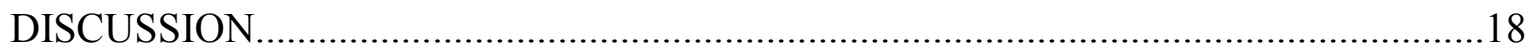

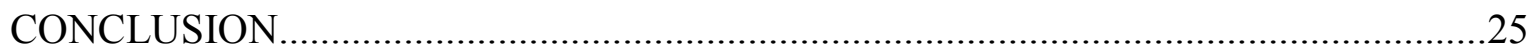

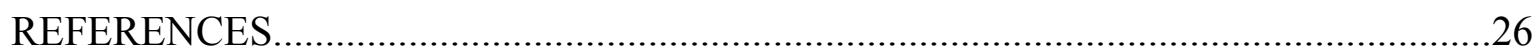

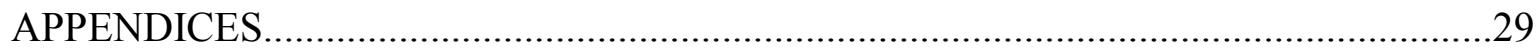

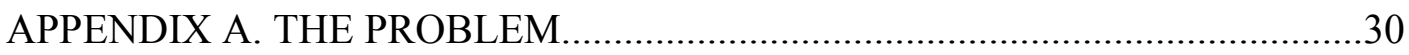

APPENDIX B. LITERATURE REVIEW................................................................

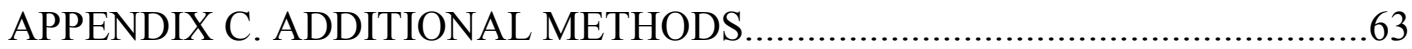

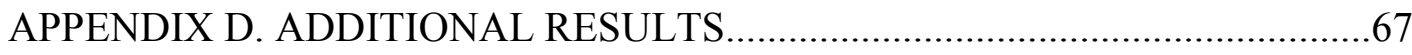

APPENDIX E. RECOMMENDATIONS FOR FURTHER RESEARCH................95

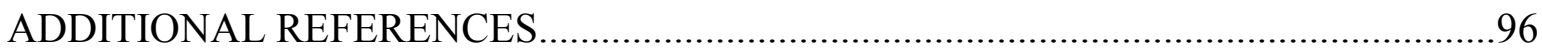


Tables

\section{LIST OF TABLES}

B1. Comparison of Cryotherapy Studies........................................... 51

B2. Comparison of Massage Treatment Studies.......................................55

B3. Comparison of Electrical Stimulation Studies.......................................59

B4. Comparison of Kinesio Tape Studies..........................................61

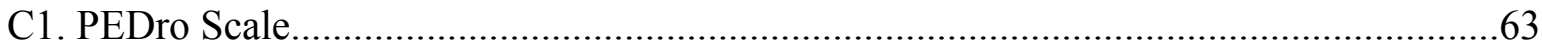

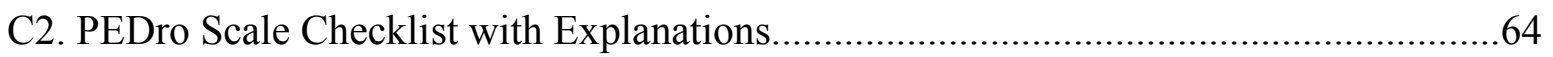

C3. Protocol For Determining Studies.............................................................................66

D1. Cryotherapy Treatment Studies..............................................67

D2. Compression Treatment Studies...............................................69

D3. Massage Treatment Studies................................................... 70

D4. Electrical Stimulation Treatment Studies........................................ 71

D5. Comparison of Overall PEDro Scores..........................................................................72

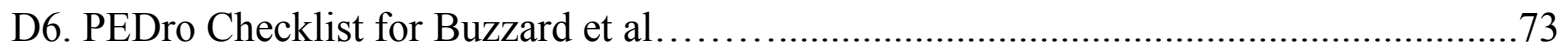

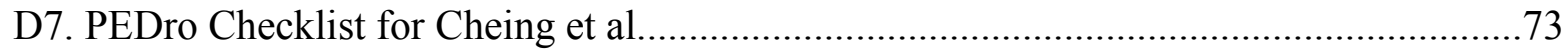

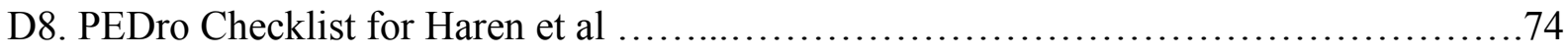

D9. PEDro Checklist for Kessler et al .............................................. 74

D10. PEDro Checklist for Knygsand et al .............................................. 75

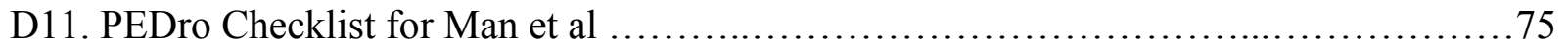

D12. PEDro Checklist for Meeusen et al..........................................................................

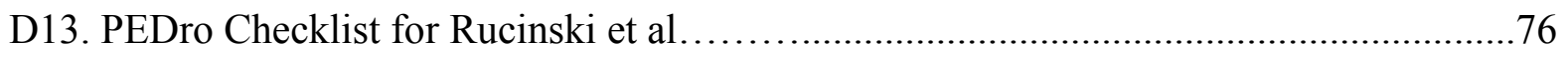

D14. PEDro Checklist for Scheffler et al.............................................................................77

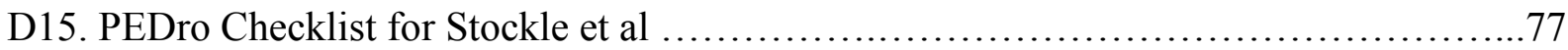


D16. PEDro Checklist for Thordarson et al ....................................... 78

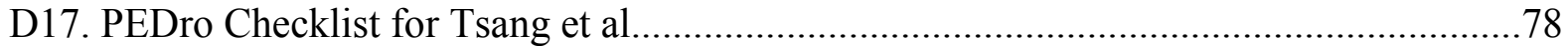

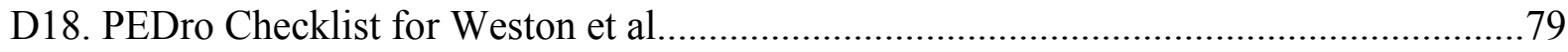




\section{LIST OF FIGURES}

Figures $\quad$ Page

B1. Blood Flow Into the Interstitial Space ...........................................................44

B2. Funnel Arrangement of Lymphatic Valves ......................................................44

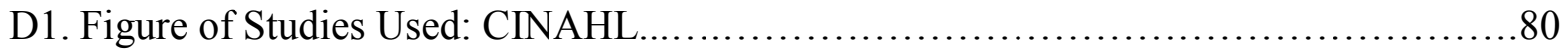

D2. Figure of Studies Used: SPORTdiscus..................................... 81

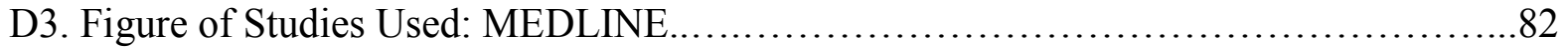

D4. Figure of Studies Used: MDConsult...................................... 83

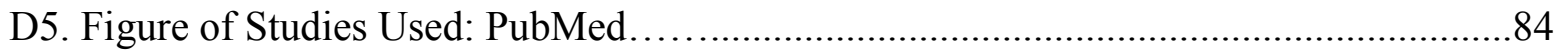

D6. Figure of Studies Used: Cochran.. ............................................................. 85

D7. Figure of Studies Used: Google Scholar............................................................. 86

D8. Figure of Studies Used: Science Direct....................................... 87

D9. Figure of Studies Used: PEDro Database.................................... 88

D10. Effect Size Comparison.................................................... 89 


\section{INTRODUCTION}

Acute musculoskeletal injuries can often have associated inflammation producing swelling and edema. The resulting inflammation of the traumatic event is not entirely destructive in nature as the inflammatory process is important due to a "consistent and lasting response" which allows for tissue healing. The more damage an area sustains the more necrotic tissue arises resulting in a longer time for the removal, thus increasing return to play timelines. ${ }^{2}$ The tissue repair process is marked by three distinct stages, the inflammatory stage, the proliferation stage and the maturation stage. ${ }^{1,3,4,5}$ Each stage has a specific role in the healing of tissues, however, there is still very little agreement on the exact timeline of these phases and it is generally believed to overlap. ${ }^{1,3,4,5}$ If the initial stage is not managed properly then there is potential risk of secondary injury due to ischemia and hypoxia. ${ }^{2}$ There has been little research conducted to further examine secondary injury since Kinght's secondary injury model presented over 20 years ago. ${ }^{2}$

Removal of edema is important and the role of the lymphatic system is paramount. Edema along with range of motion and equal strength all have an effect on making a return to play decision. There are several modalities and lymphatic drainage techniques that have been evaluated in the literature that assist edema reduction by including the lymphatic system. These include but are not limited to cryotherapy, compression units, manual lymphatic drainage techniques, bandaging and exercising. ${ }^{6}$ Cryotherapy is one of the oldest and most widely used modalities. Cryotherapeutic treatments cause a decrease in tissue temperature which in turn causes a decrease in cell metabolism, vasoconstriction, decrease in spasm and a decrease in inflammation. ${ }^{7}$ These effects can be increased with the application of compression with cryotherapy, moreover, compression can also be used alone in treatment. ${ }^{8}$ Compression alone 
causes a change in the pressure forcing the edema out of the affected tissues and into noncompressed areas. $^{8} \quad$ Manual lymphatic drainage techniques are interventions employed by medical personnel and allied health clinicians during a rehabilitation protocol. ${ }^{9}$ These techniques are used to open up new pathways in the superficial lymphatic system in the skin which will assist in moving the fluid into the reservoir to be filtered and drained. ${ }^{6}$ Other recent techniques are Hivamat and Kinesio Tape. Despite their popularity, there is very little research on the use of Hivamat as compared to other modalities such as electrical stimulation or ultrasound. Anecdotal evidence suggests the Hivamat "creates a fascial change by applying an intermittent electrostatic charge to the collagen matrix." ${ }^{11}$ Specifically the "HIVAMAT ${ }^{\circledR} 200$ operates at the level of the connective tissue using a pulsing electrostatic field, producing an intense resonant vibration within the tissues involved. The repetition of this phenomenon in rapid succession generates rhythmic deformations of the tissue. This action permits fiber and tissue layers to reacquire motility and malleability."11 Depending on the goals of the treatment Kineaio Tape can be used to improve active range of motion, relieve pain, adjust misalignment, or improve lymphatic circulation. ${ }^{12}$ Increased lymphatic circulation is achieved via the waves in the tape as it raises and folds the layers of the epidermis lifting the skin. ${ }^{12}$

Several studies ${ }^{9,12,13,14,15}$ have been performed examining the effects of therapeutic modalities and manual therapy. Evaluation of the methodological quality of these studies has been conducted in treating acute injuries. Despite the present investigations there has been little research conducted to examine the effects of these treatments on edema reduction through the lymphatic system. Because of this, it can be difficult for athletic trainers to determine whether treatments are truly effective and whether or not they can be applied clinically. Determining a treatment effect does not appear to be examined in the literature. This comparison can be useful 
when making the transition from basic science to practice. A methodologically sound study does not necessarily have clinical implications. Therefore, comparing the effect sizes of the group or treatment will demonstrate if that treatment favors the experimental group over the control. If the effect size favors the treatment group versus the control then it shows that the treatment was effective. From there it can be determined the treatment can be applied clinically since it was shown to be effective.

This study will evaluate the literature as it pertains to treatment methods of edema reduction through the lymphatic system during the acute phase of the inflammation process. The treatments investigated will include cryotherapy, compression, electrical stimulation, lymphatic drainage techniques and alternative methods. Evaluation will be performed using two separate techniques: 1) to evaluate the methodological quality of included studies using the PEDro scale and 2) to evaluate the effect size of these studies. Though several previous systematic reviews have examined the methodological quality, this review will empirically evaluate group and treatment results. This will assist the clinician to determine the effectiveness of a treatment and whether to use in clinical practice.

\section{METHODS}

Design

The design of this study is a systematic review. Studies were obtained through searches on specific databases using keywords, combinations of keywords, or cross referencing which were then evaluated using the PEDro Scale and a comparison of the effect sizes. Randomized control trials (RCTs) often give the medical field information about a certain treatment, however, a systematic review of those RCTs can offer methodological evaluation of those studies. ${ }^{16}$ These reviews have been believed by many authors to offer important information about the 
effectiveness of medical interventions. Evaluation can reveal lesser quality studies that may provide biased results of treatment effectiveness.

Instrumentation

The Physiotherapy Evidence Database (PEDro) scale is a tool used to evaluate the methodological quality of RCTs. ${ }^{16}$ The PEDro scale is an 11 item scale which was developed based on the 9 item Delphi scale ${ }^{17,18}$ and the 3 item Jadad scale. ${ }^{16}$ Each item receives one point which is added to the overall total score that ranges from $0-10$ with the exception of item one, which examines external validity and does not receive a point. ${ }^{16,18}$ In a study performed by Maher et al. ${ }^{16}$ using the PEDro scale in two separate studies, intracalss correlation coefficient (ICC) for interrater reliability was .55 at a 95\% confidence interval (CI) in the first study, and .56 at a $95 \% \mathrm{CI}$ in the second study. The ICC for consensus rating was .68 at a 95\% CI. Therefore, due to these findings it can be concluded that the PEDro score can be assessed with "fair" to "good" reliability. ${ }^{16}$ Further information can be found regarding the PEDro score in Table C1 and $\mathrm{C} 2$.

Data Sources

First, Pubmed (1951-2010), MEDLINE, CINAHL with Full Text (1982-2010), SPORTDiscus Full Text (1800-2010), MDConsult (1980-2010), Science Direct (1940-2010), Google Scholar and PEDro were searched using the terms lymphatic system, inflammation process individually. Second, the term lymphatic system was combined with each of the following words: injury, acute, treatment, edema, cryotherapy, electrical stimulation, compression, deep oscillation and Kinesio Tape. Third, citations were cross referenced from studies to include literature not found in the original search. This was performed for each individual database. All results were limited to peer reviewed studies available in the English 
language using human subjects. Once studies were selected they were compared to the inclusion/exclusion criteria to determine final inclusion into the study. The included studies were then evaluated with the PEDro Scale and a comparison of effect sizes was performed if data was provided.

Study Selection

Studies were included based on the following inclusion criteria: 1) available in the English language; 2) edema reduction or a form of the word lymphatic must be in the title; 3) the abstract must include the terms lymphatic system, edema, modalities and treatment; 4) acute injury must be the chief complaint in the study; and 5) the study must be a randomized controlled trial. The exclusion criteria included any chronic injuries or conditions.

Data Extraction

There were two forms of data extraction in this review. The first was the use of the PEDro scale to evaluate the methodological quality. The second was an examination of the effect size estimate based on the determination of Cohen's d.

Both investigators obtained training using the PEDro scale and met the requirements set forth by the developers. This was achieved through the use of the PEDro website. Once the training was completed, the studies that had been selected based on the inclusion criteria were evaluated. The studies were read first without the use of the PEDro scale, followed by a second reading which were then evaluated using the PEDro scale. Once this had been completed the studies were given a score from 0 to 10 based on the checklist. Both investigators compared their scores and if discrepancies occurred, discussion continued until a final score was agreed upon. The PEDro scale was chosen because it has been shown to have sufficient reliability when used in systematic reviews. ${ }^{16}$ 
The effect size estimate was utilized to examine the results of the study to determine if the final results can be applied to the population and whether the results offered enough of a difference to be considered a valid treatment. The Conhen's d effect size comparison has a standard scale in which less than a 0.4 is considered weak, from 0.41 to 0.7 as moderate and greater than 0.7 as strong. ${ }^{19}$ To determine which treatments or combination thereof was most effective at reducing edema, along with the hypotheses, this study had two questions. First, is cryotherapy combined with compression is more effective at reducing edema than the other treatments? Secondly, which treatment method alone is more effective in reducing edema? The effect size comparisons used the difference between the means at pre test and post test measurements for the experimental and the control groups. Due to the fact that there have been several previous systematic reviews, the effect size estimate will provide a quantitative approach in addition to the systematic review.

\section{DATA SYNTHESIS}

\section{Study Quality}

The 13 studies $^{20,21,22,23,24,25,26,27,28,29,30,31,32}$ that met the inclusion criteria and were evaluated varied in population, location, injury, inclusion/exclusion criteria and methodological quality. The subject populations consisted of volunteers and hospitalized patients that were recruited. Of the 13 studies, 5 of the studies had specific criteria for inclusion and exclusion from the study. ${ }^{21,23,24,28,30}$ The remaining 8 studies had a detailed inclusion or exclusion criteria but not both or had both but one was not thoroughly detailed. ${ }^{20,22,25,26,27,29,31,32}$ The inclusion criteria included acute injuries, ${ }^{20,27,30,31,32}$ surgical intervention, ${ }^{22,23,28,30}$, and one study used healthy subjects ${ }^{26}$. The exclusion criteria included any chronic lymphatic conditions, ${ }^{20} 21,23,24,25$, 
28,29 excessive musculoskeletal injury, ${ }^{20,21,23,25,29,30}$ and several other general medical exclusions that were inconsistent between studies. ${ }^{20,21,23,24,25,29}$

The methodological quality ranged from a $2^{28}$ to $8^{25}$ with a mean average score of 4.5 . The PEDro scores can be found in Table D5-D18. There were some discrepancies between the two raters, especially when evaluating for criteria 9. Steps were taken to insure understanding of the criteria and applied to the studies. Of the 13 studies most met some aspect of the inclusion criteria of this study. One of the inclusion criteria that was not met by all studies pertained to the chief complaint must be an acute injury. Six of the studies ${ }^{22,23,24,28,29,30,29}$ used subjects following a surgical repair, ${ }^{23,28,29,30}$ while others were used after an immobilization period. ${ }^{22,24}$ One other study used healthy subjects. ${ }^{26}$ This study was included because it was a rare study that examined the effects of lymphatic flow when ice and compression was applied. All but 4 studies $^{20,26,28,32}$ used random allocation for group assignment. Blinding was rarely performed in any of these studies. None of the studies blinded the therapist providing the therapy, while one $\mathrm{e}^{25}$ blinded the evaluators and only three ${ }^{21,24,25}$ blinded the subjects. Haren et $\mathrm{al}^{22}$ was the only study that did not perform a baseline measure. Information of the studies with PEDro scores can be found in Table D1-D4.

Treatment Techniques

Cryotherapy: This area of treatment was by far the most investigated with six of the 13 studies evaluating the effects on the lymphatic system and edema reduction. The greater number of studies performed on cryotherapy in comparison to other techniques is based on use in the clinical setting. Buzzard et al. ${ }^{20}$ examined the effects of pulsed shortwave diathermy versus ice therapy in the reduction of edema following calcaneal fractures. The author did not describe any of the allocation used to determine the experimental or control groups. Once demographic 
information and delay from injury to starting treatment were recorded baseline circumference measurements were taken of the affected foot and ankle. The measurements were performed "around the malleoli, around the calcaneum diagonally, and the forefoot at the level of the head of the fifth metatarsal. ${ }^{20}$ A goniometer was used to measure dorsiflexion, plantarflexion and subtalar inversion and eversion. These measurements were performed daily at 8:00 AM and 4:00 PM during the hospitalization in order to measure swelling, range of motion and any fracture blisters. The pulsed shortwave diathermy group received treatment twice a day using a pulse duration of $200 \mathrm{~ms}$, a pulse frequency of $26 \mathrm{~Hz}$ and an intensity of $35 \mathrm{~W}$ for 15 minutes. The cryotherapy group received Cryocuff treatment 6 times a day for 20 minutes. The author suggested that there is little evidence to support an optimum protocol for use of the cryocuff. Significant increases were reported for ankle range of motion $(\mathrm{P}=0.007)^{20}$ however, there was very little reduction in edema around the calcaneum, malleoli or forefoot in either group $(\mathrm{P}=$ $0.22)^{20}$. In the Cryocuff group, circumferential measurements were taken from day 1 to day 5 around the calcaneus $(33 \pm 2,33 \pm 2)$, malleolar $(27 \pm 2,27 \pm 2)$ and forefoot $(24 \pm 2,24 \pm 2)$. In the shortwave diathermy treatment there was only one difference in the calcaneal measurement $(34 \pm 2,33 \pm 2)$, with no other difference noted. Scheffler et al. ${ }^{28}$ observed the effect of the Cryocuff on the control of postoperative pain and edema. Allocation utilized to group the patients was not mentioned. The patients were instructed to use the Cryocuff for $30 \mathrm{~min}$ out of every hour and only perform this when awake. The Cryocuff was evaluated using three different methods consisting of the circumference of the experimental foot versus the control foot, the patients perceived pain at the first, second, third, and fourth postoperative visits, and the overall comfort of the Cryocuff. The only data presented by the study was that a standard deviation of 0.032 below circumference mean was noted in the group using the device, while a standard 
deviation for the control group was +0.167 above circumference mean. Individuals using this device on the test foot reported $80 \%$ less pain than the control foot. ${ }^{28}$ The perceived comfort was graded on a 0 to 5 scale with 0 being worst and 5 being best. The perceived comfort score using the Cryocuff was between a 4.64 and a 4.8 on the given criteria. This can be seen in Table D1.

Stockle et al. ${ }^{29}$ randomized 60 patients by assigning a continuous number according to the date of admission and then alternated the subjects into one of the three treatment groups. Each of the three groups consisted of 20 patients; the cool pack cryotherapy, continuous cryotherapy and an intermittent impulse compression group. Circumference measurements were taken at the ankle, midfoot and forefoot prior to surgery, the second day after surgery and then every 24 hours until the patient was discharged which was typically within six days. The cool pack therapy was changed four times a day and fixed around the swollen area with an elastic dressing. Continuous cryotherapy used the Polar Care 500 device which is similar to the Cryocuff, except instead of gravity this device uses a low-voltage pump to move the water. ${ }^{29 .}$ Temperature of the water was maintained at $12^{\circ} \mathrm{C}$ for 8 hours with the ice water changed twice a day. During the day the unit was used nearly continuously. For the intermittent compression group the A-V Impulse system was used. This unit is designed to simulate weight bearing by compressing and stretching the venae comitantes of the lateral plantar artery. The pad was inflated with air to $130 \mathrm{mmHg}$ for 1 second every 20 seconds. The unit was used nearly continuously throughout the day with the patient allowed to turn the unit off at night. Prior to surgery, continuous cryotherapy and the A-V intermittent compression were both effective in decreasing edema, however, the compression unit reduced posttraumatic swelling even faster than continuous cryotherapy. This study did not present any of the statistics performed and a brief summation of their results can be found in Table D1. 
Meeusen et al. ${ }^{26}$ examined lymph flow when cryotherapy and compression were applied. Thirty-nine healthy subjects volunteered for the study with the only criteria being no history of ankle injury in the last 4 years. ${ }^{26}$ The examiners placed at least five of the 39 patients into six different protocols which were $1{ }^{\circ} \mathrm{C}$ and $25 \mathrm{mmHg}, 1^{\circ} \mathrm{C}$ and $0 \mathrm{mmHg}, 15^{\circ} \mathrm{C}$ and $25 \mathrm{mmHg}, 15^{\circ} \mathrm{C}$ and $0 \mathrm{mmHg}, 32^{\circ} \mathrm{C}$ and $25 \mathrm{mmHg}, 32^{\circ} \mathrm{C}$ and $0 \mathrm{mmHg}$. Each subject had Human Serum Albumin Tc99m injected between the first and second ray of each foot and were allowed to rest under the gamma-camera as pictures of the lymph evacuation were taken every five minutes at the foot, knee and groin. Thermistors and pressure probes were attached to the skin and temperature and pressure readings were recorded every minute. Once 30 minutes had passed the Cryocuff was applied and removed at the completion of 60 minutes. Skin temperature obviously dropped lower according to the temperature of the water. An approximate $1.5^{\circ} \mathrm{C}$ lower temperature as well as a faster decrease in tissue temperature was noted when pressure was applied. The most significant finding in the study was the increase in lymph flow with the application of $1{ }^{\circ} \mathrm{C}$ with $25 \mathrm{mmHg}(\mathrm{P}<0.01) .{ }^{26}$ When $1^{\circ} \mathrm{C}$ with $25 \mathrm{mmHg}$ was compared to the others it was found to be more significant than $15^{\circ}(\mathrm{P}=0.003)$ and $32^{\circ}(\mathrm{P}=0.002)$ with no compression.

Cheing et al. ${ }^{21}$ examined the use of cryotherapy and pulsed electromagnetic field on the reduction of swelling after distal radius fractures. Eighty-three subjects were randomly allocated into four groups. Treatment was performed for five consecutive days with group a receiving ice and pulsed electromagnetic field, group b ice and sham electromagnetic field, group c pulsed electromagnetic field alone and group $\mathrm{d}$ sham pulsed electromagnetic field treatment. The pulsed electromagnetic field was delivered through a U-shaped applicator and was delivered at a frequency of $50 \mathrm{~Hz}$, with a field intensity of 99 gauss for 30 minutes based on the user's manual. 
The sham group was able to see the readout on the display but did not receive any treatment because the circuit was not complete in the back. ${ }^{21} \mathrm{~A}$ baseline visual analogue scale (VAS), volumetric measurement and range of motion assessment were performed and assessed again at days 1,3 and 5. At the completion of day three there was no significant difference in VAS between groups, although group d experienced the least amount of reduction in pain. By day 5 the reduction in VAS score was greater in group a $(1.8 \pm 0.8)$ when compared to the other groups ( $b=1.2 \pm 0.8, c=1.0 \pm 0.8, d=0.7 \pm 0.6$ ). For the volumetric measurements, from one to day three there was a significant difference $(\mathrm{P}=0.005)$ in the reduction between three groups $(\mathrm{a}=$ $10.4 \pm 10.3, \mathrm{~b}=5.2 \pm 8.1, \mathrm{c}=6.6 \pm 7.0)$ when compared to the control $(\mathrm{d}=-0.94 \pm 12.5)$. The study claimed significant differences from day one to day five $(a=25.0 \pm 16.2, b=20.2 \pm 11.5, c=$ 13.9 $\pm 7.2, \mathrm{~d}=6.9 \pm 18.4$ ) but did not present a significance. Once the study was completed post hoc testing was performed showing group a was considerably better than groups $\mathrm{c}$ and $\mathrm{d}$, while group $\mathrm{b}$ was better than group $\mathrm{d}$. However, there was no significant difference between groups $\mathrm{b}$ and c. Range of motion results varied based on the direction of motion. The difference in flexion improved significantly $(\mathrm{P}=0.034)$ from day one to day three in the two pulsed electromagnetic field groups $(\mathrm{a}=6.3 \pm 5.7, \mathrm{c}=7.1 \pm 6.1)$ versus the two sham groups $(\mathrm{b}=3.4 \pm 4.5, \mathrm{~d}=3.1 \pm 3.6)$ and again a similar increase was noted on day five, however it was not significant $(\mathrm{P}=0.084)$. Wrist pronation did not improve from day one to three $(\mathrm{a}=6.3 \pm 5.9, \mathrm{~b}=7.5 \pm 5.7, \mathrm{c}=5.0 \pm 4.6, \mathrm{~d}=$ 4.4 \pm 6.0$)$, but was more significant $(\mathrm{P}=0.021)$ by day five $(\mathrm{a}=18.0 \pm 10.8, \mathrm{~b}=15.9 \pm 9.3, \mathrm{c}=$ 13.4 $\pm 7.0, d=9.1 \pm 8.0)$. There was a difference between groups as groups a and $b$ decreased more edema than group $\mathrm{d}$. The difference between groups $\mathrm{b}$ and $\mathrm{c}$ were minimal. ${ }^{21}$

Weston et al. ${ }^{32}$ used 15 subjects who were suffering from mild to moderate level inversion ankle sprains. Part of the inclusion criteria was the use of a written questionnaire to 
rule out certain conditions. Data was collected using a bilateral tetrapolar impedance plethysmograph to measure changes in fluid volume. The subject was first allowed to sit for 10 minutes before lying prone for 10 minutes with their knees placed in $15-20^{\circ}$ of flexion throughout the remainder of the session. When 10 minutes had passed the resting data was collected. A blood pressure cuff was placed around the patients' thigh and inflated to $20 \mathrm{mmHG}$ below the resting diastolic blood pressure to allow arterial blood flow but obstruct venous return. Over the next 20 minutes 10 measurements were taken before a cold gel pack was placed on the ankle for an additional 20 minutes. The study claimed that there was approximately a 50\% reduction in volume increase when the cold gel pack was applied. There was no significant difference found in the patients systolic $(\mathrm{P}=0.31)$, diastolic $(\mathrm{P}=0.20)$ and heart rate $(\mathrm{P}=0.42)$.

An examination of the effect size of the two cryotherapy studies ${ }^{20,21}$ compared the treatment to the control at post test. Within the control cryocuff treatment, there was no change in the measurements $(\mathrm{d}=0.00)$ while within the treatment group there was a moderate effect of 0.50 which demonstrated that the treatment favored the post test and edema decreased. This effect, however, was not significant as the confidence intervals crossed over zero. Cheing et al. ${ }^{21}$ used four treatment groups as effect sizes ranged from -0.44 to -0.10 with a small to moderate effect for group b and group d, respectively. Group a had an effect size of -0.37 and group c had an effect size of -0.17 . Treatments favored the post test resulting in a reduction of edema. The confidence intervals crossed zero which demonstrated that the treatment effect was not significant.(Figure D10)

Studies in the cryotherapy treatment group scored $2,{ }^{28} 3^{20,29,26,32}$ and one study scored as high as $6 .{ }^{21}$ These studies did not blind the subjects, therapist or assessor or presented their data appropriately. Individual PEDro scores can be found in Table D5-D18. 
Compression: Compression is used frequently by athletic trainers. As shown in the Meeusen et al. ${ }^{26}$ study, cryotherapy treatment improved when combined with compression. Rucinski et al. ${ }^{27}$ used 30 subjects with sprained ankles and randomly assigned the subjects to three different treatment groups. The treatments were an elastic treatment group, intermittent compression group and an elevated control group. For the first group a plain ace bandage was used from the metatarsal heads to approximately 12.7 centimeters above the malleoli and was applied in the typical tighter to looser fashion with $45^{\circ}$ elevation for 30 minutes. The second group used a single cell intermittent compression device while the leg was elevated to $45^{\circ}$. The study utilized a protocol following Prentice with 60 seconds on and 15 seconds off with the pressure set to a range of $40-50 \mathrm{mmHG}$ for 30 minutes. Control group subjects elevated the leg $45^{\circ}$ for 30 minutes with no compression treatment. Baseline and post measurements were performed with a volumetric tank. Surprisingly the control group showed the most significant $(\mathrm{P}<0.01)$ decrease in edema (pre $=1350.4 \pm 201.6$, post $=1335.5 \pm 203.2)$ while the other two (compression pre $=1222.0 \pm 166.7$, post $=1229.4 \pm 166.5$; wrap pre $=1340.2 \pm 128$, post $=$ 1343.9 \pm 127.4$)$ treatments had an increase in edema with intermittent compression providing the most.

Tsang et al. ${ }^{31}$ examined the effect of intermittent compression versus elevation as a control condition. This study used 12 subjects presenting with a post-acute inversion ankle sprain. The subjects started in a dependent position for 10 minutes before a baseline volumetric measurement and blood pressure were taken. The subjects were then placed in a supine position with the injured ankle elevated either with or without intermittent compression for 30 minutes. Once treatment was completed the subject went back to a gravity dependent position with both feet flat on the floor. Measurements were taken every five minutes for the first 30 minutes then 
once at 45 and 60 minutes. The intermittent compression treatment was 45 seconds of inflation with 15 seconds of deflation at a pressure based on the patients' diastolic blood pressure. The results did not directly compare the two treatment methods, but both showed a significant $(\mathrm{P}<$ $0.05)$ reduction in edema from baseline to immediately after treatment (17.25 \pm 4.05$)$. However, once the patient resumed the gravity dependent position the effects were lost within five minutes as there was only a difference of 8.91 versus 17.25 .

Thordarson et al. ${ }^{30}$ used 30 patients with a closed Weber B or C ankle fracture. The patients were randomized into a pneumatic pedal compression (PPC) treatment group and a control group. The control treatment consisted of a posterior splint, ice and elevation while awaiting surgery. The PPC treatment consisted of the placement of the device on the foot with a posterior splint applied as the leg was elevated. The PPC device "works by intermittently compressing the veins in the foot, thus facilitating venous drainage...it inflates in less than one second, compressing the foot temporarily, and then deflates more gradually."30 Volumetric baseline measurements were taken daily up until the day of surgery. The results for this study are only presented as a change in volume from day one to day two and day one to day three. There was a decrease in volume in the PPC group by $88 \mathrm{~mL}$ from day one to two while control increased $33 \mathrm{~mL}(\mathrm{P}=0.027)$. From day one to day three the experimental group decreased an addition $31 \mathrm{~mL}$ while the control increased $32 \mathrm{~mL}(\mathrm{P}=0.049)$.

Rucinski et al. ${ }^{27}$ used three treatment groups and compared compression and elevation to an elastic wrap and elevation and elevation alone. The examination of the effect size confirms the findings in the study. The compression and elevation group had a weak effect size of 0.04 and $95 \%$ CI's ranging from -0.83 to 0.92 . That the treatment favored the pre-test which means the treatment increased edema. In the elastic wrap group there was a weak effect size of 0.03 
with $95 \%$ CI's ranging from -0.85 to 0.91 . Again the treatment favored the pre-test resulting in an increase of edema. The elevation group showed the only edema reduction with a weak effect size of -0.07 and $95 \%$ Cl's ranging from -0.95 to 0.80 , showing the treatment favored the post test. Though these findings were unexpected none of them were significant as the confidence intervals crossed zero ranging from -0.95 to 0.92 collectively.(Figure D10)

Studies in this section scored a $3,{ }^{30} 5^{31}$ and a $6^{27}$. All the studies did not receive a yes score for blinding the subjects, therapists or assessors. Thordarson et al. ${ }^{30}$ did not present any data, which made it difficult to determine the treatments effectiveness.

Massage: Massage appears to be used on occasion by athletic trainers but certainly not as often as the previous two treatments. Haren et al. ${ }^{22}$ examined the effects of manual lymph drainage (MLD) to reduce edema of the hand after fracture of the distal radius. Twenty-six patients were divided randomly into an experimental group and control group. All patients regardless of group received the same conventional treatment of elevation, active and passive exercises, and compression with elastic bandage while the external fixation was in place. Once the fixation was removed wrist exercises were added using a home program. The difference was in the 10 minutes of MLD as described by Vodder. In short, this method utilized a light surface massage starting proximally near the drainage into the right and left subclavian veins, and slowly continued distally into the injured area. Measurements were performed with a volumeter at 3, 17, 33 and 68 days after removal of the external fixation. Results showed a decrease in edema for the control (day $3=64 \pm 41$, day $17=50 \pm 35$, day $33=35 \pm 26$, day $68=24 \pm 20$ ) and experimental (day $3=39 \pm 12$, day $17=27 \pm 9$, day $33=19 \pm 9$, day $68=12 \pm 11$ ), with the effect size favoring the experimental group. 
Knygsand et al. ${ }^{24}$ used 30 patients randomly assigned into a control group receiving traditional edema treatment and a experimental group receiving modified manual edema mobilization (MEM). Treatments were three times a week for four weeks, then twice a week for two weeks. ${ }^{24}$ Treatment continued until the therapist felt functional requirements were met and the patient perceived it was at a level to suit their needs. The traditional treatment included elevation, compression and functional training along with Coban applied around the digits and proximal to the wrist. The modified MEM included "deep diaphragmatic breathing, exercises that started proximally and ended distally, terminus (supraclavicular area) stimulation, axillary stimulation in the uninvolved side, and MEM to the trunk region followed by MPP stimulation to the involved upper extremity." ${ }^{24}$ Measurements were performed using a volumeter and the subjects edema, pain, AROM and ADL at inclusion and at one, three, six, nine and 26 weeks. No significant difference between the two groups reduction of edema at inclusion (experimental $=86.8 \mathrm{~mL}$, control $=96.3)$, one week $(68.2,77.3)$, three week $(41.1,54.0)$, six weeks $(28.6$, $43.3)$ or nine weeks $(12.1,28.3)$ was evident. $(\mathrm{P}=0.33,0.40,0.31,0.13,0.06)^{24}$

Kessler et al. ${ }^{23}$ randomized 23 subjects with hindfoot surgery into two groups to assess the effectiveness of manual lymph drainage versus a control. Both groups received the same standard physiotherapy protocol consisting of thrombosis prophylaxis instructions, active and passive ankle movements and daily gait training on crutches. The ankle movements consisted of dorsiflexion and plantarflexion performed 50 times without resistance as well as 25 with resistance the same time of the day prior to the MLD. For the intervention group "gentle manual pressure was applied to each of the dermal lymphotomes to direct lymph flow to the nonobstructed lymph nodal areas...a firm pressure was applied to watershed areas..."23 for 30 minutes a day. This treatment was unique to each patient's needs and performed by the same 
licensed physiotherapist. A volumeter was utilized to measure the potential edema reduction measured two days after surgery and again at time of discharge. The study claimed that based on the results there was a significant $(\mathrm{P}=0.032)$ decrease in lower extremity swelling when compared to the control group. Data was only presented using a graph.

Haren et al. ${ }^{22}$ was the only study in this treatment group to present complete data to assess effect size. Measurements were at baseline then at three more points within the control group from baseline to the first measurement and then again from baseline to the end of the study the effect sizes were weak $(d=-0.34)$ and large $(d=-0.98)$ effect, respectively. The $95 \%$ confidence intervals for the shorter time period ranged from -1.09 to 0.40 and the longer time period ranged from -1.76 to -0.19 . Thus demonstrating the treatment favored the post test in both measures but was only significant and therefore effective over the longer period of time. The treatment group showed there was a large effect $(\mathrm{d}=-1.00, \mathrm{~d}=-2.25)$ for the treatment group favoring the post test with both demonstrating a significant and effective treatment with 95\% CI's ranging from -1.85 to -0.15 and -3.27 to -1.23 , respectively.(Figure D10)

This treatment group as a whole had higher scores than the previous two treatment groups. Two studies ${ }^{22,23}$ scored a 5 while one ${ }^{24}$ scored a 7 . These studies were not awarded points for the blinding of subjects, therapists and evaluators.

Electrical stimulation: Man et al. ${ }^{25}$ used 34 subjects with an acute ankle sprain and randomly assigned into either the neuromuscular electrical stimulation group (NMES), the submotor electrical stimulation or a group with electrodes but no electrical stimulation applied. Ankle girth measurements as well volumetric measurements were performed at baseline. The electrodes were placed over the tibialis anterior muscle of the injured limb. The electrical stimulation treatments lasted 30 minutes. Intensity was increased with the NMES group to the 
subjects maximum tolerance. The submotor group used an EMS unit turned up until a flicker of muscle contraction was seen, then the intensity was lowered. The subjects in the sham treatment received the same electrode placement but no electrical stimulation. No statistically significant differences were found in any of the three groups (NMES group $=$ pre $1522 \pm 262$, post $1515 \pm 230$; submotor group $=$ pre $1597 \pm 339$, post $1573 \pm 314$, sham $=$ pre $1324 \pm 215$, post $1352 \pm 213)$ when compared pre-test and post test $(\mathrm{P}>0.017){ }^{25}$

Examining the measures for the treatments in this study, the sham treatment had a weak effect size of 0.13 with $95 \%$ CI's ranging from -0.67 to 0.93 , indicating that the treatment favored the pre-test, but the treatment was not significant and ineffective as the CI's crossed zero. The submotor group had a weak effect size of -0.07 with $\mathrm{CI}$ 's ranging from -0.91 to 0.77 , which demonstrated that the treatment favored the post-test measurement but was not a significant effect as the CI's crossed zero. Examination of the NMES group showed a weak effect with an effect size of -0.03 and $95 \%$ CI's ranging from -0.86 to 0.81 . The treatment favored the post treatment measurement but the CI's crossed zero.(Figure D10)

Though there was only one study performed on humans pertaining to lymph treatment the study scored well and received an 8 . One point was not awarded as the therapist providing the treatment was not blinded and the intention to treat analysis was not provided.

Included in this search was alternative treatments which included the Hivamat and the Kinesio Tape method. No treatments pertained to the reduction of edema in an acute injury and were not used in this study. The Hivamat studies were on lymphedema which did not pertain to this study. The Kinesio Tape studies primarily dealt with pain reduction and chronic lymphedema treatment also. 


\section{DISCUSSION}

The purpose of this study was to examine the methodological quality of treatment studies for edema reduction and lymphatic evacuation found in the current literature. Along with the hypotheses, this study also asked two questions: First, is cryotherapy combined with compression is more effective at reducing edema than the other treatments? Secondly, which treatment method alone is more effective in reducing edema? Based on the effect sizes it can be stated that cryotherapy and compression, although effective in their respective studies, were ultimately ineffective as the confidence intervals of each group crossed zero. As per the second question, there was only one treatment to be truly effective. Haren et al. ${ }^{22}$ reported that the treatment group that received massage had a large significant effect demonstrating the treatment favored the post-test measurement. Therefore, the only treatment shown to be effective was manual lymphatic drainage. All of the other treatments were found to be ineffective. One problem, however, with the studies that received the effect size comparison is the sample size used. Therefore, there might be a larger effect size if the subject population size was larger. This can be seen further in Figure D10.

This review had three experimental hypotheses. The first one stated that there will be a difference in outcomes between the different treatment techniques. The second one stated that the severity of the traumatic event can have an effect on the type and amount of lymphatic management. The third one stated that there will be enough information in each study to be scored via the PEDro scale. Given the information provided, the first and third hypotheses were confirmed. There was not enough information presented in the studies reviewed to confirm or reject the second hypothesis. 
The methodological scores of the studies ranged from a 2 to an 8 with an average score of 4.5 which demonstrated that overall the studies were of poor quality. Most of the studies in this review used volumetric or girth measurement to evaluate the effectiveness of the treatments. Some studies examined range of motion and pain, however, due to the focus of this systematic review did not pertain. The outcomes of the studies had some positive findings and some unexpected ones as well. Several of the cryotherapy studies ${ }^{21,26,28,}$ supported the use of cryotherapy while other studies ${ }^{20,29,32}$ did not discredit but did not state that cryotherapy assisted in the reduction of edema. Compression treatments were shown to be effective, ${ }^{31}$ however, elevation is more effective and compression had an adverse effect. ${ }^{26}$ Tsang et al..$^{31}$ noted the effects last less than five minutes before edema begins to re-enter the area. All three of the massage treatment studies ${ }^{22,23,24}$ found success with treatment. The one stimulation study ${ }^{25}$ noted some changes but stated that it could have been attributed to the difference at baseline. Evaluation of Positive Outcomes

Cryotherapy and Compression: Some of the studies evaluated did find some positive outcomes for their respective treatments. The cryotherapy group rarely utilized a cryotherapy treatment alone and when it did it was found to be the least effective. ${ }^{29,32}$ The remainder of the studies utilized some form of compression mainly with a Cryocuff unit or similar. Buzzard et al. ${ }^{20}$ was the only study that did not notice a difference with the use of the Cryocuff. In their study shortwave diathermy was used in comparison instead of a control treatment or another cryotherapy treatment. Meanwhile, Meeusen et al. ${ }^{26}$ reported that a cryotherapy treatment was effective but the application of compression increased the effectiveness. Stockle et al. ${ }^{29}$ reported that the compression unit was the most effective but that the combination was more effective than a cryotherapy treatment alone. These effects could be due to vasoconstriction that occurs 
during the application of cryotherapy treatment as well as the decreased metabolic rate of the cells. ${ }^{29,26}$ Vasoconstriction can in fact reverse if the treatment is too cold but this was not the case in the studies reviewed. Meeusen et al. ${ }^{26}$ adds that the compression makes the treatment even more effective because the outside pressure results in an increase in hydrostatic pressure causing the fluid to flow out of the area.

The compression studies provided the most unexpected results found in this review. In the Rucinski et al. ${ }^{27}$ study the control group had the largest decrease in edema while the other two increased the amount of edema present. After the elevation or compression treatment ended and as soon as the athlete regained a gravity dependent position the effects gained in the treatment started to decrease within five minutes. ${ }^{31}$ The last study ${ }^{30}$ in this group used a nontraditional type of compression with a pneumatic pedal compression unit. This unit is applied to the foot and the attempt is to mimic the venous flow during ambulation. This is performed by allowing the vessels to fill, as they would during the swing phase, when the pump is off, then emptying, as they would during the stance phase, as the pump inflates. ${ }^{30}$ Positive results showed change by $121 \mathrm{~mL}$ by day one and an additional $63 \mathrm{~mL}$ on day two. Some explanation of the results was presented by Rucinski et al. ${ }^{27}$ as to why there was an increase in findings. The uniform pressure caused by compression can allow for a back flow of lymph, known as the rebound phenomenon, which can occur when the athlete changes position from elevation to a gravity dependent position. ${ }^{31}$ There was an increase in blood volume due to the response of the intermittent compression and a potential increase in temperature due to the application. As with the cryotherapy compression studies it is believed that the compression caused that change in the pressure gradient with an increase in lymphatic flow. ${ }^{30}$ 
Massage: The massage treatment studies scored well with PEDro scores of $5^{22,23}$ and $7 .^{24}$ The limitation to this section is the subjects used and not using acute injuries. Two of the studies $^{22,24}$ used subjects who were recovering from immobilization after a distal radius fracture. They were included because the patients were treated during an acute stage of rehabilitation where edema is present. The results varied on the effectiveness of massage as a helpful tool for the reduction of edema. Haren et al. ${ }^{22}$ found significantly less edema in the treatment group receiving the manual lymph drainage than in the control. Another type of massage was investigated by Knygsand et al. ${ }^{24}$ and manual edema mobilization was found to be statistically insignificant in edema reduction. The remaining study ${ }^{23}$ examined patients' immediately after surgery and discovered there was a significant difference in the group receiving the manual lymph drainage. While each of the studies presented different methods for performing the massage techniques, all used light circles that started up the chain working in an area ahead of the swelling. ${ }^{22,23,24}$

Electrical Stimulation: Electrical stimulation treatment has been very well supported using animal models, however, when applied to humans it appeared to be ineffective. ${ }^{25} \mathrm{~A}$ significant difference however, was attributed to a difference in baseline measurements. In the discussion by Man et al., ${ }^{25}$ possibilities are provided as to why the protocols were not effective. The greatest factor is the protocols could potentially be more effective in a situation where the swelling had occurred due to prolonged motionless standing causing venous return problems versus a capillary permeability. ${ }^{25}$ A motor reaction would cause stimulation of the musculovenous pump. Man et al. ${ }^{25}$ continues to theorize that such capillary permeability present in injuries for example ligament sprains, might respond better to submotor ES such as high volt. 
This was evaluated by Mendel et al. ${ }^{63}$ with positive results and can be read in further detail in Appendix B.

Limitations of the Study

Even though there were positive outcomes in the reported studies used, there are limitations that should be discussed. The first area pertains to the blinding of the subjects by the studies reviewed. Following the outline of the criteria for the PEDro scale only three studies $^{21,24,25}$ out of 13 blinded the subjects and even less blinded the assessor. ${ }^{25}$ It is difficult to speculate as to the reasons there was such little blinding performed in the studies. Blinding of subjects during treatments may be difficult in that the patient can feel ice or massage. Because blinding was not performed many of the studies were not awarded points. Six studies $^{20,26,28,29,30,31}$ out of the 13 received a score less than a 5/10. Mosley et al. ${ }^{17}$ points out that score of 5 or higher out of 10 is considered to have moderate to high methodological quality. Therefore, it can make it difficult to apply the results of those studies to clinical practice due to poor study design and potential biases.

The largest limitation of this study by far has to be the lack of literature on edema reduction for acute injuries and more specifically as it pertains to the lymphatic system. Athletic trainers are often charged with returning athlete's to play in a more accelerated mode and utilization of the lymphatic system may assist with this, but little evidence based support is available. Along with a lack of literature was a lack of data presented by the studies included, which meant evaluation of the effect size could not be performed on all studies. This could potentially be due to the time at which the studies were published where a graph of the data was more acceptable than presenting a table of means and standard deviations. Use of different treatment protocols for compression and cryotherapy are used but little is known about how 
much pressure to apply or the temperature of the ice bag. Meeusen et al. ${ }^{26}$ suggested that temperature of the water should be $1^{\circ} \mathrm{C} 25 \mathrm{mmHg}$ of pressure.

One of the inclusion criteria was that the study must be available in the English language, or an English translation. This could have caused a number of foreign studies not available in English to be excluded from the study that might have pertained to the other inclusion criteria. There were no studies on acute treatment for two widely used clinical products in Kinesio Tape and the Hivamat machine. The studies that were found in the search focused primarily on pain and chronic lymphedema, particular post mastectomy. Both are used on a daily basis in many athletic training rooms without knowledge of the exact mechanism of treatment effectiveness.

Though the PEDro scale is a widely accepted tool to grade the methodological quality there are still many others that are in use today. Though there is training to assist the raters in understanding the criteria there is still the human element and it is possible that the raters missed some of the information and scored a study either higher or lower than it was worthy. It is also unclear based on the criteria if some criteria are worth more than others despite only getting one point. For instance, many of the studies did not blind the subjects, therapists or assessors but that does not mean they were not good quality studies.

\section{Clinical Relevance}

The information in this review does provide some useful information to athletic trainers in that lymphatic treatment is not very well understood at this moment in time. Until more research can be conducted, the best option is clinical practice with some assistance from evidence based to determine treatment of acute injuries. Even the current studies lack high methodological quality resulting in potentially poor application to treatment of athletes. This is supported by an examination of the effect size of five studies. ${ }^{27,20,21,22,25}$ Comparing pre and 
post test within the group, one study demonstrated a strong effective size in both the treatment and control. Haren's study ${ }^{22}$ used a standard treatment for both groups which significantly reduced edema. The treatment group did slightly better and received the same treatment plus 10 minutes of manual lymphatic drainage technique. Therefore it can be concluded that the treatment was effective and the manual lymphatic drainage technique did assist in edema reduction.

Of the treatments reviewed in this study despite some low methodological quality studies, cryotherapy combined with compression is better than cryotherapy alone. Massage can be an effective tool to treat the lymphatic system after casting and immobilization. It may be a worthy treatment in an acute injury as pain allows. With only one EMS study it is difficult to recommend electrical stimulation in the treatment of edema. It might be good for pain modulation in an acute injury, but not to reduce edema.

\section{CONCLUSIONS}

Return to play is based on several different markers including, but not limited to, range of motion, strength, functional ability and edema. This study only examined one of those aspects. The results of this study show that the treatments employed by athletic trainers for edema reduction may not perform to the level that is expected despite their clinical following. Based on the studies found in this review and the only treatment that could potentially be effective is the manual lymphatic drainage massage technique. Research on edema reduction via the lymphatic system is an area that needs to be explored more in depth. It can be an effective resource if athletic trainers activate the lymphatic system to assist in edema reduction. Currently, the methods athletic trainers use are best clinical practice and not evidence based. 


\section{REFERENCES}

1. Smith C, Kruger M, Smith R, Myburgh K. The inflammatory response to skeletal muscle injury: illuminating complexities. Sports Med. 2008;38(11):947-969.

2. Merrick M. Secondary injury after musculoskeletal trauma: a review and update. $J$ Athl Train. 2002;37(2):209-217.

3. Houglum P. Soft tissue healing and its impact on rehabilitation. J Sport Rehabil. 1992;1:19-39.

4. Sharma P, Maffulli N. Tendon injury and tendinopathy: healing and repair. J. Bone Joint Surg. Am. 2005;87:187-202.

5. Kellet J. Acute soft tissue injuries - a review of the literature. Med Sci Sports Exerc. 1986;18(5):489-500.

6. Ellis S. Structure and function of the lymphatic system: an overview. The Lymphoedema Supplement. 2006;S4-S6.

7. Knight K. Cryotherapy in sports injury management. Int Perspect Physiother. 1989;4:163-185

8. Block J. Cold and compression in the management of musculoskeletal injuries and orthopedic operative procedures: a narrative review. J Sports

Med. 2010;1:105-113

9. Vairo G, Miller S, McBrier N, Buckley W. Systematic review of efficacy for manual lymphatic drainage techniques in sports medicine and rehabilitation: an evidence-based practice approach. J Manual Manipulative Ther. 17(3):E80-E89.

10. Comeaux Z. Dynamic fascial release and the role of mechanical/vibrational assist devices in manual therapies. J Bodywork Movement Ther. 2010;1-7.

11. Gasbarro V. Ruolo dell'oscilazione profunda (HIVAMAT 200) nel trattamento fisico del linfedema degil arti(Abstract only). La Medicina Estetica. 2006;30:473-479.

12. Tsai H, Hung H, Yang J, Huang C, Tsauo J. Could kinesio tape replace the bandage in decongestive lymphatic therapy for breast-cancer-related lymphedema? a pilot study. Support Care Cancer. 2009;17:1353-1360.

13. Bleakley C, McDonough S, MacAuley D. The use of ice in the treatment of acute softtissue injury: a systematic review of randomized controlled trials. Am J Sports Med. 2004;32(1):251-261.

14. Hubbard T, Aronson S, Denegar C. Does cryotherapy hasten return to participation? a systematic review. J Athl Train. 2004;39(1):88-94. 
15. Hubbard T, Denegar C. Does cryotherapy improve outcomes with soft tissue injury? (Abstract) J Athl Train. 2004;39(3):278-279.

16. Maher C, Sherrington C, Herbert R, Moseley A, Elkins M. Reliability of the PEDro scale for rating quality of randomized controlled trials. Phys Ther. 2003;83(8):713-721.

17. Moseley A, Herbert R, Sherrington C, Maher C. Evidence for physiotherapy practice: a survey of the physiotherapy evidence database (PEDro). Australian J Physiotherapy. 2002;48:43-49.

18. Sherrington C, Herbert R, Maher C, Moseley A. PEDro. a database of randomized trials and systematic reviews in physiotherapy. Manual Ther. 2000;5(4):223-226.

19. Mckeon P, Hertel J. Systematic review of postural control and lateral ankle instability, part 1: can deficits be detected with instrumented testing. J Ath Train. 2008;43(3):293-304.

20. Buzzard BM, Pratt RK, Briggs PJ, Siddique MS, Tasker A, Robinson S. Is pulsed shortwave diathermy better than ice therapy for the reduction of oedema following calcaneal fractures? Preliminary trial. Physiotherapy. 2003;89(12):734-742.

21. Cheing G, Wan J, Lo S. Ice and pulsed electromagnetic field to reduce pain and swelling after distal radius fractures. $J$ Rehabil Med. 2005;37:372-377.

22. Haren K, Backman C, Wiberg M. Effect of manual lymph drainage as described by vodder on oedema of the hand after fracture of the distal radius: a prospective clinical study. Scand $J$ Plast Reconstr Hand Surg. 2000;34:367-372.

23. Kessler T, Bruin E, Brunner F, Vienne P, Kissling R. Effect of manual lymph drainage after hindfoot operations. Physio Research International. 2003;8(2)101-110.

24. Knygsand-Roenhoej K, Maribo T. A randomized clinical controlled study comparing the effect of modified manual edema mobilization treatment with traditional edema technique in patients with a fracture of the distal radius. J Hand Ther. 2011.

25. Man I, Morrissey M, Cywinski J. Effect of neuromuscular electrical stimulation on ankle swelling in the early period after ankle sprain. Phys Ther. 2007;87:53-65.

26. Meeusen R, van der Veen P, Joos E, Roeykens J, Bossuyt A, De Meirlier K. The influence of cold and compression on lymph flow at the ankle. Clin J Sport Med. 1998;8:266-271.

27. Rucinski T, Hooker D, Prentice W, Shields E, Cote-Murray D. The effects of intermittent compression on edema in postacute ankle sprains. J Orthop Sport Phys Ther. 1991;14(2):65-69. 
28. Scheffler N, Sheitel P, Lipton M. Use of Cryo/Cuff for the control of postoperative pain and edema. J Foot Surg. 1992:31(1):141-148.

29. Stockle U, Hoffmann R, Schutz M, von Fournier C, Sudkamp N, Haas N. Fastest reduction of posttraumatic edema: continuous cryotherapy or intermittent impulse compression. Foot Ankle Int. 1997;18(7):432-438.

30. Thordarson D, Ghalambor N, Perlman M. Intermittent pneumatic pedal compression and edema resolution afte acute ankle fracture: a prospective, randomized study. Foot Ankle Int. 1997;18(6):347-350.

31. Tsang K, Hertel J, Denegar C. Volume decreases after elevation and intermittent compression of postacute ankle sprains are negated by gravity-dependent positioning. $J$ Athl Train. 2003;38(4):320-324.

32. Weston M, Taber C, Casagranda L, Cornwall M. Changes in local blood volume during cold gel pack application to traumatized ankles. J Orthop Sport Phys Ther. 1994;19(4):197-199 
APPENDICIES 


\section{APPENDIX A}

\section{THE PROBLEM}

\section{Research Question}

Clinicians have experience in an array of different acute injuries and often these injuries have associated swelling and edema. The resulting inflammation of the traumatic event is not entirely destructive in nature as the inflammatory process is important due to the "consistent and lasting response." ${ }^{\prime}$ Injury requires time to heal and the more damage an area sustains the more necrotic tissue arises resulting in a longer time for the removal, thus increasing return to play timelines. ${ }^{2}$ The tissue repair process is marked by three distinct stages, the inflammatory stage, the proliferation stage and the maturation stage. ${ }^{1,3,4,5}$ Each stage has a specific role in the healing of tissues, however, there is still very little agreement on the exact time line of these phases and is generally believed that they overlap. ${ }^{1,3,4,5}$ If the initial stage is not managed properly then there is risk of secondary injury due to ischemia and hypoxia. In Merrick's review, Knight's secondary injury model is examined by evaluating the different theories pertaining to the phenomenon of secondary injury, however, there has been little research conducted since then to assess the true mechanism of secondary injury. ${ }^{2}$

Primary injury can involve several musculoskeletal structures including muscles, ligaments and other connective tissue as well as neurovascular structures. ${ }^{2}$ As the arteries carry fluids to the area of injury, these fluids must be reabsorbed. Once the blood is pumped into the area, the interstitial fluid between the tissues increases so that the cells can absorb nutrients. At the same time waste is being excreted, ${ }^{6}$ thus creating a balance in the interstitial space. Should an increase in pressure from the waste and increased blood flow occur, an occlusion of the vascular and lymphatic structures may take place. This results in decreased arterial flow as well 
as decreased venous return. To balance the pressure in the area the fluid enters the prelymphatic channels. ${ }^{6}$ From there, the lymphatic system drains to the closest "watershed" area which are located at each axilla and groin region. ${ }^{6}$ The lymphatic system may malfunction and if this occurs the edema remains in the area prolonging secondary injury. The removal of excessive fluid is important to maintain a functioning lymphatic system.

There are several modalities and manual therapy techniques that the clinician can employ to assist the lymphatic system. These include but are not limited to compression units, manual lymphatic drainage techniques, bandaging and exercising. ${ }^{6}$ Manual lymphatic drainage and edema reduction techniques are interventions employed by medical personnel and allied health clinicians during a rehabilitation protocol. ${ }^{7}$ These techniques are used to open up new pathways in the superficial lymphatic system in the skin which will assist in moving the fluid into the reservoir where it can be filtered and drained. ${ }^{6}$ Other new techniques are Kinesio Tape and the use of the Hivamat. There is very little research on the use of Hivamat as compared to other modalities such as electrical stimulation or ultrasound. This unit claims to "create a fascial change by applying an intermittent electrostatic charge to the collagen matrix." 10 Specifically the "HIVAMAT® 200 operates at the level of the connective tissue using a pulsing electrostatic field, producing an intense resonant vibration within the tissues involved. The repetition of this phenomenon in rapid succession generates rhythmic deformations of the tissue. This action permits fiber and tissue layers to reacquire motricity and malleability."

With a lack of understanding the lymphatic system and the many techniques available for clinicians to use, little has been reported in the literature to suggest the most effective way for lymphatic drainage. At this time, clinicians do not have a basis of comparison for evidence based and best clinical practice. Thus, how are clinicians to know which method is the most 
effective and the method that provides the most benefit? Therefore the following research question is purposed: using a methodological quality assessment tool are there any studies to suggest that one lymphatic management or edema reduction tool will be better alone or in combination with other treatments?

Experimental Hypothesis

1. There will be a difference in outcomes between different management techniques.

2. The severity of the traumatic event can have an effect on the type and amount of lymphatic management.

3. There will be enough information in each study to be scored via the PEDro scale.

Assumptions

1. All studies will meet the inclusion criteria. The inclusion criteria will include but not limited to:

1. The studies were written in or translated to English.

2. Edema reduction must appear in the title.

3. The abstract must include the terms lymphatic system, edema, modalities and treatment.

4. Acute injury must be the chief complaint in the study.

5. The study must be a randomized controlled trial.

2. No studies will meet exclusion criteria.

3. Both primary and secondary reviewers using the PEDro scale will be reliable in scoring.

4. Coding for each study using the PEDro scale will be reliable.

\section{Delimitations}

1. All studies that were used were in the English language or English translation, thus eliminating other foreign studies of importance.

Limitations

1. There may be differences between the first and second reviewer. 
2. The inexperience of the reveiwers to properly score the study.

3. If there are disagreements about a studies score, the higher score will be used to show the study in the best light possible

4. Only studies published in the English language or in an English translation will be included.

Significance of the Study

As long as there is an athletic population there will be injuries sustained, resulting in time loss. Currently clinicians may not thoroughly understand the lymphatic system and therefore may not be aware of further effective treatments to decrease this time loss. Treatment at this time is predominantly best clinical practice represented by the RICE principle instead of a treatment protocol that is evidence based. Although the RICE principle has been the standard for several years it is important to stay current on new information that may dictate a change in treatment. To explore these new techniques clinicians may or may not be consistently investigating additional treatments that may enhance the healing process to decrease time loss from competition. To decrease time loss, the goal is to increase the flow of nutrients to the area while removing the necrotic tissue to prevent secondary injury, as a result lymphatic system and edema reduction management is an area of interest. This study will examine the literature to see if one method, or a combination there of, will be more effective to enhance lymphatic drainage. Creating an understanding in the role of the lymphatic system for edema reduction via presentations and publications for athletic trainers and sports medicine professionals is a goal of this study. Furthermore, multiple experimental studies will be evaluated and critiqued in regard to methodological quality as well as comparisons of effect size to help differentiate an effective acute injury treatment. 


\section{APPENDIX B}

\section{LITERATURE REVIEW}

Introduction

After an injury is sustained fluids and cells rush to the site to start debridement and the tissue healing process. The resulting inflammation of the traumatic event is not entirely destructive in nature as the inflammatory process is important due to the "consistent and lasting response."1 Injury requires time to heal and the more damage an area sustains the greater the increase in necrotic tissue resulting in a longer time for damaged tissue removal thus increasing return to play timelines. ${ }^{2}$ The tissue repair process is marked by three distinct stages, the inflammatory stage, the proliferation stage and the maturation stage. ${ }^{1,3,4,5}$ Each stage has a specific role in the healing of tissues, however, there is still very little agreement on the exact time line of these phases and is generally believed that all three phases overlap, ${ }^{1,3,4,5}$ with the exception of one author who states that only the last two phases overlap. ${ }^{33}$ If the initial stage is not managed properly there is risk of secondary injury due to ischemia and hypoxia. Knight's secondary injury model was reviewed while examining the different theories pertaining to the phenomenon of secondary injury, however, there has been little research since then conducted to assess the true mechanism of secondary injury. ${ }^{2}$

The lymphatic system plays a critical role in assisting in the removal of cellular waste. As the arteries carry fluids to the area of injury, these fluids must be reabsorbed. Once the blood is pumped into the area, the interstitial fluid between the tissues increases so that the cells can

absorb nutrients. At the same time a balance is created as waste is excreted. ${ }^{6}$ Should an increase in pressure from the waste and increased blood flow occur, an occlusion of the vascular and lymphatic structures may take place. This results in decreased arterial flow as well as decreased 
venous return. To balance the pressure in the area the fluid enters the prelymphatic channels. ${ }^{6}$ From there, the lymphatic system drains into the closest "watershed" area which are located at each axilla and groin region. ${ }^{6}$ The lymphatic system may malfunction and if this occurs the edema remains in the area prolonging secondary injury. The removal of excessive fluid is important to maintain a functioning lymphatic system.

There are several different techniques that clinicians can employ to assist the lymphatic system. These methods can be but are not limited to compression units, manual lymphatic drainage techniques, bandaging and exercising. ${ }^{6}$ Manual lymphatic drainage techniques are interventions employed by medical personnel and allied health clinicians during a rehabilitation protocol. $^{7}$ These techniques are used to open up new pathways in the superficial lymphatic system in the skin which will assist in moving the fluid into the reservoir where it can be filtered and drained. ${ }^{6}$ Other new techniques are Kinesio Tape and use of the Hivamat. There is very little research on the use of Hivamat as compared to other modalities such as electrical stimulation or ultrasound, but clinically the use has been advocated. This literature review will focus on the inflammatory process, including all three stages, the lymphatic system and the importance of fluid removal, the treatment modalities and the theory behind assistance with lymphatic removal.

\section{Inflammatory Process}

Once an injury has occurred there is an immediate inflammatory response by the body to address the traumatic damage. The inflammatory process is divided into three phases, the inflammatory phase, proliferation phase, and remodeling phase. At the beginning of the process the following signs and symptoms of heat, redness, swelling, and pain are evident. ${ }^{3,5,34-35}$ Of 
these, swelling can cause the most damage by inducing secondary injury. The second phase begins the repair of tissues while the last phase starts to prepare the tissues to return to a near normal functional level. Tendons and ligaments have similar structures ${ }^{36}$ of "bundles of parallel fibers made of dense connective tissue that play an important role in mediating normal movement and stability of joints, respectively." ${ }^{37}$ The difference in ligaments and tendons lies in the composition, ligaments contain approximately two-thirds water with the remaining one-third collagen, elastin, glycosaminoglycans(GAGs), fibroblasts and other substances. ${ }^{36}$ The amount of collagen in ligaments is less than that of protein, with greater proportions of type III collagen and GAGs than tendons. ${ }^{36}$ When muscle, tendon or ligaments are injured they are repaired via scar formation that connects the two ends of the torn tissue, and unlike bone, muscle, ligament and tendon cells do not regenerate. ${ }^{5,33}$ These soft-tissue structures all follow a similar healing process, impacted only by the severity and size of the damaged area. ${ }^{3}$

Inflammatory phase: The inflammatory phase should not be thought of as a negative episode but as an essential component of the healing process. During this time the foundation for the later stages of healing is developed. ${ }^{3}$ Immediately after the injury occurs there is a disruption of vascular structures and the capillaries become more permeable allowing for tissue fluids to enter the area. ${ }^{1,3,4,535}$ This increase in permeability and fluids results in the formation of a hematoma ${ }^{4,33,38}$ and causes a change in the hydrostatic and osmotic pressure. ${ }^{39}$ These two processes are responsible for maintaining the equilibrium for fluid exchange. ${ }^{39}$ The platelets entering the area attach to the exposed collagen fibers and release phospholipids to stimulate the clotting mechanism. ${ }^{3}$ Fibrin and fibronectin then enter the area and form cross-links with tissue collagen to construct a temporary and fragile plug to reduce the hemorrhaging and acts as the tissues only source of tensile strength. ${ }^{3}$ 
Neutrophils are responsible for the destruction of tissue via the production of destructive oxidizing agents and the removal of the resulting necrotic tissue from the area through a process called phagocytosis. There is however discrepancy in the time frame as to just how long the neutrophils are present. Oakes et al. ${ }^{40}$ stated that initially the inflammatory cells and polymorphonuclear cells are present first and within 24 hours monocytes and macrophages enter. Smith et al. ${ }^{1}$ stated that the neutrophils peak at 24-48 hours following injury and remain for up to 5 days, while Butterfield ${ }^{34}$ stated that neutrophils are dominant for the first four to 24 hours. Sharma et al. ${ }^{4}$ agreed with Oakes et al. ${ }^{40}$ stating that it is the monocytes and macrophages which are present and responsible for the phagocytosis of the necrotic tissue during the first 24 hours. The disagreement in the literature reflects a discrepancy in an exact timeline for the inflammatory process. Logic would argue that the reduced time that neutrophils are present would result in a decrease of injury, however, the interaction between these destructive enzymes and the repairing macrpophages is an important one. Without the presence of neutrophils the macrophage repair would occur at a slower rate. ${ }^{4}$ As a result, the neutrophils cause tissue damage to assist in tissue healing.

Along with these early cellular mediators are significant vasodiolators in the form of bradykinin and prostaglandins (PGs). The bradykinin is triggered by enzymes released after the injury and acts as a potent vasodiolator as well as increasing vascular permeability. ${ }^{3}$ Bradykinin also plays a role in the amount of calcium present in a cell which can be problematic during injury as an increase in bradykinin can lead to an increase in calcium causing damage to the mitochondria and the cell. ${ }^{41}$ Prostaglandins are released by the kinin system ${ }^{3}$ and $\mathrm{PGE}_{2}$ is one of the major prostanoids produced at the beginning of the inflammation process. ${ }^{42} \mathrm{PGE}_{2}$ is a significant vasodilator but has to be paired with a separate enzyme to increase permeability. ${ }^{42}$ 
The PGs also have an anti-inflammatory action as well due to an immunosuppressive effect which suppresses lymphocyte proliferation, migration, cell mediated cytotoxicity and secretion of cytokines. $^{42}$

As the process continues the macrophages arrive at the site of injury providing three main functions; antigen presentation, phagocytosis, and immunomodulation through production of various cytokines and growth factors. ${ }^{35}$ These cells originate in the bone marrow then circulate in the blood before maturation and are activated in different tissues. Prior to entering an injured tissue a monocyte "undergoes transformation into a larger phagocytic cell, the macrophage."35 The macrophages have three specific actions. Antigen presentation is a cellular function that produces antigens that lymphocytes receive to promote lymphocyte initiation. Macrophages assist in phagocytosis, ${ }^{4}$ which is the elimination of waste and debris as well as the termination of invading pathogens. ${ }^{35}$ The macrophages action, unlike the neutrophils, is specific to necrotic tissue and does not destroy healthy cells. These cells also express receptors that activate cells to produce cytokines and microbicidal substances and receptors that stimulate the migration/chemotaxis of the cells to sites of infection. ${ }^{35}$ The final role of the macrophages involves the release of cytokines that affect the regulation of immune and inflammatory responses. These cytokines act on the Th cells and either cause a cell-mediated response or a humoral response. Cell-mediated responses are used to defend against intracellular pathogens such as mononuclear and granuloma cells, while humoral responses are used in the defense in extracellular pathogens such as neutrophils. The later type of response assists with the mediation of tissue repair. These cells release more cytokines that are responsible for the recruiting and activation of fibroblasts which will ultimately secrete collagen to start the repair process. ${ }^{34}$ The cytokines triggered by the macrophages can also become pro or anti-inflammatory. This is 
determined based on the macrophages and the challenges faced in the injured area as well as enzyme exposure. ${ }^{43}$

Once these two primary inflammatory cells have completed preliminary tasks the resolution of inflammation can begin. Although the complete process nor the body's ability to switch from a pro-inflammatory state to an anti-inflammatory process is not entirely understood some components are a cellular response called apoptosis, formation of soluble mediators, and production of direct effectors. ${ }^{35}$ Apoptosis is a program in eukaryotic cells that causes cells to die and marks them for removal by the phagocytes. Although cellular death typically causes inflammation due to this process there is limited elevation of inflammation. This process is the normal route by which inflammatory cells are removed from the injured area. Should this process become defective, or there is a persistence of apoptotic cells that escape removal, chronic inflammation may result. The second aspect of inflammation resolution is soluble mediators. These are cells that are released by the body that decrease the inflammation process such as antiinflammatory cytokines and suppressor of cytokine signaling proteins. The final component utilizes antioxidants and protease inhibitors. The antioxidants are used to protect the host cells and prevent tissue damage. During the inflammatory process protease tissue destruction is normal. To prevent excessive tissue damage the body releases protease inhibitors. ${ }^{34,35}$

Should any of the aforementioned enzymes and cells not receive the appropriate signals or if there are large amounts of inflammation in the area, then the area can be subject to secondary injury. Secondary injury occurs when the edema from the primary injury causes damage to healthy uninjured cells. Merrick et al. ${ }^{2}$ suggested that there are two types of secondary injury. The first one is based on enzymes released from the lysosomes of the dead and dying cells. Although it is not well understood, some possibilities of enzymes release are acid 
hydrolases, phospholipases, various proteases, and possibly neutrophills. The more believed theory is secondary injury is due to hypoxic injury. This ischemia is achieved due to a combination of events: hemorrhage from damaged blood vessels, hemostasis from the clotting cascade, reduced blood flow from the inflammation induced increase in blood viscosity, and the increased extravscular pressure from an expanding hematoma and muscle spasm. ${ }^{2}$ This combination of events creates a hypoxic period which causes a metabolic imbalance and can result in oncosis, acidosis, and lysosomal digestion. This is important because vascular structures are unable to deliver oxygen to the uninjured cells and therefore are unable to use the oxygen for oxidative phosphorylation leading to dependence on the glycolytic pathway for adenosine triphosphate. This method is acceptable but only for a short period of time before the glycolytic pathway can no longer provide adequate ATP thus resulting in failure of systems within the cell consequentially causing cellular death and necrosis. ${ }^{2}$

The timing of this phase, and the entire inflammatory process, is not well understood, which causes discrepancies in the length. Houglum et al. ${ }^{3}$ presented some of these discrepancies. In a review of the literature, one study ${ }^{40}$ agreed with Kellet et al. ${ }^{5}$ that this phase lasts less than 4 days, while others disagree stating it lasts anywhere from 3 to 4 to $5^{33,44}$ days, 4 to 6 days and even 5 days or maybe longer ${ }^{1}$. Nonetheless, the overlapping of time between the phases during the inflammation process does exist, despite no definitive timeline. This is an area of research that needs to be emphasized as there are only theories as to the mechanisms during this phase but there is very little research to substantiate these theories. This discrepancy in the timeline could be resolved by conducting more in depth studies.

Proliferative phase: The second phase of the inflammatory process is the proliferative phase. This stage is marked by the removal of necrotic debris and an increase in friboblasts, 
myofibroblasts in musculoskeletal structures, and endothelial cells. ${ }^{3}$ The fibroblasts begin to synthesize the extracellular matrix (ECM) while the capillary buds develop ${ }^{5}$ to begin communication with existing capillaries. This combination of tissues is referred to as granulation tissue. The ECM plays an important role in the structure of the cell and soft-tissues by providing a scaffolding structure but also functions as a medium for the transportation of nutrients. ${ }^{38,45}$ Houglum et al. ${ }^{3}$ hypothesized that this structure plays a major role in tensile strength by dispersing stress throughout the structure, which prevents large amounts of force to be applied to weak points. The ground substance formed by proteoglycans and glycosaminoglycans ${ }^{3,4,38,45}$ which interact with the fibrous components of the ECM, continueing to help increase the stability. ${ }^{45}$ These roles can be hindered by the increase in fluid flux ${ }^{45}$ or damaged sustained from the injury resulting in cellular death. The rebuilding of the ECM is important during this phase to return stability to the injured soft-tissue by acting as an anchor for the fibroblasts. ${ }^{33,38}$ The fibroblasts are able to preserve the ECM by undergoing proliferation and secreting proteins involved in the production and remodeling. ${ }^{42}$ The proper reconstruction of the ECM is necessary for soft-tissue repair. ${ }^{43}$

As the fibroblasts increase, and the ECM regains stability, the original clot decreases and is replaced with a more densely packed permanent one. Although this structure is more stable than the previous one constructed during the inflammatory phase, the tensile strength of the structure is at the lowest level and is very prone to damage. ${ }^{3,5}$ The fibroblasts and fibronectin become more active and begin to lay down type III collagen ${ }^{4}$ which has thin, weak fibers. ${ }^{33,38}$ The type III collagen formed at this stage is "disorganized and gelatinous" until cross-linking ${ }^{38}$ occurs with the soluble tropocollagen molecules to create insoluble tropocollagen molecules that will form collagen fibrils. ${ }^{4}$ This cross-linking leads to maturation of the collagen giving it 
mechanical stability. ${ }^{33}$ Collagen fibers are organized in a hierarchichal levels that increase in complexity. ${ }^{4}$ This hierarchy begins with tropocollagen, fibers, fascicles, tertiary bundles and the soft-tissue structure itself. Collagen fibers are the smallest unit within the soft-tissue that can be tested mechanically. ${ }^{4}$ Although the scar continues to develop pressure sensitive and tension sensitive nerve endings, the vascular system remains immature and weak and can tear and bleed easily. As the scar continues to mature, around 10 days post-injury it has reached the stage at which it is not the weakest link. ${ }^{33}$ According to Houglum et al. ${ }^{3}$ by day seven there is a significant increase in the amount of collagen in the area which increases the tensile strength of the wound and by day 12 the type III collagen is replaced by type I which is more mature and much stronger. $\mathrm{Ng}$ et al. ${ }^{36}$ stated that collagen synthesis reaches its peak at about 3 weeks post injury. The final stages of this phase result in a reduction of the size of the hematoma, the capillaries decrease, the collagen fibers are more mature and are more densely packed. ${ }^{3}$ Some authors believe this stage extends to approximately 21 days after injury while others believe it can extend up to 6 weeks ${ }^{40}$ with the range somewhere between 3 to 14 weeks. ${ }^{3,4,5}$

Maturation phase: The final phase of the inflammatory process is the maturation phase. The literature agrees that this phase may take up to and potentially a year or longer post injury. $3,4,5,36,38,40$ During this phase the amount of type I collagen fibers continue to increase and begins to form bundles as the scar thickens. During the earlier portion of this phase the repair tissue changes from cellular to fibrous. ${ }^{4}$ The scar becomes more defined gaining strength from the increased tensile load ${ }^{3}$ as collagen fibers become aligned in the direction of stress. ${ }^{4}$ The originally random placement of type III collagen rearranges and reorients itself to a normal linear orientation. ${ }^{38}$ During the rehabilitation process it is important to stress the tissues in a controlled manner that will simulate how the structures will be stressed during activity. 
Lymphatic System

The lymphatic system has a significant role in the flow of body fluids, which can be even more important in the presence of an injury. The lymphatic system consists of lymph, lymphatic capillaries, pre-collector vessels, collectors, lymphatic trunks and lymphatic ducts, the structural layers of a lymphatic vessel, lymph nodes and lymphatic ducts. ${ }^{39,46}$ Each structure is another step closer to the elimination of excess fluid and cellular waste from the body. To assist in the movement of lymph through the system the body relies on built in pumps as well as muscular contractions.

Lymphatic anatomy: The smallest portion of the lymphatic system is not technically part of the lymphatic system. The ECM plays a critical role in the structure ${ }^{39,45}$ and beginning flow of the lymph from the interstitial space. ${ }^{39}$ The scaffolding support is important because of assistance in maintaining the structure and port of entry for the lymphatic fluid through the attachments of the anchoring filaments which sit perpendicular to the capillaries. The first stage of the lymphatic system is the formation of lymph which is clear or a pale-light yellow and consists of water, macromolecules, dying cells and other waste. ${ }^{46}$ Blood travels through the arterial capillaries plasma fluid and proteins are forced into the interstitial space. ${ }^{39}$ A majority of this solution is reabsorbed into the post-capillary venules but due to osmotic forces resulting from protein exravasation, there is some fluid left behind. This vacant fluid is absorbed through the interstitium and into the non-contractile initial lymphatics. ${ }^{47}$ This can be seen in Figure B1. Once this fluid is formed, it is collected in the first lymphatic vessels located in the superficial layer of the dermis which are permeable to macromolecules and serve a primary role in maintaining osmotic and hydrostatic pressures within the interstitial space. ${ }^{39}$ These vessels are referred to as capillaries and are described as "blind-ended" tubes consisting of endothelial layers 
and are made of attenuated epithelium..$^{39,46,47}$ At this level the vessels begin to produce one way valves and smooth muscle proceeding into the lower levels of the dermis. The space between the valves are known as lymphangions and each one serves as a contractile element which force the lymph to the next section. ${ }^{39,46}$ These elements can be seen in Figure B2.

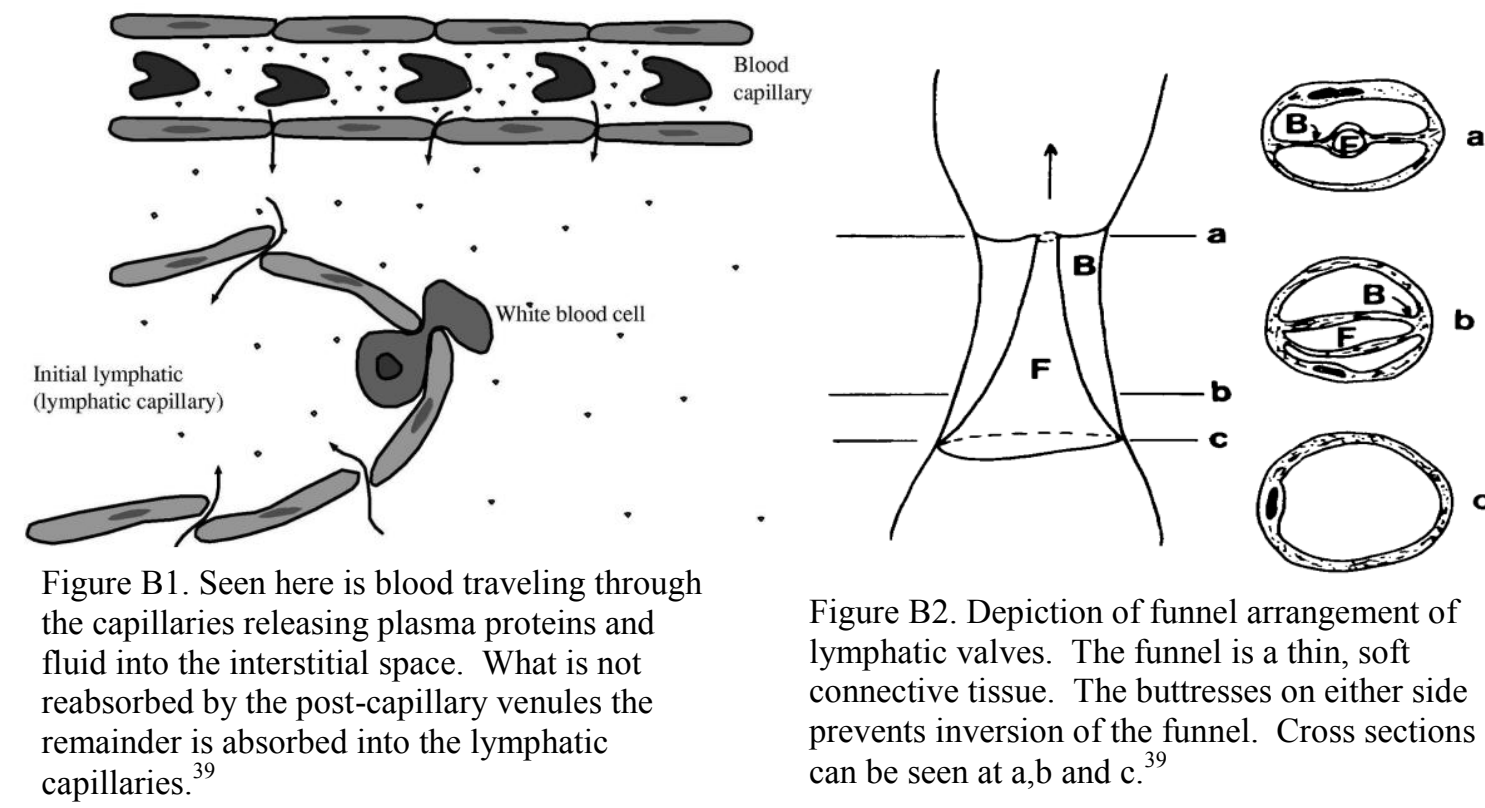

From there the lymph enter the collector vessels which resemble venous structures and less like the initial lymphatic structures, containing more valves and stronger contractile elements and no longer require attachments to the ECM. ${ }^{39,46}$ As the collector vessels course through the body in fewer numbers than the initial capillaries, they pass through the hundreds of lymph nodes scattered throughout. The lymph nodes vary in size and are covered in a fibrous tissue that enters into the node forming compartment dividers known as trabeculae which divide the node into three sections. These sections are the cortex, paracortex and medulla. In the cortex lymphocytes are packed densely into lymphatic nodules. The outer circle of the nodules contain 
T-lymphocytes, or T-cells, and macrophages, while the inner circle contains B-lymphocytes, or B-cells. The paracortex contains T-cells and the medulla contains both T- and Blymphocytes. $^{39,46}$

The final phase of the lymphatic system is for the collector vessels to enter the lymphatic trunks. $^{39,46}$ The exception to this are the lymph ascending from the lower limbs, pelvic and abdominal cavities, left side of the chest, head and neck and the left arm. These regions all drain into the lymphatic duct known as the cisterna chyli. The remaining vessels of the right side of the chest, head, neck and right arm enter the right lymphatic duct located at the base of the neck. Both the cistern chyli and the right lymphatic duct then drain into the left and right subclavian vein, respectively. ${ }^{39,46}$

Lymphatic flow: The edema from secondary injury can cause further damage and one cause can be due to a disruption of lymphatic drainage. ${ }^{39}$ When edema is present it distorts the mechanical equilibrium. This failure to maintain equilibrium can be due to a blockage of the lymph node, buildup of osmotic forces within the interstitium, ${ }^{47}$ damage to the interstitial lymphatic connections or changes in the mechanical properties or composition of the ECM. ${ }^{39}$ Once the tissues begin to swell, cells may release enzymes that recruit inflammatory cells which aggravate the situation causing ECM degradation. Once this happens the forces normally placed on the anchoring filaments by the ECM would decrease due to the loss in structure resulting in a collapse of the beginning lymphatics. ${ }^{39}$

Unlike the circulatory system the lymphatic system lacks any sort of mechanical pump to force fluids through the system. ${ }^{39,46}$ The lymph enters the lymphatic capillaries due to the increase of lymph placing radial stress on the anchoring filaments from the ECM. The diameter of the openings are increased and the overlapping of the sides act as a one-way valve to prevent 
any back flow. Once this takes place the continuation of the pressure within these tissues forces the lymph along through the pre-collectors and into the collectors. ${ }^{39,46,47}$ The one way valves and the lymphangions assist in maintaining the flow. As the lymph fluid enters one lymphangion the smooth muscle of the vessel walls contracts ${ }^{47}$ forcing lymph through the one way valve and into the next lymphangion. There are several external forces also acting on the lymphatic system. ${ }^{39,46}$ Due to the often close proximity to vascular structures of the circulatory system, the pulsations of the neighboring structures assists in the flow. ${ }^{39,46}$ Another method is the contraction of the surrounding muscles which help to force the lymph through the vessels when compressed by the muscle..$^{39,46,47}$ The final external force on the lymphatic system is the low pressure force created in the thoracic cavity during respiration. Due to the location of the ducts in the thoracic cavity the low pressure helps pull the lymph through the vessels towards the ducts. ${ }^{39,46}$

Lymphatic course: The course of the lymphatic system is very extensive ranging from the head, down each arm and into the legs. As the arterial vessel enter the tissues there is communication with the venular vessels to create a meshwork of arterioles called arcade arterioles. ${ }^{47}$ These arterioles continue and connect to the capillaries via the transverse arterioles. The lymphatic vessels lie adjacent to the arterioles and follow their course. They follow the transverse minimally but do not follow the capillaries. ${ }^{47}$ The first level of the lymphatic system are the capillaries and therefore the structures discussed will be primarily the collecting vessels. The collecting vessels in the foot have two layers a superficial and a deep layer that track with the superficial and major vascular bundles, respectively. ${ }^{48}$ The medial superficial lymphatic vessels tend to be larger and more numerous than those on the lateral side and are responsible for draining the medial side of the dorsum and sole of the foot. These vessels congregate on the great saphenous vein and run with it to the vertical group of the superficial inguinal lymph nodes 
and then to the deep inguinal lymph nodes along the proximal femoral vein as well as possibly enter the external iliac lymph nodes located along the external iliac vein. On the opposite side the lateral superficial lymphatic vessels drain the lateral side of the dorsum and sole of the foot. A majority of these vessels pass posterior to the lateral malleolus and accompany the small saphenous vein to the popliteal fossa entering the popliteal lymph nodes along with the deep lymphatic vessels of the foot. In the popliteal fossa there are two lymph nodes, the superficial popliteal group and the deep popliteal group. The superficial nodes are small and are located in the subcutaneous tissue. A node is located at the termination of the small saphenous vein and receives lymph from the lymphatic vessel that corresponds with the vein. The deep popliteal nodes envelop the vessels and receive lymph from the joint capsule of the knee and the vessels that accompany the deep veins of the leg. From there the lymph pass through the femoral vessels to the inguinal nodes and then on to the iliac nodes. Drainage of the gluteal region follows the superior and inferior gluteal lymph nodes to the internal, external and common iliac lymph nodes and end in the lateral aortic lumbar nodes. Lymph from the superficial gluteal tissues enters the superficial inguinal lymph nodes. ${ }^{48}$

Drainage of the upper limbs starts with superficial lymphatic vessels arising from the lymphatic capillaries in the fingers, palm and dorsum of the hand and course with the cephalic and basilic veins. ${ }^{48}$ The vessels running with the basilic vein enter the cubital nodes which are located proximal to the medial epicondyle and medial to the basilic vein. From this point the vessels ascend the arm into the humeral axillary lymph nodes. The majority of the superficial lymphatic vessels that run with the cephalic vein cross the proximal portion of the arm and the anterior aspect of the glenohumeral joint to enter the apical axillary lymph nodes although some vessels may enter the deltopectoral lymph nodes. 
The deeper vessels are less numerous and run with the major deep veins in the upper limb and terminate in the humeral axillary lymph nodes. They are responsible for draining the joint capsules, periosteum, tendons, nerves, muscles and ascend with the veins and encounter fewer lymph nodes than superficial. The axillary lymph nodes are divided into five groups, pectoral, subscapular, humeral, central and apical. The pectoral nodes are located along the medial wall of the axilla, around the lateral thoracic vein and the inferior border of the pectoralis minor and consists of three to five nodes. These nodes receive lymph from the thoracic wall including the breast quadrant and subareolar plexus. The subscapular nodes are located along the posterior axillary fold, subscapular blood vessel, consist of six or seven nodes and are fed by the posterior aspect of the thoracic wall and scapular region. The humeral nodes are located along the lateral wall of the axilla, medial and posterior to the axillary vein and consist of four to six nodes. These nodes are responsible for almost all the lymph from the upper limb except for what is carried by the lymphatic vessels running with the cephalic vein which drains to the apical and infraclavicular nodes. After passing through one of these three lymph nodes the lymph moves to the central nodes, which are comprised of three to four large nodes located deep to the pectoralis minor near the base of the axilla along with the second part of the axillary artery. After moving through the central nodes lymph passes through the apical nodes which are located at the apex of the axilla along the medial side of the axillary vein and the first part of the axillary artery. These nodes receive lymph from the other axillary lymph nodes along with the lymphatics running with the cephalic vein. The efferent vessels from the apical nodes ultimately form the subclavian lymphatic trunk however, some vessels might drain through the clavicular nodes. Once the subclavian trunk is formed it may be joined by the jugular and bronchomediastinal trunks on the 
right side to form the right lymphatic duct. On the left side the subclavian trunk most commonly joins the thoracic duct. ${ }^{48}$

Lymphatic Treatment and Edema Reduction Assistance

The secondary injury is a process that should be avoided and thus it is believed, and many athletic trainers practice, that decreasing the present edema and preventing further edema in the area is important. Treatment of the lymphatic system and edema reduction in the occurrence of acute injuries has not been studied as much as other areas in the treatment of athletes. The typical treatment of acute injuries consists of cryotherapy ${ }^{49,50}$ and compression ${ }^{8}$. This section will aim to discuss the physiological effects and theory behind cryotherapy, compression, massage, electrical stimulation, other less studied modalities and manual therapy.

Cryotherapy: Cryotherapy is one of the most common modalities for the treatment of acute musculoskeletal injuries. Athletic trainers typically use this when treating athletes without prior knowledge of the cellular effects. This may be because there is be little research into the exact physiological response to cryotherapy. ${ }^{14}$ It is generally believed that when the tissue temperature is decreased, pain, cellular metabolism and muscle spasm decreases. ${ }^{50}$ In some studies, cryotherapy decreased tissue temperature which reduced oxygen demand and cellular metabolic activity and decreased vasodilation decreasing the circulating blood volume. ${ }^{51}$ The result of this is an attenuation of the hydrostatic pressure which causes local edema in the presence of damaged cells. ${ }^{51}$ It is also believed that by using cryotherapy the inflammatory response will decrease and therefore decrease recovery time. Pain and muscle spasm is thought to decrease by the slowing of the nerve conduction velocity when the skin reaches $15^{\circ} \mathrm{C}$. By decreasing the cellular metabolism secondary injury is believed to be decreased. Vasoconstriction occurs first, therefore limiting the future delivery of more tissue fluids into the 
area of insult, and secondly, reduces the hypoxic injury due to the decrease in metabolic requirements.

Currently there is little research to support the length of treatment parameters. Bleakley et al. ${ }^{49}$ used treatment parameters ranging from 10-20 minutes two to four times a day, up to 2030 minutes and even 30-45 minutes every 2 hours. Hubbard et al. ${ }^{14}$ reported that there have been no studies with good methodological quality of clinical trials of cryotherapy as well as no studies evaluating the effects of cryotherapy on muscle contusions or strains. Schaser et al. ${ }^{51}$ studied the effects of prolonged cryotherapy after inflicted trauma on rats. They found that continuous cryotherapy for six hours after insult within the first 24 hours improved nutritive tissue perfusion, preserved cellular viability and attenuated leukocyte mediated tissue destruction. In addition, most of the studies reviewed by the previously mentioned authors, included an adjunct of compression and/or elevation, therefore making it difficult to evaluate the true effects of the cryotherapy treatment. The brief review of the literature shows that though there have been many experimental studies performed on human subjects, very few have been of good methodological quality. Bleakley et al. ${ }^{49}$ performed one of the more extensive searches comparing several treatments methods involving cryotherapy. Despite the number of studies examining cryotherapy not one study was graded higher than a 5/10 on the PEDro scale. The PEDro scale was developed to rate randomized control trials on the Physiotherapy Evidence Database. ${ }^{16}$ This scale is an 11 item scale to assess the methodological quality. For each criteria that is satisfied, with the exception of item one, one point is awarded to the total score. ${ }^{16}$ Though perfect scores on the PEDro scale are not obtainable due to the inability to blind subjects to the exposure of cold, higher scores should be achieved. ${ }^{15}$ Each of the studies examined in systematic 
Table B1. Comparison of Cryotherapy Studies

\begin{tabular}{|c|c|c|c|}
\hline Study & Subjects & Treatment & Results \\
\hline Schaser $^{51}$ & $\begin{array}{l}21 \text { Male Sprague- } \\
\text { Dawley Rats }\end{array}$ & $\begin{array}{l}3 \text { groups, } 1 \text { ) room temp } \\
\text { saline, } 2 \text { ) cold saline } 8^{\circ} \mathrm{C}, 3 \text { ) } \\
\text { No treatment }\end{array}$ & $\begin{array}{l}\text { Cryotherapy was confirmed } \\
\text { to decrease secondary tissue } \\
\text { damage by a decrease in } \\
\text { posttraumatic capillary } \\
\text { dysfuntion and leukocyte- } \\
\text { edothelial cell interaction }\end{array}$ \\
\hline $\begin{array}{l}\text { Bleakley and } \\
\text { McDonough }^{49}\end{array}$ & $\begin{array}{l}70 \text { patients who had a } \\
\text { grade } 1 \text { or grade } 2 \\
\text { lateral ankle sprain }\end{array}$ & $\begin{array}{l}2 \text { groups, } 1 \text { ) ice bag } \\
\text { application } 20 \text { minutes every } \\
\text { two hours, } 2 \text { ) intermittent } \\
\text { group applied ice for } 10 \\
\text { minutes, removed for } 10 \\
\text { mintues then reapplied for } \\
10 \text { minutes }\end{array}$ & $\begin{array}{l}\text { Intermitent cryotherapy } \\
\text { significantly reduced the } \\
\text { level of subjective pain on } \\
\text { activity, one week after } \\
\text { injury when compared. } \\
\text { There was no other } \\
\text { signifcant differences } \\
\text { between groups. }\end{array}$ \\
\hline Block $^{8}$ & $\begin{array}{l}\text { Systematic review, } 21 \\
\text { studies }\end{array}$ & $\begin{array}{l}\text { Examined cryotherapy on } \\
\text { ankle sprains, knee ligament } \\
\text { repair, total knee } \\
\text { arthroplasty, four } \\
\text { miscellaneous. }\end{array}$ & $\begin{array}{l}\text { The studies were not } \\
\text { uniform in their choices of } \\
\text { experimental and control } \\
\text { groups, study duration, } \\
\text { sample size or surgical } \\
\text { procedure }\end{array}$ \\
\hline $\begin{array}{l}\text { Bleakley, } \\
\text { McDonough } \\
\text { and MacAuley } \\
50\end{array}$ & $\begin{array}{l}\text { Systematic review, } 22 \\
\text { studies }\end{array}$ & $\begin{array}{l}\text { Examined randomized } \\
\text { controlled trials describing } \\
\text { human subjects recovering } \\
\text { from acute soft tissue } \\
\text { injuries, and employed } \\
\text { cryotherapy in isolation or in } \\
\text { combination with other } \\
\text { treatments }\end{array}$ & $\begin{array}{l}\text { Mean PEDro scale score of } \\
3.4 / 10 \text {. Little evidence to } \\
\text { supports the use of } \\
\text { cryotherapy in a wide realm } \\
\text { of settings, no optimal mode } \\
\text { or duration was established } \\
\text { either. }\end{array}$ \\
\hline $\begin{array}{l}\text { Hubbard and } \\
\text { Aronson }^{14}\end{array}$ & $\begin{array}{l}\text { Systematic review, } 4 \\
\text { studies }\end{array}$ & $\begin{array}{l}\text { Randomized controlled trials } \\
\text { of cryotherapy on return to } \\
\text { participation measures }\end{array}$ & $\begin{array}{l}\text { Scored from } 2 \text { to } 4 / 10 \text { on the } \\
\text { PEDro scale. Despite the } \\
\text { wide use of cryotherapy few } \\
\text { authors have examined the } \\
\text { effect of cryotherapy alone } \\
\text { on return to participation }\end{array}$ \\
\hline $\begin{array}{l}\text { Hubbard and } \\
\text { Denegar }^{15}\end{array}$ & $\begin{array}{l}\text { Systematic review, } 22 \\
\text { studies }\end{array}$ & $\begin{array}{l}\text { Examined cryotherapy on a } \\
\text { number of levels, including } \\
\text { with other therapies, } \\
\text { comparisons with no } \\
\text { treatment, placebo, different } \\
\text { protocols, outcome } \\
\text { measures of function, pain, } \\
\text { swelling, ROM }\end{array}$ & $\begin{array}{l}\text { PEDro scores ranged from } 1 \\
\text { to } 5 \text { out of } 10 \text {, avg score } 3.4 \text {. } \\
\text { Based on current evidence } \\
\text { cryotherapy seems to be } \\
\text { effective in decreasing pain. } \\
\text { The exact effect should be } \\
\text { studied. }\end{array}$ \\
\hline
\end{tabular}


reviews were able to present positive findings, however, caution must be taken when applying them due to the low PEDro scores. Studies need to be performed to preserve methodological quality. In addition, it is evident that cryotherapy needs to be further researched to truly understand the effects on many criteria, particularly, on the inflammation process, lymphatic absorption and flow.

Compression therapy: Cryotherapy typically is used with some form of compression to force the edema away from the compression where the lymphatic system is less affected and can be reduced more effectively. The two combined modalities collectively increased the rate, magnitude and depth of penetration as well as increased lymph evacuation. ${ }^{8}$ The compression can be of varying types to assist in static, modified compression and intermittent compression. ${ }^{52}$ The effects of compression include action on the lymphatic system, reducing edema, skeletal muscle contractions and create local pressure gradients. ${ }^{52}$ For edema reduction, the external pressure gradient is the critical component. After the acute injury and the inflammatory process, compression can cause the tissues to return to a normal hydrostatic pressure overcoming the osmotic pressure and can cause the effusion to slow or even stop. The other positive component to compression is the decreased space between tissues for more swelling to accumulate. ${ }^{52}$

Guidelines should be followed to achieve maximum benefit and prevent further damage or regression. Application of compression, unlike cryotherapy, can and should be applied continuously for the first 72 hours according to Kreamer et al. ${ }^{52}$ Next, it is beneficial to have a pressure gradient that forces the tissue fluids and edema from distal to proximal. Lastly, when applying compression it is important to insure that the pressure does not exceed the diastolic pressure. Pressure between 35 and $55 \mathrm{mmHg}$ has shown an increase in venous flow. ${ }^{52}$ 
Compression has recently been accepted as an adjunct modality and research has found compression helpful in diminishing the swelling presented with acute soft tissue injury, improving alignment and mobility of scar tissue and progress proprioception. ${ }^{52}$ Similar to cryotherapy, compression therapy studies have difficulty satisfying methodological qualifications. Two of the studies examined in Table B1 for cryotherapy also used a compression component. ${ }^{8,49}$ Block's review of the literature was a narrative review and presented the studies versus a critical evaluation. Bleakley et al ${ }^{49}$ critically evaluated several cryotherapy studies, including those in which were paired with compression. In one such study comparing ice with different modes of compression, insufficient data was reported and few conclusions could be drawn. Some of the other studies that Bleakley et al. ${ }^{49}$ examined compared ice and compression versus no ice, ice and compression versus ice, and ice and compression versus compression. One treatment of ice and compression was just as beneficial as no treatment when it came to reducing pain, edema and increasing ROM, however, insufficient data was provided. Though there was no control across subjects in the lone study, it was found that the combination of treatment was more effective than icing alone. This was determined by the observation of a reduction in intramuscular and oral analgesia after ACL reconstruction. There were several studies that attempted to determine the effects of compression without ice. Of these studies four did not use the same mode of compression between the intervention and the control group thus making it difficult to confirm the efficacy of the treatment. In an additional eight studies, type of compression applied was strictly controlled across groups. Of these studies only two found significant support for the use of ice and compression versus compression alone, however, the PEDro scores were low. ${ }^{49}$ Research performed to evaluate the treatments that 
many athletic trainers are utilizing on a daily basis cannot be validated as a methodological study and therefore it is difficult to apply the findings clinically.

Lymphatic massage: Lymphatic massage is the hands on approach to edema reduction. It has been utilized for centuries throughout civilization. ${ }^{53,54,55}$ There are several different techniques that can be instituted during a regular tissue massage, however, there are special manual techniques that can be used when targeting the lymphatic system. As cited in Williams ${ }^{56}$ manual lymphatic drainage was originally illustrated by Vodder and is often used in the treatment of lymphedema patients. It is believed that this method is effective because of the sensitive nature of the lymph vessels to mechanical stimulation. ${ }^{22}$ The increase of the lymph fluid flow ${ }^{53,57}$ into the lymphatic capillaries as well as increasing the collector contraction rate is promoted. $^{56}$ The basis for the use of manual lymphatic drainage lies in the theories that stimulating the lymphatic system increases lymph circulation. ${ }^{7}$ Expediting the removal of biochemical wastes from body tissues, enhancing body fluid dynamics resulting in edema reduction, decreasing muscle tone to create a non stressed body frame work state are some of the positive results. $^{7}$

Techniques for massage treatment will vary between clinicians even though some basic procedures have remained unchanged. ${ }^{54}$ The basic types of massage are effleurage, petrissage, friction, tapotement and vibration. ${ }^{54,58}$ The resulting action of these causes a manipulation, methodical pressure, friction, rubbing and kneading type effect depending on the stroke utilized. ${ }^{55}$ Some other techniques that can be utilized is friction massage, particularly augmented soft tissue mobilization (ASTM) $)^{57,59}$ to assist in the healing of tendons. ${ }^{53,57,59}$ The pressure of the massage induces an increase in fibroblast presence thus the resulting fibroblast activation and proliferation causes an increased rate in tendon healing. ${ }^{57,59}$ 
This soft tissue mobilization technique is often utilized in the management of different conditions including pre- and post-exercise inflammatory response, muscle soreness and increased lymphatic flow. ${ }^{57}$ However, despite these claims, there is very little evidence to support massage usage, ${ }^{7,54,57,58}$ therefore, this may be poorly understood. ${ }^{55}$ In reviewing the literature there is very little evidence to support the use of massage. One study ${ }^{59}$ was able to find and report evidence of a form of massage having a positive effect yet at the same time, another study ${ }^{60}$ negated the claims as to why massage works. There are several literature reviews available, however, these reviews do not evaluate the literature for methodological quality. One study did, but due to the inclusion criteria only three studies fulfilled the inclusion criteria to be evaluated. While these studies scored well, there is still not enough research available on the physiologic effects of massage or to confirm wide spread usage as is evident throughout the literature. , $^{73,54,55,57,58}$.

Table B2. Comparison of Massage Treatment Studies

\begin{tabular}{|c|c|c|c|}
\hline Study & Subjects & Treatment & Results \\
\hline Gehlsen $^{59}$ & $\begin{array}{l}30 \text { male White } \\
\text { Sprague-Dawley rats }\end{array}$ & $\begin{array}{l}5 \text { groups, 1)tendinitis, 2) } \\
\text { tendinitis plus light ASTM, 3) } \\
\text { tendinitis plus medium } \\
\text { ASTM, 4) tendinitis plus } \\
\text { extreme ASTM, 5) control } \\
\text { with surgery only }\end{array}$ & $\begin{array}{l}\text { ASTM stimulates fibroblasts } \\
\text { proliferation, the response is } \\
\text { dependent upon the magnitude } \\
\text { of the pressure. }\end{array}$ \\
\hline $\begin{array}{l}\text { Shoemaker } \\
60\end{array}$ & 10 healthy subjects & $\begin{array}{l}\text { One group, massaged forearm } \\
\text { and thigh in all subjects, used } \\
\text { effleurage, petrissage and } \\
\text { tapotement }\end{array}$ & $\begin{array}{l}\text { None of the massage } \\
\text { techniques proved to increase } \\
\text { arterial blood flow. }\end{array}$ \\
\hline Vairo $^{7}$ & $\begin{array}{l}3 \text { human-subject } \\
\text { studies were selected } \\
\text { for PEDro grading, } 6 \\
\text { others were examined }\end{array}$ & $\begin{array}{l}\text { Examined studies if they were } \\
\text { systematic reviews, } \\
\text { randomized control trials, or } \\
\text { cohort studies evaluating the } \\
\text { effects of manual lymphatic } \\
\text { drainage. }\end{array}$ & $\begin{array}{l}\text { The } 3 \text { studies scored } 6 \text { or a } 7 \\
\text { out of } 10 \text {. These techniques } \\
\text { are based upon hypothesis, } \\
\text { theory and preliminary } \\
\text { evidence. Little research is } \\
\text { present to determine the } \\
\text { physiologic response. }\end{array}$ \\
\hline
\end{tabular}


Electrical stimulation: Another clinical modality used by athletic trainers is high voltage electric stimulation. ${ }^{61}$ High voltage has shown to be effective at curbing edema in laboratory animals. ${ }^{61}$ It is believed this is due to the decrease in permeability of microvessels, however, the exact mechanism remains unknown. According to Cook et al. ${ }^{62}$ there are two schools of thought. The first is that edema is prevented and the second is that edema is reduced. It is hypothesized that the high voltage stimulation restricts leakage from the microvasculature by decreasing permeability to proteins. A reduction in the already present edema is hypothesized to occur by the "high voltage stimulation enhancing the movement of charged proteins into the lymphatic channels. ${ }^{, 62}$ More specifically once the electric field is induced the charged proteins are forced to move and advancement of the lymph into the lymphatic channels is accelerated. Therefore, the osmotic pressure of the lymphatic channels is increased resulting in faster fluid absorption from the interstitial space. ${ }^{62}$ Mendel et al. ${ }^{63}$ examined the effect of different treatment parameters on acute edema in frog legs. Upon completion, they found that "cathodal high voltage pulsed current (CHVPC) at 120 pps at $90 \%$ of visible motor threshold delivered via immersion technique" curbed edema. A single 30 minute treatment could slow edema for more than four hours but that a series of four 30 minute treatments with significant rest time would curb edema for up to 24 hours. Therefore, they recommend that it be applied for 30 minutes at a time every four hours. ${ }^{63}$ In a similar study performed by Dolan et al. ${ }^{61}$ findings were confirmed that an extended treatment was more effective. They applied the CHVPC for three continuous hours and noted that swelling was limited to $50 \%$ as compared to control limbs.

Man et al. ${ }^{25}$ evaluated the effects of motor level electrical stimulation on edema reduction. With this type of stimulation the desired effect is to elicit some form of muscle contraction which can cause a compression of the venous and lymphatic vessels. There appear to 
be many benefits of this activation of the muscle pump including the decrease in edema, reduction in venous pooling, increase lymph flow, and increase in lymph propulsion. Despite the potentially positive effects, the results of the study by Man et al. ${ }^{25}$ did not support the theory that motor level stimulation would decrease edema. However, Cook et al. ${ }^{62}$ examined the effectiveness of high voltage stimulation on the effect of lymph flow via the transportation of a blue dye and found the experimental group showed a change in position in the blue dye but not in decreased limb volume. These two studies present a good case as to why the treatments should be effective, yet are unable to present data in support.

Recent studies of electrical stimulation appear to show that CHVPC is an effective modality to use and though the tests have been on laboratory animals it can be transferred to human subjects given the similar tissue responses. Though these studies support the use of this treatment they must be critically evaluated for methodological quality. In the examination of Table B3 it can be seen that a majority of the studies were performed on animals. Frogs and rats have been used in multiple studies to examine the inflammatory response as we share a large portion of genomes with these fellow vertebrates. ${ }^{63,64}$ It is difficult to apply results of these studies to human subjects directly, however, it is possible that these results are predictors of human response and merit clinical trials. ${ }^{63}$ There still remains one area of electric stimulation that has yet to be studied and that is the physiological effects. Mendel et al.$^{63}$ openly stated that studies provided no solid hypothesis as to how HVPC works due to the fact that the short duty cycle of the HVPC or the placement of the anodal HVPC did not increase the edema, and therefore it makes it difficult to hypothesize that it is due to the electrical field effect. Studies examining the exact effect of CHVPC on the tissues may reveal a modality that can truly reduce edema and may then provide insight into other treatments that may assist. 
Miscellaneous Treatments

Research is available on Kinesio tape and Deep Oscillation (Hivamat 200) but information is limited and effects have yet to be fully evaluated.

Kinesio tape was originally developed in 1963 as elastic tape to mimic human skin. It is approximately the thickness of the epidermis and can be stretched $30 \%$ to $40 \%$ of its resting length. The tape is the key to this method and when applied correctly it can facilitate weakened muscles and relaxed overused muscles. Depending on the goals the tape can be used to improve active range of motion, relieve pain, adjust misalignment, or improve lymphatic circulation. ${ }^{67,68,8}$ Lymphatic circulation is achieved via the waves in the tape as it raises and folds the layers of the epidermis ${ }^{67}$ lifting the skin. ${ }^{8}$ Supposedly, this causes an increase in blood flow capacity in the area and leads to improvement of the lymph transportation from the lymph capillaries of the papillae to the subpapillary network of blood vessels. ${ }^{67,11}$ Therefore, as "normal fasciae tension occurs, blood and lymph flow is activated, pain decreased and function is rectified."67

Most of the information available on kinesio tape has been reported from studies examining the effects on structural and muscular conditions and breast cancer lymphedema. The effects of kinesio tape on acute edema has not yet been studied. Therefore, more studies need to be conducted in the realm of acute edema before it can be confirmed as a useful modality to be used by athletic trainers. Deep oscillation has very little evidence based research even though it is advocated on the website and is used by most professional teams. This treatment is an “electromechanical therapeutic procedure using resonant vibration of the tissue with deep oscillation equipment (Hivamat). 
Table B3. Comparison of Electrical Stimulation Studies

\begin{tabular}{|c|c|c|c|}
\hline Study & Subjects & Treatment & Results \\
\hline Cook $^{62}$ & 28 Male rats & $\begin{array}{l}2 \text { groups injected with } \\
\text { albumin labeled with evans } \\
\text { blue dye (AL-EBD), 1) } 1 \\
\text { hour of subcontraction } \\
\text { high-voltage stimulation } \\
\text { (SC-HVS); } 2 \text { ) sham } \\
\text { treatmetn }\end{array}$ & $\begin{array}{l}\text { Higher amounts of AL-EBD } \\
\text { were taken up by the } \\
\text { lymph of the experimental } \\
\text { group animals compared to } \\
\text { control group }\end{array}$ \\
\hline $\operatorname{Man}^{25}$ & $\begin{array}{l}34 \text { patients who } \\
\text { were recovering } \\
\text { from a lateral ankle } \\
\text { sprain }\end{array}$ & $\begin{array}{l}3 \text { groups, 1) NMES applied } \\
\text { to lower leg; 2) sub motor } \\
\text { ES applied to lower leg; } 3 \text { ) } \\
\text { electrodes applied with no } \\
\text { current }\end{array}$ & $\begin{array}{l}\text { No statistically significant } \\
\text { differences between ankle- } \\
\text { foot volume and self- } \\
\text { assessed ankle function. } \\
\text { Differences in ankle girth } \\
\text { could have been due to } \\
\text { difference in values at } \\
\text { baseline. Only NMES } \\
\text { showed significant } \\
\text { differences from session } 1 \\
\text { to } 3\end{array}$ \\
\hline Mohr ${ }^{65}$ & 40 male rats & $\begin{array}{l}2 \text { groups, 1) control group; } \\
\text { 2) group treated with high } \\
\text { voltage stimulation }\end{array}$ & $\begin{array}{l}\text { No significant difference in } \\
\text { traumatic paw edema }\end{array}$ \\
\hline Dolan ${ }^{61}$ & 21 rats & $\begin{array}{l}3 \text { groups, 1) IBU, 2) } \\
\text { cathodal high-voltage } \\
\text { pulsed current, 3) } \\
\text { Combination of both }\end{array}$ & $\begin{array}{l}\text { All treatments decreased } \\
\text { edema when compared to } \\
\text { control limbs, but no one } \\
\text { treatment was better than } \\
\text { the other }\end{array}$ \\
\hline Taylor ${ }^{66}$ & 24 bullfrogs & $\begin{array}{l}\text { Both legs received trauma, } \\
\text { one leg was treated with } \\
\text { cathodal HVPC, the other } \\
\text { no treatment }\end{array}$ & $\begin{array}{l}\text { HVPC treatment } \\
\text { significantly curbed edema } \\
\text { formation for at least } 4 \\
\text { hours as compared to } \\
\text { untreated limbs. }\end{array}$ \\
\hline $\begin{array}{l}\text { Thornton } \\
64\end{array}$ & $\begin{array}{l}19 \text { Zucker-Lean rats, } \\
14 \text { brown Norway } \\
\text { rats, } 11 \text { Sprague- } \\
\text { Dawley rats }\end{array}$ & $\begin{array}{l}\text { Both legs received trauma, } \\
\text { one leg was treated with } \\
\text { cathodal HVPC, the other } \\
\text { no treatment }\end{array}$ & $\begin{array}{l}\text { Sprague-Dawley rats } \\
\text { showed no difference } \\
\text { between limbs. Zucker- } \\
\text { Lean rats showed a } \\
\text { decrease in treated limbs } \\
\text { after second treatment. } \\
\text { Brown Norway rats showed } \\
\text { a decrease in treated limbs } \\
\text { after first treatment. }\end{array}$ \\
\hline
\end{tabular}


Aliyev et al. ${ }^{69}$ claimed this is achieved via an electrostatic attraction and friction, to produce mechanical vibrations in treated tissues of the body that penetrates to deeper tissues. In another review, Comeaux et al. ${ }^{10}$ claims the unit is used to "create a fascial change by applying an intermittent electrostatic charge to the collagen matrix." Specifically the "HIVAMAT® 200 operates at the level of the connective tissue using a pulsing electrostatic field, producing an intense resonant vibration within the tissues involved. The repetition of this phenomenon in rapid succession generates rhythmic deformations of the tissue. This action permits fiber and tissue layers to reacquire motricity and malleability." ${ }^{11}$ Despite widespread use, there is very little research available to the American consumer on the product. Many of the studies have been performed in its country of origin but have yet to be performed in the United States. There are many verbal accounts of positive results with this modality but until more studies are performed it will remain less utilized in the treatment of acute edema.

\section{SUMMARY}

Returning athletes to participation after an injury is one of the many roles athletic trainers have. Therefore, an understanding of the inflammatory process, the lymphatic system and different treatment methods can assist in this. The inflammatory process is divided into three phases, the inflammatory phase, proliferation phase and the maturation phase. Timelines of these phases are of great controversy and are continuing to be studied. The inflammatory phase is marked by an influx of cellular tissues including leukocytes, neutrophils and macrophages. If this phase is not properly managed then secondary injury can ensue and can increase the time it takes to return the athlete. The proliferation phase begins the repair of the injury by the formation of ECM and type III collagen. 
Table B4. Comparison of Kinesio Tape Studies.

\begin{tabular}{|c|c|c|c|}
\hline Study & Subjects & Treatment & Results \\
\hline Tsai $^{12}$ & $\begin{array}{l}41 \text { patients with } \\
\text { unilateral breast- } \\
\text { cancer-related } \\
\text { lymphedema }\end{array}$ & $\begin{array}{l}2 \text { groups, } 1 \text { ) treatment with } \\
\text { a short-stretch bandage, } 2 \text { ) } \\
\text { kinesio tape }\end{array}$ & $\begin{array}{l}\text { No significant difference } \\
\text { between all outcome } \\
\text { variables, but there was a } \\
\text { difference in a couple of } \\
\text { the variables that could } \\
\text { prove kinesio tape a } \\
\text { suitable alternative. }\end{array}$ \\
\hline Thelen $^{68}$ & $\begin{array}{l}42 \text { subjects } \\
\text { diagnosed with } \\
\text { rotator cuff } \\
\text { tendonitis/ } \\
\text { impingement }\end{array}$ & $\begin{array}{l}2 \text { groups, } 1 \text { ) therapeutic } \\
\text { kinesio tape, } 2 \text { ) sham } \\
\text { kinesio tape. Self-reported } \\
\text { pain and disability and pain } \\
\text { free AROM }\end{array}$ & $\begin{array}{l}\text { Therapeutic kinesio tape } \\
\text { showed immediate } \\
\text { improvement in pain-free } \\
\text { shoulder abduction, } \\
\text { otherwise there was no } \\
\text { difference in groups }\end{array}$ \\
\hline Kaya $^{70}$ & $\begin{array}{l}55 \text { patients with } \\
\text { shoulder } \\
\text { impingement } \\
\text { syndrome }\end{array}$ & $\begin{array}{l}2 \text { groups, 1) treated with } \\
\text { kinesio tape, 2) treated } \\
\text { with local modalities daily. } \\
\text { Evaluated eith disability of } \\
\text { arm, shoulder and hand } \\
\text { scale, and visual analog } \\
\text { scale scores. }\end{array}$ & $\begin{array}{l}\text { Scores and disability scales } \\
\text { decreased significantly in } \\
\text { both treatment groups as } \\
\text { compared with baseline } \\
\text { levels at week } 1 \text {, the rest, } \\
\text { night and movement } \\
\text { median pain scores were } \\
\text { statistically significantly } \\
\text { lower at the first week. }\end{array}$ \\
\hline
\end{tabular}

Finally, the maturation phase starts the final process of the maturing of the type III collagen to type I collagen. This will provide a more permanent scar to complete the inflammatory process.

The lymphatic system plays an important role in the flow of body fluids and is of particular importance in the presence of acute edema after an injury. The anatomy of the lymphatic system is very similar to that of the venous system, it has week capillaries progressing to stronger vessels that have a contractile element and one way valves. Unlike the cardiovascular system, however, there is no central pump, so the flow of the fluid is maintained via constant pressure as well as neighboring structures. This system is extensive covering the human body from head to toe stopping at major intersections of the body to transfer fluid at lymph nodes. 
Any breakdown in this system can cause chronic edema and treatment methods to prevent that is very important.

Currently treatment includes but is not limited to cryotherapy, compression, massage, electrical stimulation, kinesio tape and Hivamat. Cryotherapy is a staple in the treatment of acute edema by the athletic trainer. Despite this being the most accepted treatment, there has been very little research to study the physiology behind the use of cryotherapy. The same can be said for compression, however, there have been even fewer studies to support the use. Massage is one of the oldest treatments used and there have been more literature reviews to present the experimental studies instead of critically evaluating them. One type of massage has been confirmed to assist in the healing of tendonous injury. The most researched and supported modality in the treatment of edema is cathodal high voltage pulsed current. Despite studies not examining the physiological effects, a decrease and even prevention of edema from entering the injured area is evident. Kinesio tape and Deep Oscillation are less studied than the previously mentioned modalities. Kinesio tape is designed to mimic the skins properties and claims to, along with other actions, increase lymphatic flow. Deep Oscillation therapy was developed in Germany and to this point the studies conducted on this modality have been performed there with very little research conducted in the United states. Though treatment of acutely injured athlete's is what sets athletic trainers apart from other health care professionals ${ }^{\text {dolan }}$ there is still much to be learned about the modalities used. 


\section{APPENDIX C}

\section{ADDITIONAL METHODS}

Table C1. PEDro Scale ${ }^{71}$

1. Eligibility criteria were specified

2. Subjects were randomly allocated to groups (in a crossover study, subjects were randomly allocated an order in which treatments were received)

no _yes

no _ yes

no _ yes

3. Allocation was concealed

4. The groups were similar at baseline regarding the most important prognostic indicators

5. There was blinding of all subjects

6. There was blinding of all therapists who administered the therapy

no _ yes

no _ yes

no _ yes

no _ yes _

7. There was blinding of all assessors who measured at least one key outcome

8. Measures of at least one key outcome were obtained from more than $85 \%$ of the subjects initially allocated to groups

9. All subjects for whom outcome measures were available received the treatment or control condition as allocated or, where this was not the case, data for at least one key outcome was analysed by "intention to treat"

no _ yes _

10. The results of between-group statistical comparisons are reported for at least one key outcome

11. The study provides both point measures and measures of variability for at least one key outcome no _ yes

no _ yes _ 
Table C2. Pedro Scale with Explanations. ${ }^{16,71}$

Criteria 1. Eligibility criteria were specified.

Explanation: This criterion is satisfied if the report describes the source of the subjects and a list of criteria used to determine who was eligible to participate in the study.

Criteria 2. Subjects were randomly allocated to groups (in a crossover study, subjects were randomly allocated an order in which treatments were received)

Explanation: A study is considered to have used random allocation if the report states that allocation was random. The precise method of randomization need not be specified. Procedures such as coin tossing and dice rolling should be considered random. Quasi-randomization allocation procedures such as allocation procedures such as allocation by hospital record number or birth date, or alternation, do not satisfy this criterion.

\section{Criteria 3. Allocation was concealed.}

Explanation: Concealed allocation means that the person who determined if a subject was eligible for inclusion in the trial was unaware, when this decision was made, of which group the subject would be allocated to. A point is awarded for this criterion, even if it is not stated that allocation was concealed, when the report states that allocation was by sealed opaque envelopes or that allocation involved contacting the holder of the allocation schedule who was "off-site."

\section{Criteria 4. The groups were similar at baseline regarding the most important prognostic indicators.}

Explanation: At a minimum, in studies of therapeutic interventions, the report must describe at least one measure of the severity of the condition being treated and at least one (different) key outcome measure at baseline. The rater must be satisfied that the groups' outcomes would not be expected to differ, on the basis of baseline differences in prognostic variables alone, by a clinically significant amount. This criterion is satisfied even if only baseline data of subjects completing the study are presented.

\section{Criteria 4, 7-11.}

Explanation: Key outcomes are those outcomes that provide the primary measure of the effectiveness (or lack of effectiveness)of the therapy. In most studies, more than one variable is used as an outcome measure.

\section{Criteria 5-7.}

Explanation: Blinding means the person in question (subject, therapist, or assessor) did not know which group the subject had been allocated to. In addition, subjects and therapists are only considered to be "blind" if it could be expected that they would have been unable to distinguish reported (eg, visual analog scale, pain diary), the assessor is considered to be blind if the subject was blind. 
Criteria 8. Measures of at least one key outcome were obtained from more than $85 \%$ of the subjects initially allocated to groups.

Explanation: This criterion is satisfied only if the report explicitly states both the number of subjects initially allocated to groups and the number of subjects from whom key outcome measurements were obtained. In trials in which outcomes are measured at several points in time, a key outcome must have been measured in more than $85 \%$ of subjects at one of those points in time.

Criteria 9. All subjects for whom outcome measures were available received the treatment or control condition as allocated or, where this was not the case, data for at least one key outcome was analysed by "intention to treat."

Explanation: An intention-to-treat analysis means that, where subjects did not receive treatment (or the control condition) as allocated and where the measures of outcomes were available, the analysis was performed as if subjects received the treatment (or control condition) they were allocated to. This criterion is satisfied, even if there is no mention of analysis by intention to treat, if the report explicitly states that all subjects received treatment or control conditions allocated.

Criteria 10. The results of between-group statistical comparisons are reported for at least one key outcome.

Explanation: A between-group statistical comparison involves statistical comparison of one group with another. Depending on the design of the study, this may involve comparison of 2 or more treatments of comparison of treatment with a control condition. The analysis may be a simple comparison of outcomes measured after the treatment was administered or a comparison of the change in one group with the change in another (when a factorial analysis of variance has been used to analyze the data, the latter is often reported as a group X time interaction.) The comparison may be in the form of hypothesis testing (which provides a $\mathrm{P}$ value, describing the probability that the groups differed only by chance) or in the form of an estimate (eg. The mean or median difference, or a difference in proportions, number needed to treat a relative risk or hazard ratio) and its confidence interval.

\section{Criterion 11. The study provides both point measures and measures of variability for at least one key outcome.}

Explanation: A point measure is a measure of the size of the treatment effect. The treatment effect may be described as a difference in group outcomes or as the outcome in (each of ) all groups. Measures of variability include standard deviations, standard errors, confidence intervals, interquartile ranges (or other quartile ranges), and ranges. Point measures and/or measures of variability may be provided graphically (eg, standard deviations may be given as error bars in a figure) as long as it is clear what is being graphed (eg, as long as it is clear whether error bars represent standard deviations or standard errors). Where outcomes are categorical, this criterion is considered to have been met if the number of subjects in each category is given for each group. 
Table C3. Protocol for Determining Studies

1. The studies were written in or translated to English.

2. Edema reduction or a form of the word lymphatic must appear in the title.

3. The abstract must include the terms lymphatic system, edema, modalities and treatment.

4. Acute injury must be the chief complaint in the study.

5. The study must be a randomized controlled trial. 


\section{APPENDIX D}

\section{ADDITIONAL RESULTS}

Table D1. Cryotherapy Treatment Studies

\begin{tabular}{|c|c|c|c|c|c|}
\hline Study & Subjects & $\underline{\text { Treatment }}$ & $\underline{\text { Results }}$ & $\underline{\text { Statistics }(\text { mean } \pm \mathrm{SD})}$ & $\begin{array}{l}\text { PEDro } \\
\text { Score }\end{array}$ \\
\hline $\begin{array}{l}\text { Buzzard et } \\
\text { al. }{ }^{20}\end{array}$ & $\begin{array}{l}39 \text { patients } \\
\text { with acute } \\
\text { calcaneal } \\
\text { fractures }\end{array}$ & $\begin{array}{l}2 \text { groups, 1) cryocuff } \\
\text { 2) shortwave } \\
\text { diathermy }\end{array}$ & $\begin{array}{l}\text { Pulsed shortwave diathermy was not } \\
\text { found to be substantially more effective } \\
\text { than Cryocuff. }\end{array}$ & $\begin{array}{l}\text { Cryocuff = calcaneal }(\mathrm{cm}) \\
\text { day } 1(33 \pm 2) \text {, day } 5(33 \pm \\
2) ; \text { malleolar }(\mathrm{cm}) \text { day } 1(27 \\
\pm 2) \text {, day } 5(27 \pm 2) \text {; forefoot } \\
(\mathrm{cm}) \text { day } 1(24 \pm 2) \text {, day } 5 \\
(24 \pm 2) \\
\text { Short wave diathermy }= \\
\text { calcaneal }(\mathrm{cm}) \text { day } 1(34 \pm \\
2), \text { day } 5(33 \pm 2) ; \text { malleolar } \\
(\mathrm{cm}) \text { day } 1(27 \pm 2) \text {, day } 5 \\
(27 \pm 2) \text {; forefoot }(\mathrm{cm}) \text { day } 1 \\
(24 \pm 2) \text {, day } 5(24 \pm 2)\end{array}$ & $4 / 10$ \\
\hline $\begin{array}{l}\text { Meeusen et } \\
\text { al. }{ }^{26}\end{array}$ & $\begin{array}{l}39 \text { healthy } \\
\text { subjects }\end{array}$ & $\begin{array}{l}\text { Tested six different } \\
\text { protocols of } 1^{\circ} \mathrm{C} \text {, } \\
15^{\circ} \mathrm{C}, 32^{\circ} \mathrm{C} \text { each with } \\
0 \mathrm{~mm} \mathrm{Hg} \text {, and } 1^{\circ} \mathrm{C} \text {, } \\
15^{\circ} \mathrm{C}, 32^{\circ} \mathrm{C} \text { each with } \\
25 \mathrm{mmHg} \text {, each } \\
\text { protocol had at least } 5 \\
\text { of the } 39 \text { patients. } \\
\text { Each patient served } \\
\text { as their own control. }\end{array}$ & $\begin{array}{l}\text { For the first } 30 \text { minutes prior to } \\
\text { application of the treatment there was no } \\
\text { significant difference between ankles. } \\
\text { The application of the } 1^{\circ} \mathrm{C} \text { without } \\
\text { pressure influenced lymph significantly. } \\
\text { The addition of } 25 \mathrm{~mm} \mathrm{Hg} \text { also } \\
\text { influenced the flow significantly. }\end{array}$ & $\begin{array}{l}\text { Presented figures but no } \\
\text { numbers }\end{array}$ & $4 / 10$ \\
\hline $\begin{array}{l}\text { Weston et } \\
\text { al. }\end{array}$ & $\begin{array}{l}15 \text { subjects } \\
\text { suffering } \\
\text { from mild to } \\
\text { moderate } \\
\text { lateral ankle } \\
\text { sprains }\end{array}$ & $\begin{array}{l}1 \text { group of patients } \\
\text { that received the } \\
\text { control testing then } \\
\text { put through the cold } \\
\text { gel pack application }\end{array}$ & $\begin{array}{l}\text { No statistical significance found between } \\
\text { the blood pressure at rest and with cold } \\
\text { gel pack application }\end{array}$ & $\begin{array}{l}\text { Presented figures but no } \\
\text { numbers }\end{array}$ & $4 / 10$ \\
\hline
\end{tabular}




\begin{tabular}{|c|c|c|c|}
\hline $\begin{array}{l}\text { Stockle et } \\
\text { al. }^{29}\end{array}$ & $\begin{array}{l}60 \text { patients } \\
\text { with lower } \\
\text { leg trauma }\end{array}$ & $\begin{array}{l}3 \text { groups 1) cool pack } \\
\text { cryotherapy, 2) } \\
\text { continuous } \\
\text { cryotherapy, 3) } \\
\text { intermittent impulse } \\
\text { compression }\end{array}$ & $\begin{array}{l}\text { After first } 24 \text { hours of treatment there } \\
\text { was } 47 \% \text { reduction in swelling with the } \\
\text { AV impulse system, } 33 \% \text { with } \\
\text { continuous cryotherapy and } 17 \% \text { with } \\
\text { cold packs. After } 4 \text { days the AV } \\
\text { impulse showed a } 74 \% \text { reduciton while } \\
\text { continuous cryotherapy and cold packs } \\
\text { had } 70 \% \text { and } 45 \% \text { respectively. }\end{array}$ \\
\hline $\begin{array}{l}\text { Cheing et } \\
\text { al. }^{21}\end{array}$ & $\begin{array}{l}83 \text { subjects } \\
\text { with stable } \\
\text { distal radius } \\
\text { fractures } \\
\text { treated with } \\
\text { closed } \\
\text { reduction }\end{array}$ & $\begin{array}{l}4 \text { groups 1) ice plus } \\
\text { PEMF, 2) ice plus } \\
\text { sham PEMF, 3) } \\
\text { PEMF alone, 4) sham } \\
\text { PEMF }\end{array}$ & $\begin{array}{l}\text { Evaluated based on VAS, volumetric } \\
\text { measurements and ROM. By day } 5 \text { the a } \\
\text { greater cumulative reduction in the VAS } \\
\text { score was noted in group } 1 \text { over the } \\
\text { other } 3 \text {. For volumeteric measurements } \\
\text { group } 1 \text { performed better than group } 4 \\
\text { but not group } 2 \text {. }\end{array}$ \\
\hline $\begin{array}{l}\text { Scheffler et } \\
\text { al. }{ }^{28}\end{array}$ & $\begin{array}{l}25 \text { patients } \\
\text { with post } \\
\text { surgical } \\
\text { trauma }\end{array}$ & $\begin{array}{l}1 \text { group of patients } \\
\text { that had a treatment } \\
\text { foot that received } \\
\text { cryocuff and control } \\
\text { that did not }\end{array}$ & $\begin{array}{l}\text { Evaluated based on circumference, pain } \\
\text { assessment and by evaluation of comfort } \\
\text { of the cryocuff which was rated on a } 5 \\
\text { point scale. There was a standard } \\
\text { deviation of } .032 \text { lower in circumference } \\
\text { mean in the cryocuff treatment. } 80 \% \text { of } \\
\text { patients noted less pain in the treatment } \\
\text { foot. Comfort: } 4.64 \text {, ease of use: } 4.64 \text {, } \\
\text { amt of cold: } 4.8 \text {, leaking: } 4.56 \text {, safety: } \\
4.88 \text {, convenience: } 4.6 \text {, compression: } \\
4.8 \text {, stays in place: } 4.8 \text {. }\end{array}$ \\
\hline
\end{tabular}

cool pack $=$ ankle $(\mathrm{mm})$ pre

(265); midfoo

(mm) pre (272) day 6 (254);

forefoot (mm) pre (238) day

6 (232). Continuous $=$ ankle

(mm) pre (279), day (262);

midfoot (mm) pre (268) day

6 (258); forefoot ( $\mathrm{mm})$ pre

(244) day 6 (234).

Compression $=$ ankle $(\mathrm{mm})$

pre (280), day (265);

midfoot (mm) pre (277) day

6 (258); forefoot ( $\mathrm{mm}$ ) pre

(253) day 6 (243).

Group $A=$ day $1(462 \pm 73)$,

$(452 \pm 72)$, day $5(437$

\pm 67 ); Group B = day 1 (430

$\pm 45)$, day $3(425 \pm 44)$, day 5

(410 \pm 47$)$; Group C = day 1

$(442 \pm 83)$, day $3(436 \pm 81)$,

day $5(428 \pm 82)$ Group $D=$

day $1(445 \pm 68)$, day 3 (446

$\pm 72)$, day $5(438 \pm 73)$

No calculations presented

4.8 , stays in place: 4.8 
Table D2. Compression Treatment Studies

\begin{tabular}{|c|c|c|c|c|c|}
\hline Study & Subjects & $\underline{\text { Treatment }}$ & $\underline{\text { Results }}$ & $\underline{\text { Statistics (mean } \pm \mathrm{SD} \text { ) }}$ & $\frac{\text { PEDro }}{\text { Score }}$ \\
\hline $\begin{array}{l}\text { Rucinski et } \\
\text { al. }^{27}\end{array}$ & $\begin{array}{l}30 \text { patients with } \\
\text { postactute ankle } \\
\text { sprains }(>24 \mathrm{hrs})\end{array}$ & $\begin{array}{l}3 \text { treatment } \\
\text { groups, 1) elastic } \\
\text { wrap, 2) } \\
\text { intermittent } \\
\text { compresion, 3) } \\
\text { elevated control } \\
\text { group. }\end{array}$ & $\begin{array}{l}\text { Found that the } \\
\text { elevated group had } \\
\text { the least amount of } \\
\text { edema and the two } \\
\text { compression } \\
\text { protocols increased } \\
\text { edema. }\end{array}$ & $\begin{array}{l}\text { elastic wrap }=\text { Pre }(1340.2 \\
\pm 128) \text { post }(1343.9 \pm \\
127.4) \text { Compression } t x= \\
\text { pre }(1220 \pm 166.7) \text { post } \\
(1229.4 \pm 166.5) \text { Control } \\
=\text { pre }(1350.4 \pm 201.6) \\
\text { post }(1335.5 \pm 302.2)\end{array}$ & \\
\hline $\begin{array}{l}\text { Thordarson } \\
\text { et al. }{ }^{29}\end{array}$ & $\begin{array}{l}30 \text { patients with } \\
\text { an ankle fracture } \\
\text { requiring open } \\
\text { reduction }\end{array}$ & $\begin{array}{l}2 \text { groups, 1) } \\
\text { received } \\
\text { pneumatic pedal } \\
\text { compression, 2) } \\
\text { control group }\end{array}$ & $\begin{array}{l}\text { Found a difference } \\
\text { between groups of } \\
121 \mathrm{~mL} \text { in support of } \\
\text { the PPC on day one } \\
\text { and } 63 \mathrm{~mL} \text { on day } \\
\text { two. }\end{array}$ & No data presented & $6 / 10$ \\
\hline $\begin{array}{l}\text { Tsang et } \\
\text { al. }^{31}\end{array}$ & $\begin{array}{l}12 \text { college } \\
\text { students with } \\
\text { inversion ankle } \\
\text { sprains }\end{array}$ & $\begin{array}{l}2 \text { groups, an } \\
\text { elevation group } \\
\text { and an elevation } \\
\text { with compression } \\
\text { group }\end{array}$ & $\begin{array}{l}\text { Both groups } \\
\text { provided a decrease } \\
\text { in edema } \\
\text { immediately after } \\
\text { treatment however } \\
\text { after } 5 \text { minutes the } \\
\text { effects became less } \\
\text { seen. }\end{array}$ & $\begin{array}{l}\text { Elevation }=616.67 \pm \\
121.41 \text { At } 0^{\prime} \Delta \mathrm{mL}=-22.5, \\
\text { es }=-0.19, \text { at } 5^{\prime} \Delta \mathrm{mL}=- \\
14.5 \text {, es }=-0.12, \text { at } 60^{\prime} \\
\Delta \mathrm{mL}=-8.34,-0.07 \\
\text { Elevation \& compression } \\
=875.5 \pm 169.21 \text { At } 0^{\prime} \\
\Delta \mathrm{mL}=-12, \text { es }=-0.07, \\
\text { at } 5^{\prime} \Delta \mathrm{mL}=\quad-3.33, \text { es }= \\
-0.02, \text { at } 60^{\prime} \Delta \mathrm{mL}=-4.33, \\
-0.03\end{array}$ & $6 / 10$ \\
\hline
\end{tabular}


Table D3. Massage Treatment Studies

\begin{tabular}{|c|c|c|c|c|c|}
\hline$\underline{\text { Study }}$ & $\underline{\text { Subjects }}$ & - $\quad$ Treatment & - $\underline{\text { Results }}$ & $\underline{\text { Statistics (mean } \pm \text { SD) }}$ & $\frac{\text { PEDro }}{\text { Score }}$ \\
\hline $\begin{array}{l}\text { Haren et } \\
\text { al. }^{22}\end{array}$ & $\begin{array}{l}26 \text { patients } \\
\text { with distal } \\
\text { radius } \\
\text { fractures that } \\
\text { were } \\
\text { repaired with } \\
\text { external } \\
\text { fixation }\end{array}$ & $\begin{array}{l}2 \text { groups, both } \\
\text { received a } \\
\text { standard } \\
\text { protocol, 1) } \\
\text { experimental } \\
\text { group received } 10 \\
\text { treatments of } \\
\text { manual lymphatic } \\
\text { drainage(MLD), 2) } \\
\text { the control that } \\
\text { did not receive } \\
\text { MLD }\end{array}$ & $\begin{array}{l}\text { Via volumeteric measurements it } \\
\text { was found that the experimental } \\
\text { group had significantly less edema } \\
\text { in the injured hand than the } \\
\text { control. }\end{array}$ & $\begin{array}{l}\text { Experimental }=(\mathrm{mL}) \\
\text { day } 3(39 \pm 12) \text {, day } \\
17(27 \pm 9) \text {, day } 33(19 \\
\pm 9) \text {, day } 68(12 \pm 11) \\
\text { Control }=(\mathrm{mL}) \text { day } 3 \\
(64 \pm 41) \text {, day } 17(50 \pm \\
35), \text { day } 33(35 \pm 26) \text {, } \\
\text { day } 68(24 \pm 20)\end{array}$ & $6 / 10$ \\
\hline $\begin{array}{l}\text { Kessler et } \\
\text { al. }\end{array}$ & $\begin{array}{l}23 \text { subjects } \\
\text { who } \\
\text { underwent } \\
\text { hindfoot } \\
\text { surgery }\end{array}$ & $\begin{array}{l}2 \text { Groups, 1) } \\
\text { standard } \\
\text { physiotherapy } \\
\text { plus manual } \\
\text { lymph drainage, } \\
\text { 2) standard } \\
\text { phyiotherapy but } \\
\text { no manual lymph } \\
\text { drainage }\end{array}$ & $\begin{array}{l}\text { When compared to the control } \\
\text { group there was a significant } \\
\text { reduction in post-operative } \\
\text { swelling in the experimentral } \\
\text { group. }\end{array}$ & $\begin{array}{l}\text { Presented figures but } \\
\text { no numbers. }\end{array}$ & $6 / 10$ \\
\hline $\begin{array}{l}\text { Knygsand } \\
\text { et al. }{ }^{24}\end{array}$ & $\begin{array}{l}30 \text { subjects } \\
\text { with distal } \\
\text { radius } \\
\text { fractures }\end{array}$ & $\begin{array}{l}2 \text { groups, 1) } \\
\text { received manual } \\
\text { edema } \\
\text { mobilization, 2) } \\
\text { control }\end{array}$ & $\begin{array}{l}\text { There was no statistically } \\
\text { significant reduction in edema } \\
\text { between the groups at six and } \\
\text { nine weeks via volumetric } \\
\text { measurements. There was a } \\
\text { significant difference noted at } \\
\text { three weeks in activities of daily } \\
\text { living in the treatment group as } \\
\text { well as there were fewer } \\
\text { treatments needed in group } 1 .\end{array}$ & $\begin{array}{l}\text { Experimental }=(\mathrm{mL}) \\
\text { baseline }(86.8 \pm 26.1), \\
1 \mathrm{wk}(68.2), 3 \mathrm{wk} \\
(41.1), 6 \mathrm{wk}(28.6), 9 \\
\text { wk }(12.1), 26 \mathrm{wk}(2.5) . \\
\text { Control }=(\mathrm{mL}) \\
\text { baseline }(96.3 \pm 28.3), \\
1 \mathrm{wk}(77.3), 3 \mathrm{wk}(54), \\
6 \mathrm{wk}(43.3), 9 \mathrm{wk} \\
(28.3), 26 \mathrm{wk}(15.7) .\end{array}$ & $8 / 10$ \\
\hline
\end{tabular}


Table D4. Electrical Stimulation Treatment Studies

\begin{tabular}{|c|c|c|c|c|c|}
\hline Study & $\underline{\text { Subjects }}$ & $\underline{\text { Treatment }}$ & $\underline{\text { Results }}$ & Statistics (mean \pm SD) & $\frac{\text { PEDro }}{\text { Score }}$ \\
\hline Man et al. ${ }^{25}$ & $\begin{array}{l}34 \text { patients } \\
\text { recovering } \\
\text { from ankle } \\
\text { sprains }\end{array}$ & $\begin{array}{l}3 \text { groups, 1) } \\
\text { received NMES } \\
\text { treatment, 2) } \\
\text { submotor ES } \\
\text { treatment, 3) } \\
\text { received sham } \\
\text { treatment }\end{array}$ & $\begin{array}{l}\text { There were no statistically } \\
\text { significant differences } \\
\text { between groups for ankle- } \\
\text { foot volume and self-assessed } \\
\text { ankle function. There was a } \\
\text { statistically significant } \\
\text { difference in ankle girth that } \\
\text { could be attributed to the } \\
\text { differences at baseline. The } \\
\text { ankle girth measurements } \\
\text { were shown to be statistically } \\
\text { significant from session } 1 \text { to } 3 \\
\text { for the NMES group but not } \\
\text { the other } 2 \text {. }\end{array}$ & $\begin{array}{l}\text { NMES }=(\mathrm{mL}) \text { injured: pre } \\
(1522 \pm 262), \text { post }(1515 \pm \\
230) \text {; uninjured: pre }(1445 \pm \\
207), \text { post }(1459 \pm 232) . \\
\text { Submotor }=(\mathrm{mL}) \text { injured: pre } \\
(1597 \pm 339), \text { post }(1573 \pm \\
314) ; \text { uninjured: pre }(1465 \pm \\
207), \text { post (1493 } \pm 232) . \text { Sham } \\
=(\mathrm{mL}) \text { injured: pre (1324 } \pm \\
215), \text { post (1352 } \pm 213) ; \\
\text { uninjured: pre }(1296 \pm 156) \text {, } \\
\text { post (1306 } \pm 163) .\end{array}$ & $9 / 10$ \\
\hline
\end{tabular}




\begin{tabular}{|c|c|c|c|c|c|c|c|c|c|c|c|c|}
\hline Author & $\begin{array}{c}\text { Criteria } \\
1\end{array}$ & $\begin{array}{c}\text { Criteria } \\
2\end{array}$ & $\begin{array}{c}\text { Criteria } \\
3\end{array}$ & $\begin{array}{c}\text { Criteria } \\
4\end{array}$ & $\begin{array}{c}\text { Criteria } \\
5\end{array}$ & $\begin{array}{c}\text { Criteria } \\
6\end{array}$ & $\begin{array}{c}\text { Criteria } \\
7\end{array}$ & $\begin{array}{c}\text { Criteria } \\
8\end{array}$ & $\begin{array}{c}\text { Criteria } \\
9\end{array}$ & $\begin{array}{c}\text { Criteria } \\
10\end{array}$ & $\begin{array}{c}\text { Criteria } \\
11\end{array}$ & Total \\
\hline Buzzard et al. $^{20}$ & Y & $\mathrm{N}$ & $\mathrm{N}$ & Y & $\mathrm{N}$ & $\mathrm{N}$ & $\mathrm{N}$ & $\mathrm{N}$ & $\mathrm{N}$ & Y & $\mathrm{Y}$ & $3 / 10$ \\
\hline Cheing et al. ${ }^{21}$ & Y & $\mathrm{Y}$ & $\mathrm{N}$ & Y & Y & $\mathrm{N}$ & $\mathrm{N}$ & $\mathrm{Y}$ & $\mathrm{N}$ & $\mathrm{Y}$ & $\mathrm{Y}$ & $6 / 10$ \\
\hline Haren et al. ${ }^{22}$ & $\mathrm{Y}$ & $\mathrm{Y}$ & Y & $\mathrm{N}$ & $\mathrm{N}$ & $\mathrm{N}$ & $\mathrm{N}$ & $\mathrm{Y}$ & $\mathrm{N}$ & $\mathrm{Y}$ & $\mathrm{Y}$ & $5 / 10$ \\
\hline Kessler et al. ${ }^{23}$ & Y & Y & $\mathrm{N}$ & Y & $\mathrm{N}$ & $\mathrm{N}$ & $\mathrm{N}$ & Y & $\mathrm{N}$ & $\mathrm{Y}$ & $\mathrm{Y}$ & $5 / 10$ \\
\hline Knygsand et al. ${ }^{24}$ & Y & Y & $\mathrm{N}$ & $\mathrm{Y}$ & Y & $\mathrm{N}$ & $\mathrm{N}$ & $\mathrm{Y}$ & $\mathrm{N}$ & Y & Y & $7 / 10$ \\
\hline Man et al. ${ }^{25}$ & Y & Y & $\mathrm{Y}$ & $\mathrm{Y}$ & $\mathrm{Y}$ & $\mathrm{N}$ & Y & Y & $\mathrm{N}$ & Y & Y & $8 / 10$ \\
\hline Meeusen et al. ${ }^{26}$ & $\mathrm{~N}$ & $\mathrm{~N}$ & $\mathrm{~N}$ & $\mathrm{Y}$ & $\mathrm{N}$ & $\mathrm{N}$ & $\mathrm{N}$ & Y & $\mathrm{N}$ & Y & $\mathrm{N}$ & $3 / 10$ \\
\hline Rucinski et al. ${ }^{27}$ & $\mathrm{Y}$ & Y & $\mathrm{N}$ & Y & $\mathrm{N}$ & $\mathrm{N}$ & $\mathrm{N}$ & Y & $\mathrm{Y}$ & $\mathrm{Y}$ & Y & $6 / 10$ \\
\hline Scheffler et al. ${ }^{28}$ & Y & $\mathrm{N}$ & $\mathrm{N}$ & Y & $\mathrm{N}$ & $\mathrm{N}$ & $\mathrm{N}$ & $\mathrm{Y}$ & $\mathrm{N}$ & $\mathrm{N}$ & $\mathrm{N}$ & $2 / 10$ \\
\hline Stockle et al. ${ }^{29}$ & Y & $\mathrm{Y}$ & $\mathrm{N}$ & $\mathrm{Y}$ & $\mathrm{N}$ & $\mathrm{N}$ & $\mathrm{N}$ & $\mathrm{Y}$ & $\mathrm{N}$ & $\mathrm{N}$ & $\mathrm{N}$ & $3 / 10$ \\
\hline Thordarson et al. ${ }^{30}$ & Y & Y & Y & Y & $\mathrm{N}$ & $\mathrm{N}$ & $\mathrm{N}$ & $\mathrm{N}$ & $\mathrm{N}$ & $\mathrm{N}$ & $\mathrm{N}$ & $3 / 10$ \\
\hline Tsang et al. ${ }^{31}$ & Y & $\mathrm{Y}$ & $\mathrm{N}$ & Y & $\mathrm{N}$ & $\mathrm{N}$ & $\mathrm{N}$ & $\mathrm{Y}$ & $\mathrm{N}$ & $\mathrm{Y}$ & $\mathrm{Y}$ & $5 / 10$ \\
\hline Weston et al. ${ }^{32}$ & $\mathrm{Y}$ & $\mathrm{N}$ & $\mathrm{N}$ & $\mathrm{Y}$ & $\mathrm{N}$ & $\mathrm{N}$ & $\mathrm{N}$ & $\mathrm{Y}$ & $\mathrm{N}$ & $\mathrm{Y}$ & $\mathrm{N}$ & $3 / 10$ \\
\hline
\end{tabular}


Table D6. Buzzard et al. ${ }^{20}$ PEDro Score

1. Eligibility criteria were specified

2. Subjects were randomly allocated to groups (in a crossover study, subjects were randomly allocated an order in which treatments were received)

3. Allocation was concealed

no _ yes $\underline{x}$ where:

no $\underline{x}$ yes _ where: no $\underline{x}$ yes _ where:

4. The groups were similar at baseline regarding the most important prognostic indicators

5. There was blinding of all subjects

6. There was blinding of all therapists who administered the therapy

no _ yes $\underline{\mathrm{x}}$ where:

no $\underline{x}$ yes _ where:

no $\underline{x}$ yes _ where:

7. There was blinding of all assessors who measured at least one key outcome no $\underline{x}$ yes

8. Measures of at least one key outcome were obtained from more than $85 \%$ of the subjects initially allocated to groups

9. All subjects for whom outcome measures were available received the treatment or control condition as allocated or, where this was not the case, data for at least one key outcome was analysed by "intention to treat"

no $\underline{x}$ yes _ where:

10. The results of between-group statistical comparisons are reported for at least one key outcome

no _ yes $\underline{\mathrm{x}}$ where:

11. The study provides both point measures and measures of variability for at least one key outcome

no _ yes $\underline{\mathrm{x}}$ where: Total: $3 / 10$

Table D7. Cheing et al. ${ }^{21}$ PEDro Score

1. Eligibility criteria were specified no _ yes $\underline{\mathrm{x}}$ where:

2. Subjects were randomly allocated to groups (in a crossover study, subjects were randomly allocated an order in which treatments were received)

no _ yes $\underline{x}$ where:

3. Allocation was concealed

no $\underline{x}$ yes _ where:

4. The groups were similar at baseline regarding the most important prognostic indicators

no _ yes $\underline{x}$ where:

5. There was blinding of all subjects

6. There was blinding of all therapists who administered the therapy

no _ yes $\underline{x}$ where:

no $\underline{x}$ yes _ where:

7. There was blinding of all assessors who measured at least one key outcome no $\underline{x}$ yes _ where:

8. Measures of at least one key outcome were obtained from more than $85 \%$ of the subjects initially allocated to groups

no _ yes $\underline{\mathrm{x}}$ where:

9. All subjects for whom outcome measures were available received the treatment or control condition as allocated or, where this was not the case, data for at least one key outcome was analysed by "intention to treat"

no $\underline{x}$ yes _ where:

10. The results of between-group statistical comparisons are reported for at least one key outcome

no _ yes $\underline{x}$ where:

11. The study provides both point measures and measures of variability for at least one key outcome

no yes $\underline{\mathrm{x}}$ where: Total: $6 / 10$ 
Table D8. Haren et al. ${ }^{22}$ PEDro Score

1. Eligibility criteria were specified

2. Subjects were randomly allocated to groups (in a crossover study, subjects were randomly allocated an order in which treatments were received) no _ yes $\underline{\mathrm{x}}$ where:

3. Allocation was concealed

4. The groups were similar at baseline regarding the most important prognostic indicators

5. There was blinding of all subjects

6. There was blinding of all therapists who administered the therapy

no _ yes $\underline{\mathrm{x}}$ where:

no _ yes $\underline{x}$ where:

7. There was blinding of all assessors who measured at least one key outcome

no $\underline{x}$ yes _ where:

no $\underline{x}$ yes _ where:

no $\underline{x}$ yes _ where:

8. Measures of at least one key outcome were obtained from more than $85 \%$ of the subjects initially allocated to groups

9. All subjects for whom outcome measures were available received the treatment or control condition as allocated or, where this was not the case, data for at least one key outcome was analysed by "intention to treat"

no $\underline{x}$ yes _ where:

no _ yes $\underline{\mathrm{x}}$ where:

10. The results of between-group statistical comparisons are reported for at least one key outcome

no yes $\mathrm{x}$ where:

11. The study provides both point measures and measures of variability for at least one key outcome

no _ yes $\underline{\mathrm{x}}$ where: Total: $5 / 10$

Table D9. Kessler et al. ${ }^{23}$ PEDro Score

1. Eligibility criteria were specified no _ yes $\underline{\mathrm{x}}$ where:

2. Subjects were randomly allocated to groups (in a crossover study, subjects were randomly allocated an order in which treatments were received)

3. Allocation was concealed

4. The groups were similar at baseline regarding the most important prognostic indicators

no _ yes $\underline{x}$ where: no $\underline{x}$ yes _ where:

5. There was blinding of all subjects

no _ yes $\underline{\mathrm{x}}$ where:

no $\underline{x}$ yes _ where:

6. There was blinding of all therapists who administered the therapy

no $\underline{x}$ yes where:

7. There was blinding of all assessors who measured at least one key outcome no $\underline{x}$ yes _ where:

8. Measures of at least one key outcome were obtained from more than $85 \%$ of the subjects initially allocated to groups

no _ yes $\underline{\mathrm{x}}$ where:

9. All subjects for whom outcome measures were available received the treatment or control condition as allocated or, where this was not the case, data for at least one key outcome was analysed by "intention to treat"

10. The results of between-group statistical comparisons are reported for at least one key outcome

no _ yes $\underline{x}$ where:

11. The study provides both point measures and measures of variability for at least one key outcome

no yes $\underline{\mathrm{x}}$ where: Total: $5 / 10$ 
Table D10. Knygsand et al. ${ }^{24}$ PEDro Score

1. Eligibility criteria were specified

2. Subjects were randomly allocated to groups (in a crossover study, subjects were randomly allocated an order in which treatments were received) no _ yes $\underline{\mathrm{x}}$ where:

3. Allocation was concealed

4. The groups were similar at baseline regarding the most important prognostic indicators

5. There was blinding of all subjects

6. There was blinding of all therapists who administered the therapy

no _ yes $\underline{\mathrm{x}}$ where: no $\underline{x}$ yes _ where:

7. There was blinding of all assessors who measured at least one key outcome no _ yes $\underline{\mathbf{x}}$ where:

8. Measures of at least one key outcome were obtained from more than $85 \%$ of the subjects initially allocated to groups

9. All subjects for whom outcome measures were available received the treatment or control condition as allocated or, where this was not the case, data for at least one key outcome was analysed by "intention to treat"

no _ yes $\underline{x}$ where:

no _ yes $\underline{x}$ where:

no $\underline{x}$ yes _ where:

no _ yes $\underline{x}$ where:

10. The results of between-group statistical comparisons are reported for at least one key outcome

no yes $\mathrm{x}$ where:

11. The study provides both point measures and measures of variability for at least one key outcome

no _ yes $\underline{\mathrm{x}}$ where: Total: $7 / 10$

Table D11. Man et al. ${ }^{25}$ PEDro Score

1. Eligibility criteria were specified no _ yes $\underline{x}$ where:

2. Subjects were randomly allocated to groups (in a crossover study, subjects were randomly allocated an order in which treatments were received)

no _ yes $\underline{\mathrm{x}}$ where:

no _ yes $\underline{x}$ where:

3. Allocation was concealed

4. The groups were similar at baseline regarding the most important prognostic indicators

no _ yes $\underline{\mathrm{x}}$ where:

no _ yes $\underline{x}$ where:

5. There was blinding of all subjects

6. There was blinding of all therapists who administered the therapy

no $\underline{x}$ yes _ where:

7. There was blinding of all assessors who measured at least one key outcome no _ yes $\underline{x}$ where:

8. Measures of at least one key outcome were obtained from more than $85 \%$ of the subjects initially allocated to groups

no _ yes $\underline{x}$ where:

9. All subjects for whom outcome measures were available received the treatment or control condition as allocated or, where this was not the case, data for at least one key outcome was analysed by "intention to treat"

10. The results of between-group statistical comparisons are reported for at least one key outcome

no _ yes $\underline{x}$ where:

11. The study provides both point measures and measures of variability for at least one key outcome

no yes $\underline{\mathrm{x}}$ where: Total: $8 / 10$ 
Table D12. Meeusen et al. ${ }^{26}$ PEDro Score

1. Eligibility criteria were specified

2. Subjects were randomly allocated to groups (in a crossover study, subjects were randomly allocated an order in which treatments were received)

3. Allocation was concealed

no $\underline{x}$ yes _ where:

no $\underline{x}$ yes _ where: no $\underline{x}$ yes _ where:

4. The groups were similar at baseline regarding the most important prognostic indicators

5. There was blinding of all subjects

6. There was blinding of all therapists who administered the therapy

no _ yes $\underline{\mathrm{x}}$ where:

no $\underline{x}$ yes _ where:

no $\underline{x}$ yes _ where:

7. There was blinding of all assessors who measured at least one key outcome no $\underline{x}$ yes _ where:

8. Measures of at least one key outcome were obtained from more than $85 \%$ of the subjects initially allocated to groups

9. All subjects for whom outcome measures were available received the treatment or control condition as allocated or, where this was not the case, data for at least one key outcome was analysed by "intention to treat"

no _ yes $\underline{\mathrm{x}}$ where:

10. The results of between-group statistical comparisons are reported for at least one key outcome

no _yes $\underline{x}$ where:

11. The study provides both point measures and measures of variability for at least one key outcome

no $\underline{x}$ yes _ where: Total: $3 / 10$

Table D13. Rucinski et al. ${ }^{27}$ PEDro Score

1. Eligibility criteria were specified no _ yes $\underline{x}$ where:

2. Subjects were randomly allocated to groups (in a crossover study, subjects were randomly allocated an order in which treatments were received)

3. Allocation was concealed

4. The groups were similar at baseline regarding the most important prognostic indicators

no _ yes $\underline{x}$ where:

no $\underline{x}$ yes _ where:

no _ yes $\underline{x}$ where:

no $\underline{x}$ yes _ where:

no $\underline{x}$ yes _ where:

6. There was blinding of all therapists who administered the therapy

7. There was blinding of all assessors who measured at least one key outcome no $\underline{x}$ yes _ where:

8. Measures of at least one key outcome were obtained from more than $85 \%$ of the subjects initially allocated to groups

no _ yes $\underline{x}$ where:

9. All subjects for whom outcome measures were available received the treatment or control condition as allocated or, where this was not the case, data for at least one key outcome was analysed by "intention to treat"

no _ yes $\underline{x}$ where:

10. The results of between-group statistical comparisons are reported for at least one key outcome

no _ yes $\underline{\mathrm{x}}$ where:

11. The study provides both point measures and measures of variability for at least one key outcome

no _ yes $\underline{x}$ where: Total: $6 / 10$ 
Table D14. Scheffler et al. ${ }^{28}$ PEDro Score

1. Eligibility criteria were specified

2. Subjects were randomly allocated to groups (in a crossover study, subjects were randomly allocated an order in which treatments were received)

3. Allocation was concealed

no _ yes $\underline{x}$ where:

no $\underline{x}$ yes _ where: no $\underline{x}$ yes _ where:

4. The groups were similar at baseline regarding the most important prognostic indicators

5. There was blinding of all subjects

6. There was blinding of all therapists who administered the therapy

no _ yes $\underline{x}$ where:

no $\underline{x}$ yes _ where:

no $\underline{x}$ yes _ where:

7. There was blinding of all assessors who measured at least one key outcome no $\underline{x}$ yes $~$ where:

8. Measures of at least one key outcome were obtained from more than $85 \%$ of the subjects initially allocated to groups

9. All subjects for whom outcome measures were available received the treatment or control condition as allocated or, where this was not the case, data for at least one key outcome was analysed by "intention to treat"

no _ yes $\underline{\mathrm{x}}$ where:

10. The results of between-group statistical comparisons are reported for at least one key outcome

no yes _ where:

11. The study provides both point measures and measures of variability for at least one key outcome

no $\underline{x}$ yes Total: $2 / 10$

Table D15. Stockle et al. ${ }^{29}$ PEDro Score

1. Eligibility criteria were specified no _ yes $\underline{x}$ where:

2. Subjects were randomly allocated to groups (in a crossover study, subjects were randomly allocated an order in which treatments were received)

3. Allocation was concealed

4. The groups were similar at baseline regarding the most important prognostic indicators

5. There was blinding of all subjects

6. There was blinding of all therapists who administered the therapy

7. There was blinding of all assessors who measured at least one key outcome no $\underline{x}$ yes _ where:

8. Measures of at least one key outcome were obtained from more than $85 \%$ of the subjects initially allocated to groups

no _ yes $\underline{x}$ where:

9. All subjects for whom outcome measures were available received the treatment or control condition as allocated or, where this was not the case, data for at least one key outcome was analysed by "intention to treat"

10. The results of between-group statistical comparisons are reported for at least one key outcome

no $\underline{x}$ yes _ where:

11. The study provides both point measures and measures of variability for at least one key outcome

no $x$ yes _ where:

Total: $3 / 10$ 
Table D16. Thordarson et al. ${ }^{30}$ PEDro Score

1. Eligibility criteria were specified

2. Subjects were randomly allocated to groups (in a crossover study, subjects were randomly allocated an order in which treatments were received) no _ yes $\underline{\mathrm{x}}$ where:

3. Allocation was concealed

4. The groups were similar at baseline regarding the most important prognostic indicators

5. There was blinding of all subjects

6. There was blinding of all therapists who administered the therapy

no _ yes $\underline{\mathrm{x}}$ where:

no _ yes $\underline{x}$ where:

7. There was blinding of all assessors who measured at least one key outcome

no _ yes $\underline{x}$ where:

no $\underline{x}$ yes _ where:

no $\underline{x}$ yes _ where:

8. Measures of at least one key outcome were obtained from more than $85 \%$ of the subjects initially allocated to groups

9. All subjects for whom outcome measures were available received the treatment or control condition as allocated or, where this was not the case, data for at least one key outcome was analysed by "intention to treat"

no $\underline{x}$ yes _ where:

no $\underline{x}$ yes _ where:

10. The results of between-group statistical comparisons are reported for at least one key outcome

no $\underline{x}$ yes _ where:

11. The study provides both point measures and measures of variability for at least one key outcome

no $\underline{\mathrm{x}}$ yes - where: Total: $3 / 10$

Table D17. Tsang et al. ${ }^{31}$ PEDro Score

1. Eligibility criteria were specified no _ yes $\underline{x}$ where:

2. Subjects were randomly allocated to groups (in a crossover study, subjects were randomly allocated an order in which treatments were received)

3. Allocation was concealed

4. The groups were similar at baseline regarding the most important prognostic indicators

no _ yes $\underline{x}$ where:

no $\underline{x}$ yes _ where:

5. There was blinding of all subjects

no _ yes $\underline{\mathrm{x}}$ where:

no $\underline{x}$ yes _ where:

6. There was blinding of all therapists who administered the therapy

no $\underline{x}$ yes _ where:

7. There was blinding of all assessors who measured at least one key outcome no $\underline{x}$ yes _ where:

8. Measures of at least one key outcome were obtained from more than $85 \%$ of the subjects initially allocated to groups

no _ yes $\underline{\mathrm{x}}$ where:

9. All subjects for whom outcome measures were available received the treatment or control condition as allocated or, where this was not the case, data for at least one key outcome was analysed by "intention to treat"

10. The results of between-group statistical comparisons are reported for at least one key outcome

no _ yes $\underline{x}$ where:

11. The study provides both point measures and measures of variability for at least one key outcome

no _ yes $\underline{\mathrm{x}}$ where: Total: $5 / 10$ 
Table D18. Weston et al. ${ }^{32}$ PEDro Score

1. Eligibility criteria were specified

2. Subjects were randomly allocated to groups (in a crossover study, subjects were randomly allocated an order in which treatments were received)

3. Allocation was concealed

no _ yes $\underline{\mathrm{x}}$ where:

no $\underline{x}$ yes _ where: no $\underline{x}$ yes _ where:

4. The groups were similar at baseline regarding the most important prognostic indicators

5. There was blinding of all subjects

6. There was blinding of all therapists who administered the therapy

no _ yes $\underline{\mathrm{x}}$ where:

no $\underline{x}$ yes _ where:

no $\underline{x}$ yes - where:

7. There was blinding of all assessors who measured at least one key outcome no $\underline{x}$ yes _ where:

8. Measures of at least one key outcome were obtained from more than $85 \%$ of the subjects initially allocated to groups

9. All subjects for whom outcome measures were available received the treatment or control condition as allocated or, where this was not the case, data for at least one key outcome was analysed by "intention to treat"

no _ yes $\underline{x}$ where:

10. The results of between-group statistical comparisons are reported for at least one key outcome

no _ yes $\underline{x}$ where:

11. The study provides both point measures and measures of variability for at least one key outcome no $\underline{\mathrm{x}}$ yes _ where: Total: $3 / 10$ 
Figure D1. Figure of Studies Used: CINAHL
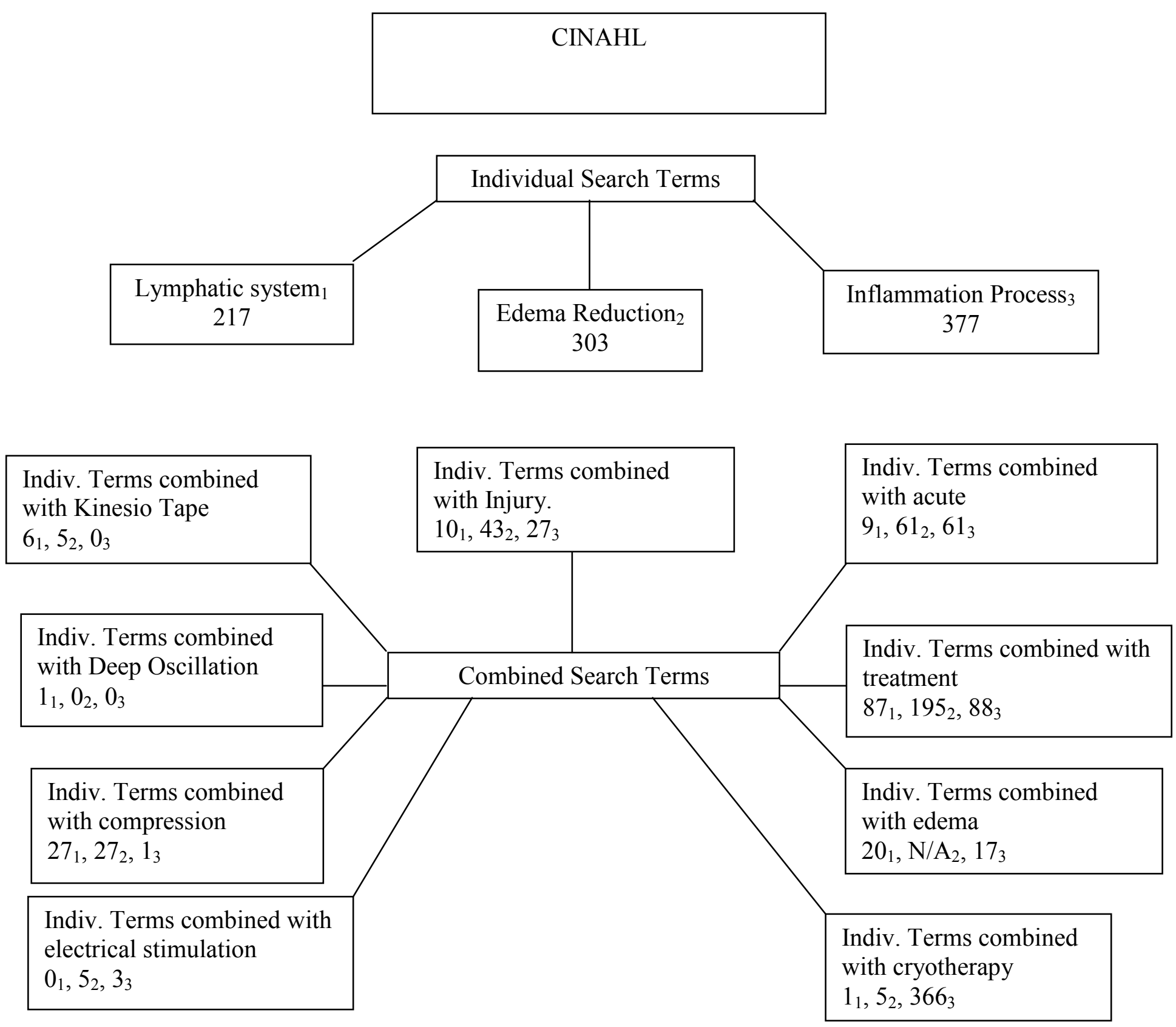
Figure D2. Figure of Studies Used: SPORTdiscus
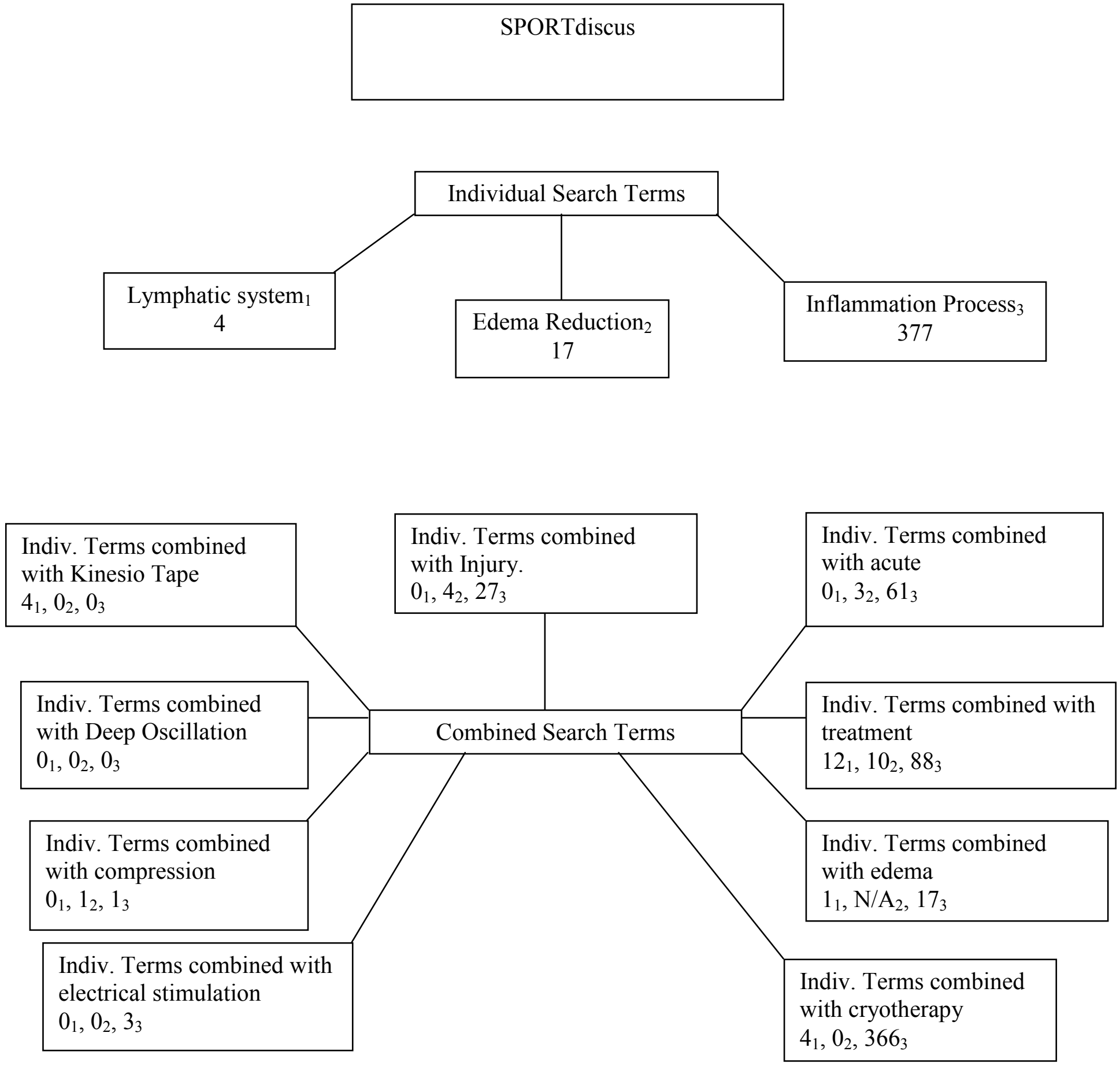
Figure D3. Figure of Studies Used: MEDLINE

MEDLINE
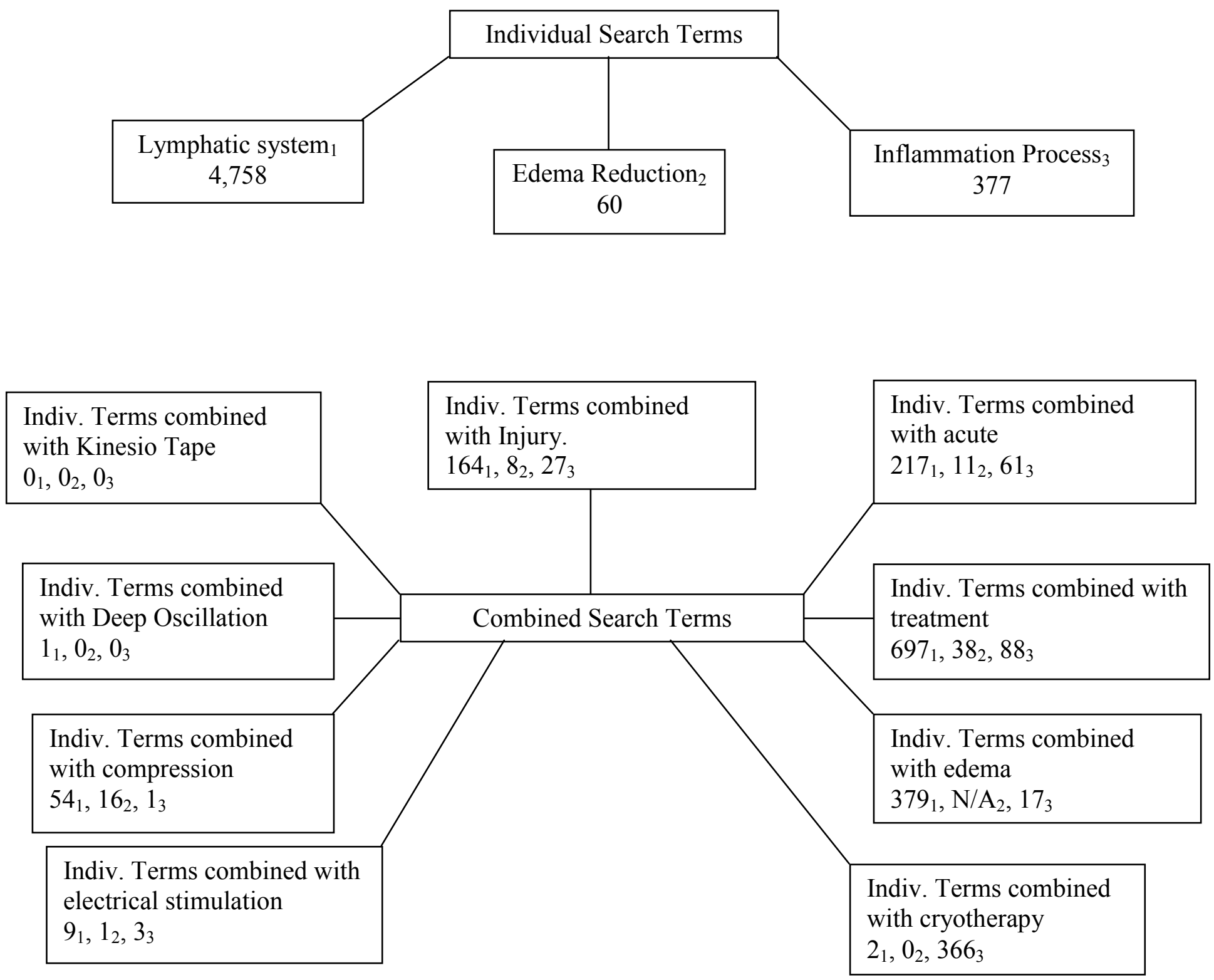
Figure D4. Figure of Studies Used: MDConsult

\begin{tabular}{|l|}
\hline MDConsult Database \\
\end{tabular}
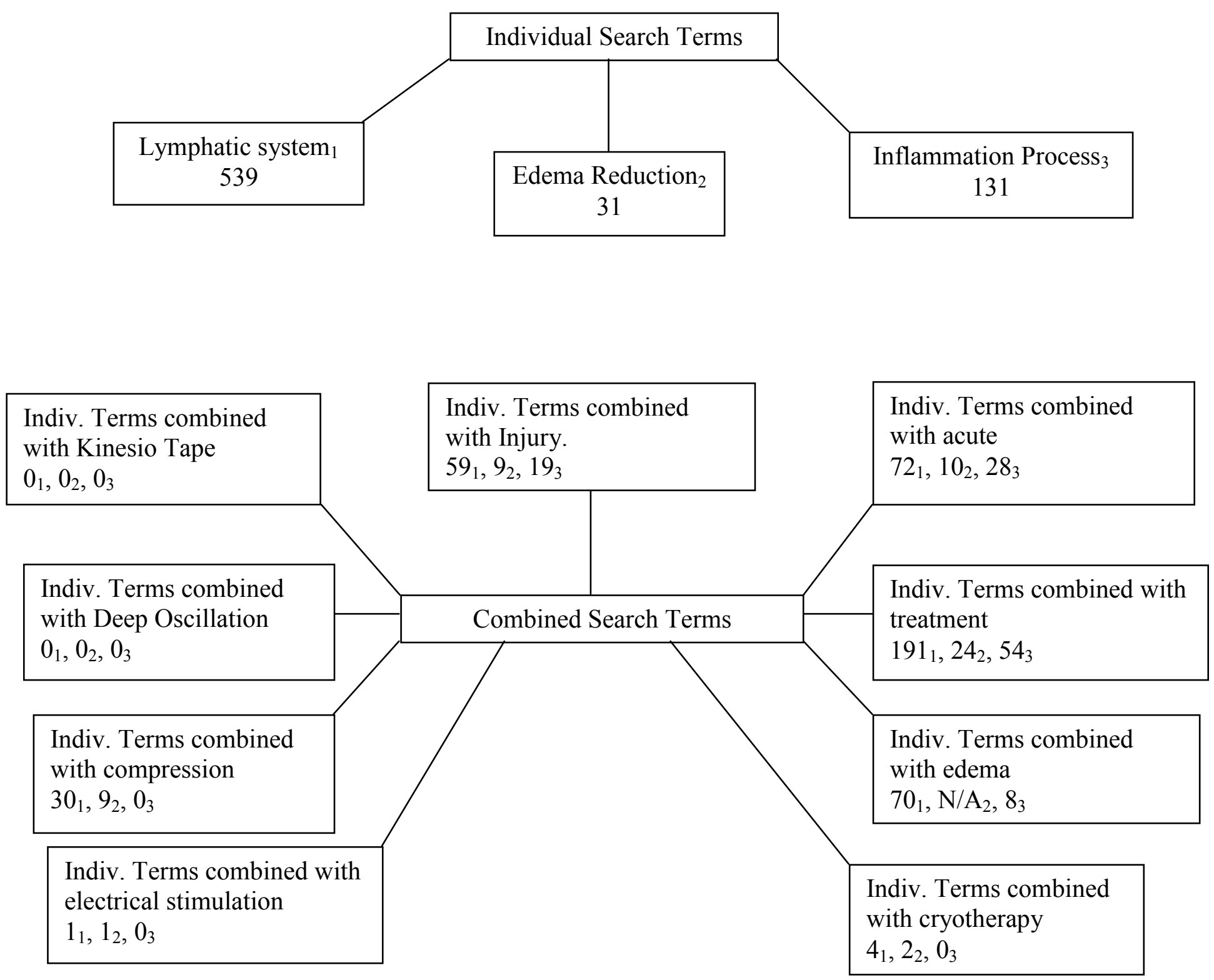
Figure D5. Figure of Studies Used: PubMed

\begin{tabular}{|c|}
\hline PubMed \\
\end{tabular}
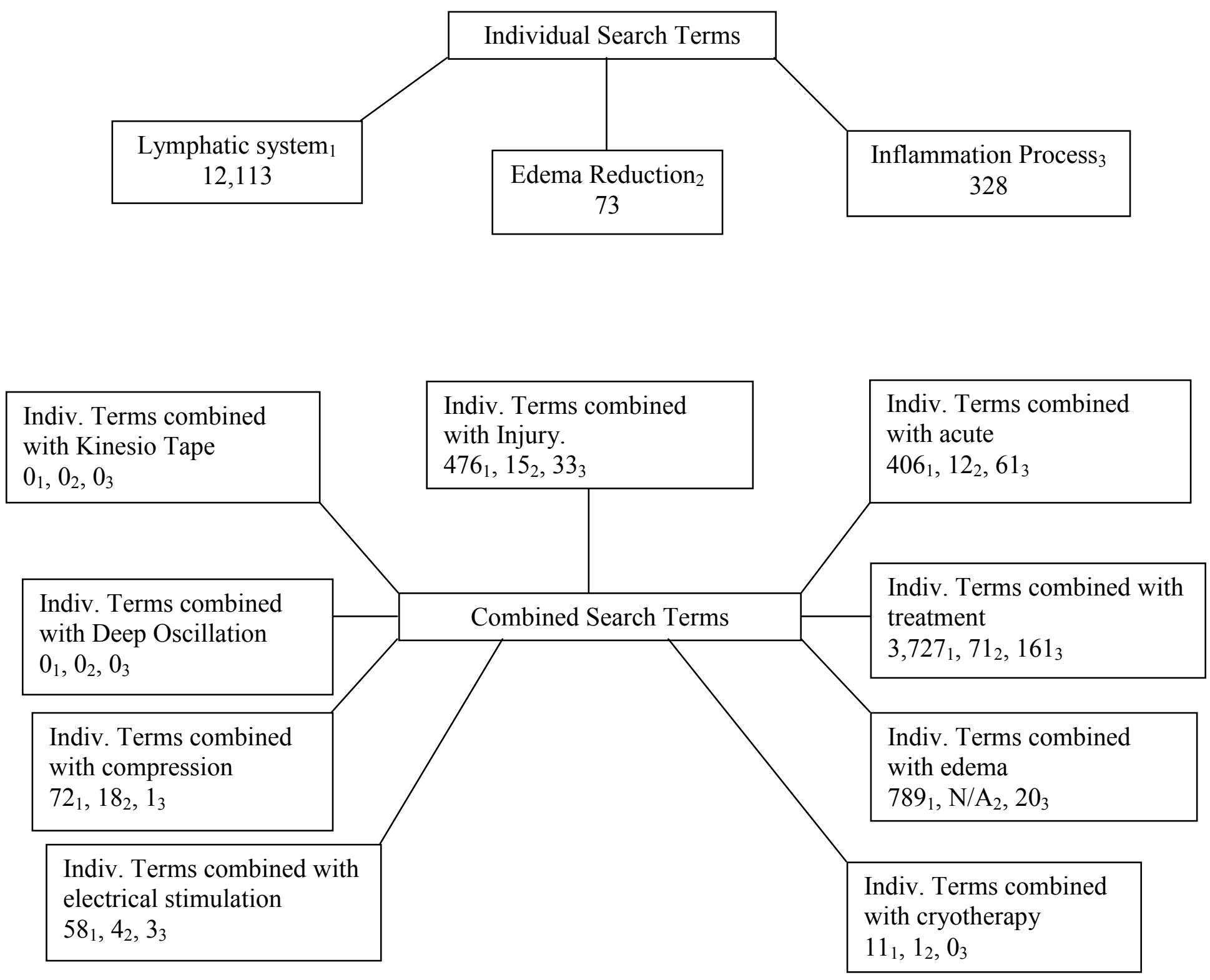
Figure D6. Figure of Studies Used: Cochran Database

\section{Cochran Database}
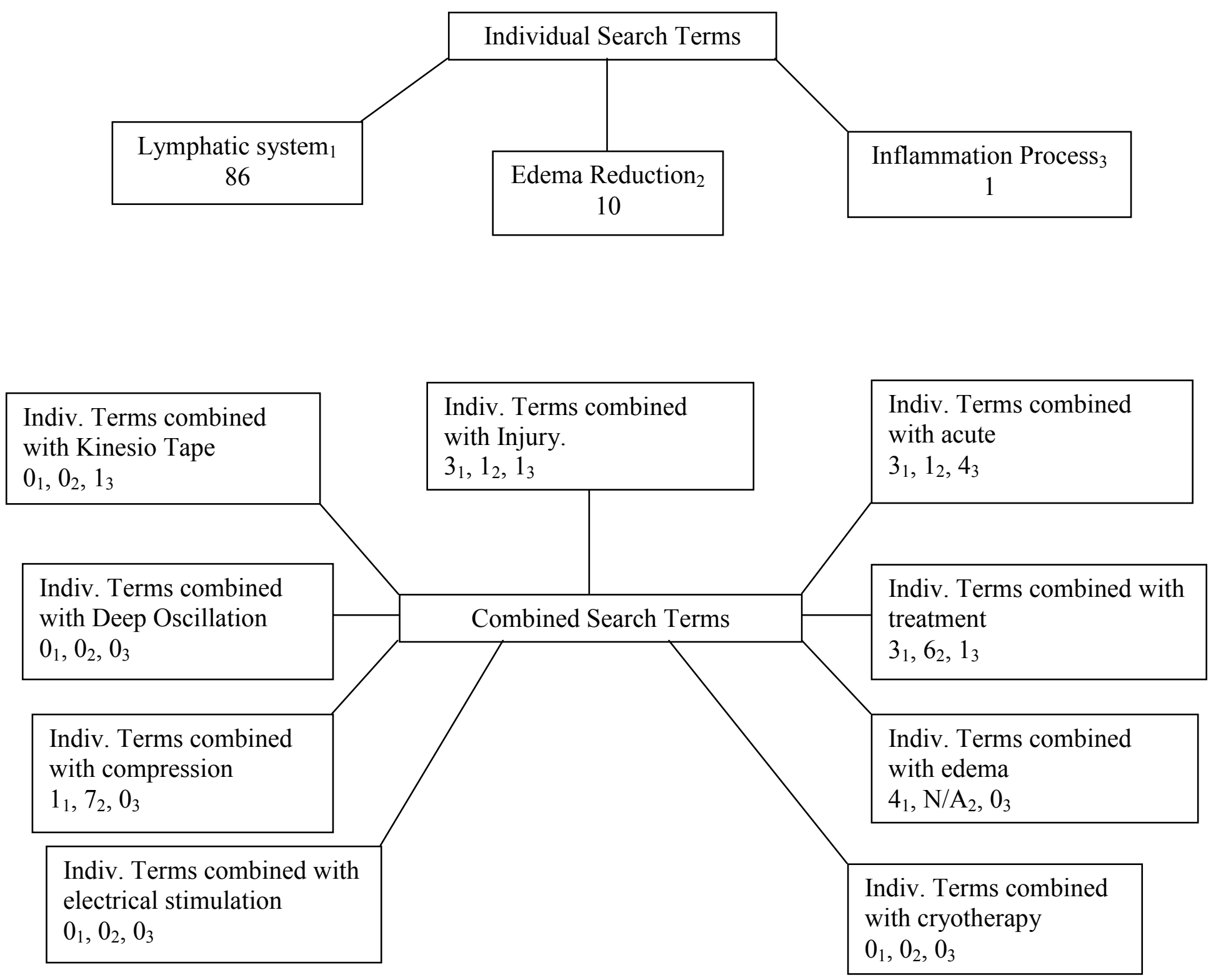
Figure D7. Figure of Studies Used: Google Scholar

\section{Google Scholar}
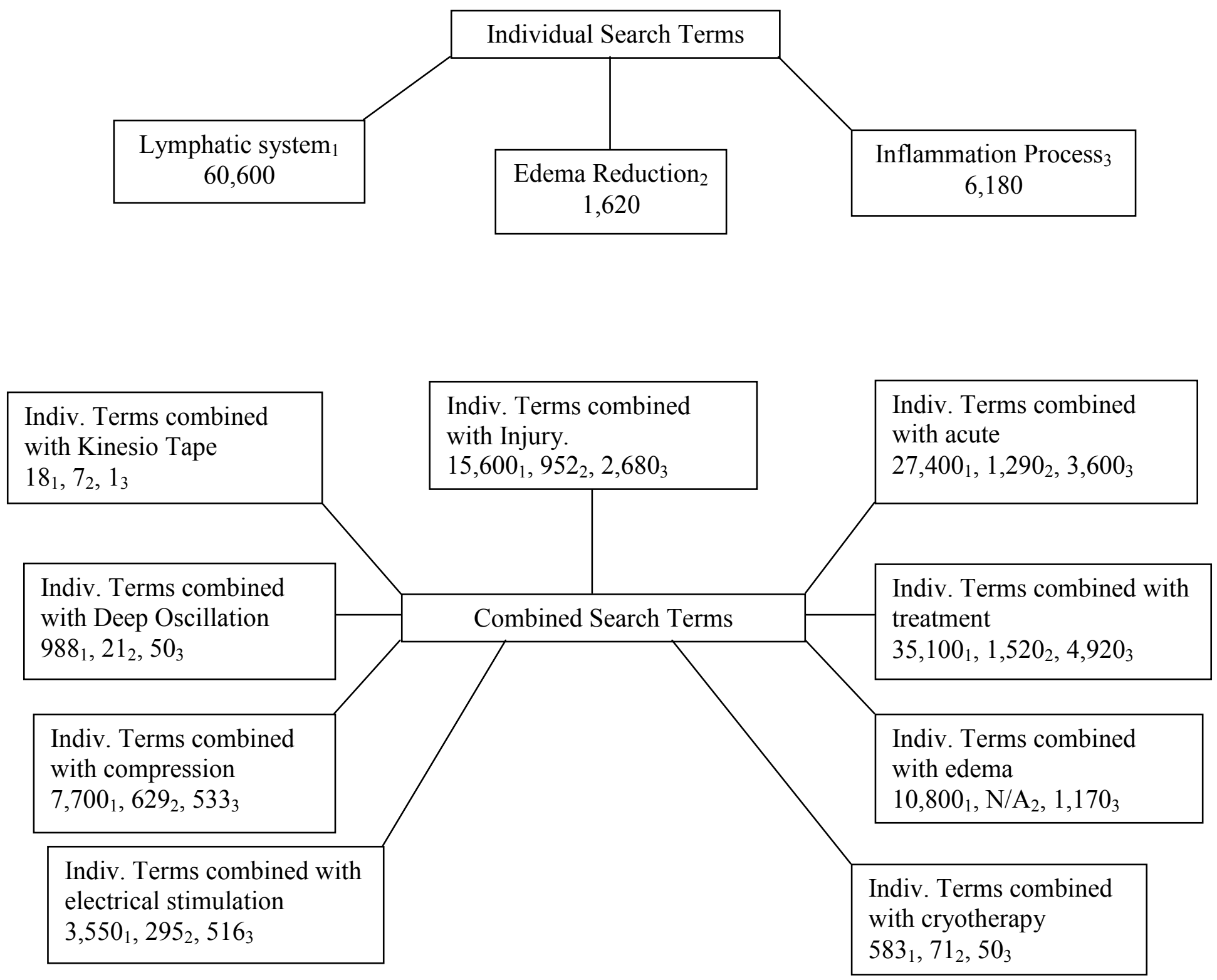
Figure D8. Figure of Studies Used: Science Direct

\section{Science Direct}
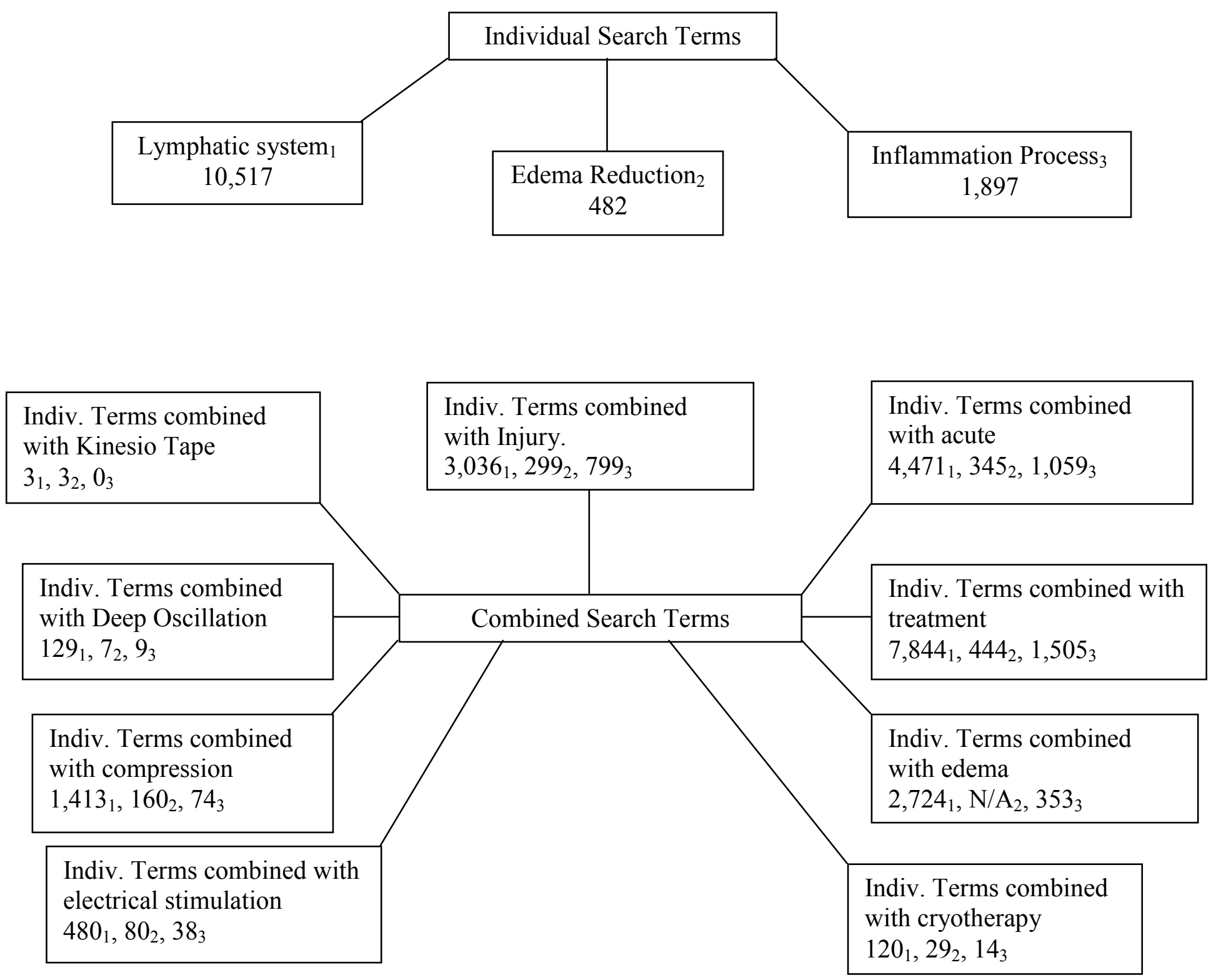
Figure D9. Figures of Studies Used: PEDro Database

PEDro Database
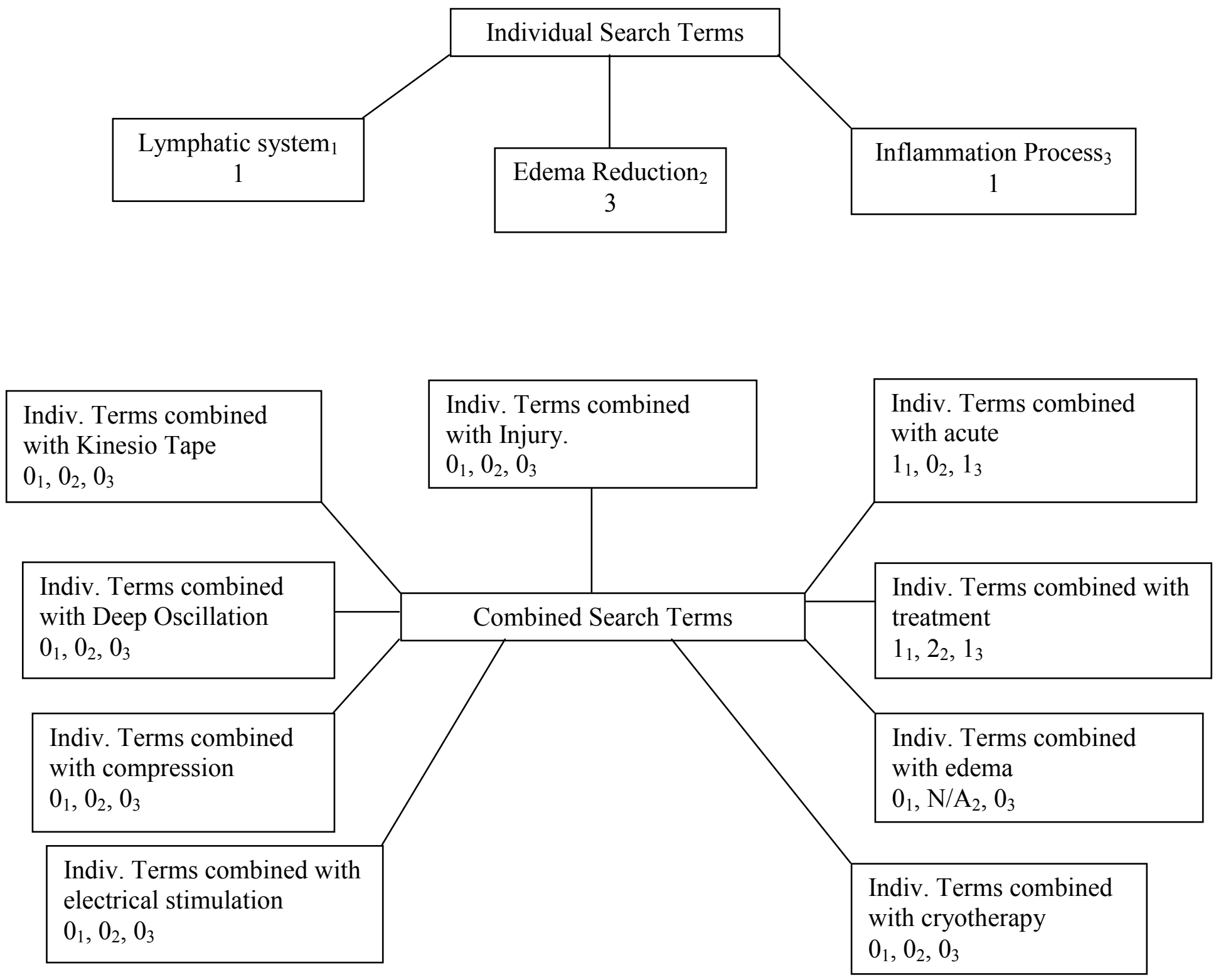
Figure D10. Effect Size Comparison

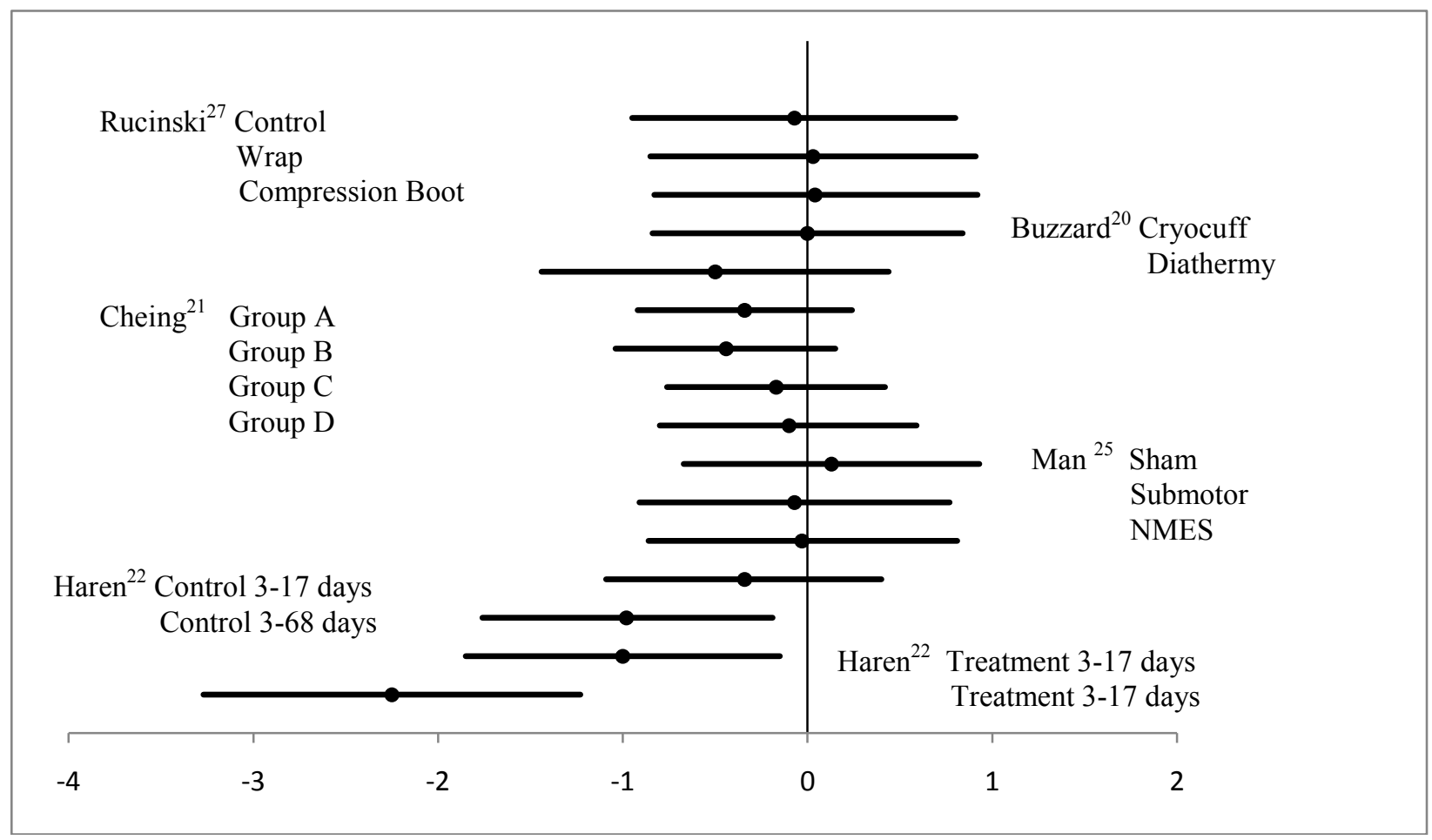




\section{APPENDIX E}

\section{RECOMMENDATIONS FOR FUTURE RESEARCH}

1. Future studies should include foreign language database and studies. This may expand the number of studies found.

2. Expanding the injuries from acute to chronic edema in traumatic injuries may provide more information.

3. Perform a study examining the further effects of each treatment, particularly massage, with larger populations.

4. Altering the inclusion criteria to expand the study to include chronic edema but excluding chronic diseases. 


\section{ADDITIONAL REFERENCES}

33. Jarvinen TA, Jarvinen TL, Kaariainen M, Kalimo H, Jarvinen M. Muscle injuries: biology and breatment. Am J Sports Med. 2005;33(5):745-764.

33. Butterfield T, Best T, Merrick M. The dual roles of nuetrophils and macrophages in inflammation: a critical balance between tissue damage and repair. $J$ Athl

Train. 2008;41(4)457-465.

35. Fujiwara N, Kobayashi K. Macrophage in inflammation. Current Drug TargetsInflammation Allergy. 2005;4(3):281-286.

36. Ng, G. Ligament injury and repair: current concepts. Hong Kong Physiotherapy J. 2002;20:22-29

37. Aslan H, Kimelman-Belch N, Pelled G, Gazit D. Molecular targets for tendon neoformation. . Clin Invest. 2008;118:439-444.

38. Sandrey M. Acute and chronic tendon injuries: factors affecting the healing response and treatment. J Sport Rehabil. 2003;12:70-91.

39. Swartz M. The physiology of the lymphatic system. Advanced Drug Delivery Reviews. 2001;50:3-20.

40. Oakes B. Tissue healing and repair: tendons and ligaments. In: Frontera W. Editor. Rehabilitation of Sports Injuries: Scientific Basis. Boston: Blackwell Science;2003;56-98.

41. Chiang W, Chen Y, Lin S, Wu K, Tsai T. Bradykinin enhances reactive oxygen species generation, mitochondrial injury, and cell death induced by ATP depletion - a role of the phospholipase C-Ca ${ }^{2+}$ Pathway. Free Radical Biology Medicine. 2007;43:702-710.

42. Gilroy D, Lawrence T, Colville-Nash P, Willoughby D. New insights into inflammatory resolution. Inflammopharmacology. 2001;9(1,2):125-130.

43. Glaros T, Larsen M, Li L. Macrophages and fibroblasts during inflammation, tissue damage and organ Injury. Frontiers in Bioscience. 2009;14:3988-3993.

44. Enwemeka C. Inflammation, cellularity, and fibrillogenesis in regeneration tendon: implications for tendon rehabilitation. Phys Ther. 1989;69(10):816-825.

45. Reed R, Rubin K. Transcapillary exchange: role and importance of the interstitial fluid pressure and the extracellular matrix. Cardiovascular Research. 2010;87:211-217.

46. Board J, Harlow W. Lymphoedema 1: components and function of the lymphatic system. Bri J of Nursing. 2002;11(5):304-309. 
47. Schmid-Schonbein G. Microlymphatics and lymph flow. Physiological Reviews. 1990;70(4):987-1028

48. Moore K, Dalley A. Clinical Oriented Anatomy. Baltimore, MD. Lippincott Williams \& Wilkins. 2006. 584, 625, 672, 748-750.

49. Bleakly C, McDonough S, MacAuley. Cryotherapy for acute ankle sprains: a randomised controlled study of two different icing protocols. Br J Sports Med. 2006;40:700-705

50. Bleakly C, O'Connor S, Tully M, Rocke L, MacAuley D, McDonough S. The Price (Protection Rest Ice Compression Elevation): design of a randomised controlled trial comparing standard versus cryokinetic ice applications in the management of acute ankle sprain. BMC Musculoskeletal Disorders. 2007;8:125-133.

51. Schaser K, Disch A, Stover J, Lauffer A, Bail H, Mittlmeier T. Prolonged superficial local cryotherapy attenuates microcirculatory impairment, regional inflammation, and muscle necrosis after closed soft tissue injury in rats. Am J Sports Med. 2007;35:93-102.

52. Kreamer W, French D, Spiering B. Compression in the treatment of acute muscle injuries in sport. Int SportMed J. 2004;5(3):200-208.

53. Ramey D, Tiidus P. Massage therapy in horses: assessing its effectiveness from empirical data in humans and animals. Compendium. 2002;24(5)418-423.

54. Callaghan M. The role of massage in the management of the athlete: a Review. Br J Sport Med. 1993;27(1):28-33.

55. Hemmings B. Physiological, psychological and performance effects of massage therapy in sport: a review of the literature. Phys Ther Sport. 2001;2:165-170.

56. Williams A. Manual lymphatic drainage: exploring the history and evidence dase. $\mathrm{Br}$ J Community Nursing. 2010:S18-S24.

57. Tiidus P. A review of human massage therapy: assessing effectiveness primarily from empirical data in the human species. AAEP Proceedings. 2000;46:302-305.

58. Tiidus P. Massage and ultrasound as therapuetic modalities in exercise-induced muscle damage. Can J App. Physiol. 1999;24(3):267-278.

59. Gehlsen G, Gannon L, Helfst R. Fibroblasts responses to variation in soft tissue mobilization pressure. Med Sci Sports Exerc. 1999;31(4):531-535.

60. Shoemaker J, Tiidus P, Mader R. Failure of manual massage to alter limb blood flow: measures by doppler ultrasound. Med Sci Sports Exerc. 1997;29(5):610-614. 
61. Dolan M, Graves P, Nakazawa C, Delano T, Hutson A, Mendel F. Effects of ibuprofen and high-voltage electric stimulation on acute edema formation after blunt trauma to limbs of rats. J Athl Train. 2005;40(2):111-115.

62. Cook H, Morales M, La Rosa E, Dean J, Donnelly M, McHugh P, Otradovec A, Wright K, Kula T, Tepper S. Effects of electrical stimulation on lymphatic flow and limb volume in the rat. Phys Ther. 1994;74(11):1040-1046.

63. Mendel F, Fish D. New perspective in edema control via electrical stimulation. $J$ Athl Train. 1993;28(1):63-74.

64. Thornton R, Mendel F, Fish D. Effects of electrical stimulation on edema formation in different strains of rats. Phys Ther. 1998;78(4):386-394.

65. Mohr T, Akers T, Landry R. Effect of high voltage stimulation on edema reduction in the rat hind limb. Phys Ther. 1987;67(11):1703-1707.

66. Taylor K, Fish D, Mendel F, Burton H. Effect of a single 30 minute treatment of high voltage pulsed current on edema formation in frog hind limbs. Phys Ther. 1992;72(1):73-78.

67. Zajt-Kwiatkowska J, Rajkowska-Labon E, Skrobot W, Bakula S, Szamotulska J. Application of kinesio taping for treatment of sports injuries. Research Yearbook. 2007;13(1)130-134.

68. Thelen M, Dauber J, Stoneman P. The clinical efficacy of kinesio tape for shoulder pain: a randomized, double-blinded, clinical trial. J Orthop Sport Phys Ther. 2008;38(7):389395.

69. Aliyev R. Clinical effects of the therapy mthod deep oscillation in treatment of sports injuries (Abstract only). XIX International Congress on Sports Rehabilitation and Traumatology.

70. Kaya E, Zinnuroglu M, Tugeu I. Kinesio taping compared to physical therapy modalities for the treatment of shoulder impingement syndrome. Clin Rheumatol. 2010.

71. Physiotherapy Evidence Database: Scale. Available at: http:// http://www.pedro.org.au/english/downloads/pedro-scale/. Accessed December 6, 2010 